\title{
Birds, bats and arthropods in tropical agroforestry landscapes: \\ Functional diversity, multitrophic interactions and crop yield
}

\author{
Dissertation \\ zur Erlangung des Doktorgrades \\ der Fakultät für Agrarwissenschaften \\ der Georg-August-Universität Göttingen
}

vorgelegt von

Bea Maas

geboren in San Francisco (USA)

Göttingen, September 2013 
Referent:

Korreferent:

Tag der mündlichen Prüfung:
Prof. Dr. Teja Tscharntke

Prof. Dr. Stefan Vidal

20. November 2013 


\section{Table of Contents}

Summary

\section{Chapter I}

General Introduction

\section{Chapter II}

Bats and birds increase crop yield in tropical agroforestry landscapes

\section{Chapter III}

Avian species identity drives predation success

in tropical cacao agroforestry

\section{Chapter IV}

Logging of large dead forest remnant trees at tropical forest margins causes a local population collapse of the endemic Grosbeak Starling

\section{Chapter V}

Synthesis

Publications

Curriculum Vitae 
The single chapters of this doctoral thesis are published or submitted to the following journals:

MaAs, B., Clough, Y. And TscharntKe, T. (published) Bats and birds increase crop yield in tropical agroforestry landscapes - Ecology Letters

Maas, B., Tscharntke, T., Shahabuddin, S., Dwi Putra, D. And Clough, Y. (submitted) Avian species identity drives predation success in tropical cacao agroforestry - Journal of Applied Ecology

MaAs, B., TscharntKe And Schulze C. H. (submitted) Logging of large dead forest remnant trees at tropical forest margins causes a local population collapse of the endemic Grosbeak Starling - Biological Conservation 


\section{Summary}

Ecosystem services such as the suppression of pest insects may increase productivity of agroforestry systems and thereby increase well-being of smallholders. Tropical birds and bats are effective predators of arthropods and move within landscapes, representing mobile links that connect habitats in space and time. But information on the effects of birds and bats on multitrophic interactions and agricultural productivity in different types of agroforestry systems is limited. Similarly, the relative importance of local agroforestry management and the tropical landscape matrix for ecosystem services mediated by birds has not been investigated so far. Last but not least, a better understanding of dynamic tropical agroforestry landscapes and the effects of habitat conversion and land use intensification on important functional groups as well as for endangered species is urgently needed.

We conducted a predator exclusion experiment in which we manipulated the access of birds and bats on 15 different cacao agroforestry sites to quantify their effects on diurnal and nocturnal insects and spiders, cacao fruit development, leaf herbivory and the final crop yield over a period of 15 months. The selected cacao agroforestry sites were located on the island of Sulawesi (Indonesia) and differed in local management and distance to forest. The absence of birds and bats led to an increased density of insect herbivores and caused a concurrent release of mesopredators such as ants and spiders despite negative effects on the development of cacao fruits and a remarkable decrease of final cacao crop yield of $31 \%$ across local and landscape gradients.

In addition to bird and bat field exclusion experiments, we investigated the group of insectivorous birds with two different sampling methods. Using an arthropod predation experiment (standardized exposure of dummy caterpillars), we quantified predation rates in relation to the identity and diversity of insectivorous birds. We discovered that responses of the insectivorous bird community and the predation activity differed with the landscape context and both increased with forest proximity. Our findings show that ecosystem services can be driven by single species rather than by overall communities of certain functional groups. Therefore, the conservation of species diversity and ecosystem services does not necessarily rely on the same management strategies, although nearby forests appeared to be of great importance for both bird diversity and avian ecosystem services. 
The importance of forest proximity and large trees in agroforestry landscapes was also shown in a species specific study we conducted on a declining local population of the Indonesian endemic Grosbeak Starling in our study area. Although this species is well adapted to anthropogenic landscapes, it is also closely associated with large remnant forest trees that remain along forest margin areas and land use systems as nesting sites. The rapid conversion of the forest margin landscape in Central Sulawesi led to a sharp decline of such nesting sites by $92 \%$ within only two years. Hence, the endemic Grosbeak Starling is likely to be currently endangered although it was locally very abundant a few years ago. These results show how fast conversion of natural habitats and resource extraction in increasingly intensified tropical agroforestry landscapes can result in changes of the local species diversity.

In conclusion, we demonstrate the importance of the quantification of final ecosystem services such as fruit productivity and crop yield to improve the valuation of ecosystem services provided by tropical birds and bats. Species diversity and species identity are both important measures for functional diversity and ecosystem functioning, although with different importance for conservation and the smallholders' economics. A single common species (Zosterops chloris) was more important for the service of arthropod suppression than overall bird species diversity. Nevertheless, nearby forest habitats and extensively used agroforests (shaded and without use of pesticides or other chemical compounds) turned out to be important for both biodiversity and ecosystem services. Multitrophic interactions between birds, bats and other natural enemies (ants and spiders) of phytophagous insects are likely to jointly impact the productivity of agroforestry systems in complex ways and therefore need to be considered simultaneously at different temporal and spatial scales. 
Chapter I

General Introduction

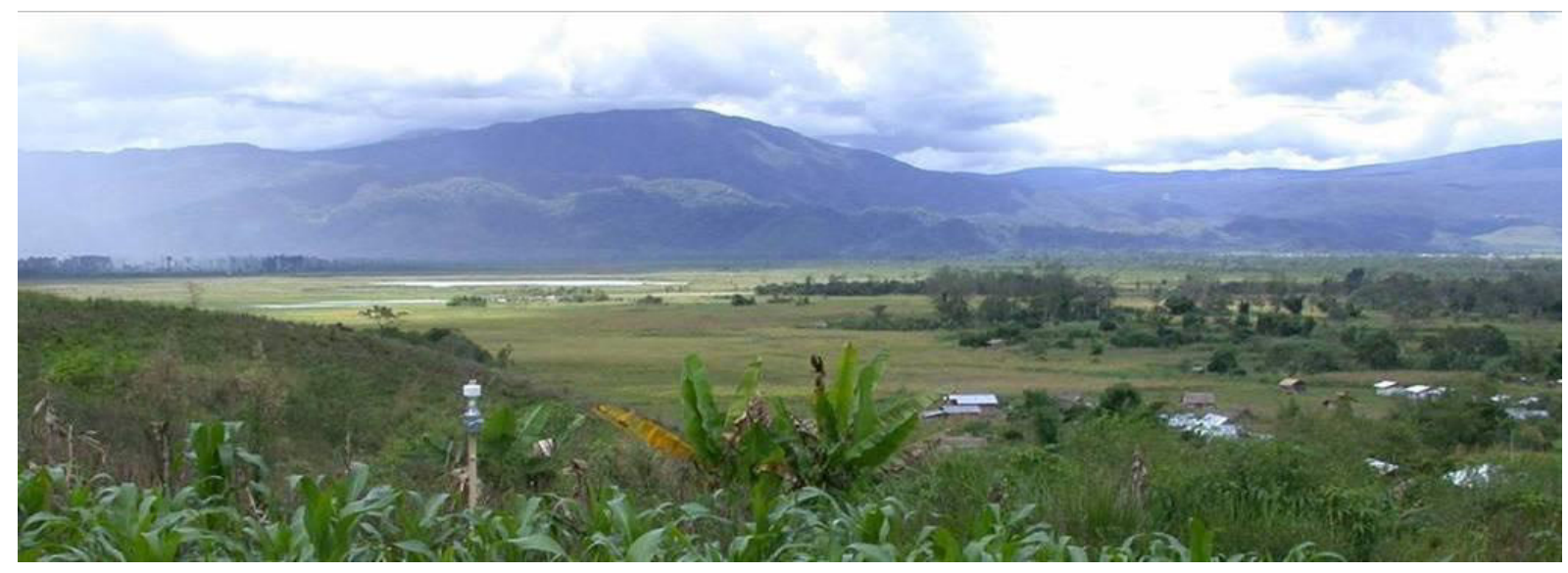




\section{Tropical landscapes - challenges and chances}

During the last two decades, the conservation of global biodiversity, ecosystem processes and services has become one of the most discussed and intensively explored topics in the scientific community and human society. Different concepts have been developed in order to prioritize global conservation efforts (Brooks et al. 2006) with relation to human well-being and population growth (Cincotta et al. 2000; MA 2005). As a result, tropical regions were defined as hotspots of worldwide terrestrial biodiversity (Myers et al. 2000) and subsequently received great attention in scientific research and conservation planning as well as extensive financial support (Myers 2003). However, although the conservation of tropical biodiversity is highly valued by the global society and supported by wealthy countries and companies, the valuation by rural populations and farmers living in these tropical landscapes is crucial for the maintenance of native wildlife and biodiversity (Schroth 2004). Most biodiversity hotspots occur in countries where poverty is widespread (Fisher et al. 2007), which makes matters worse. The conservation of the planet's biodiversity in a world of persistent poverty, accelerating resource extraction and climate change remains a challenge, which often confronts conservationists with hard choices (McShane et al. 2011). The need of the explosively growing human population (Keinan and Clark 2012) for food, fuel and fibre, biological products and many other ecosystem processes and services (MA 2005) leads to an ongoing transformation of natural tropical landscapes, mainly into agricultural land (Archard 2002). Deforestation and conversion of tropical forests as well as land use intensification drive the loss of biodiversity and many associated ecosystem services in the tropics (e.g. Lawton et al. 1998; Daily 2001; Foley et al. 2005). In this context, the combination of effective agricultural land use with biodiversity conservation represents another challenge (Tscharntke et al. 2012).

It is important to recognize available opportunities within this development. Sufficient evidence from agricultural research is available showing that certain types of agricultural land use can provide habitat and resources for a variety of plant and animal taxa and may significantly contribute to conservation efforts in fragmented tropical landscapes (e.g. Schulze et al. 2004; Tscharntke et al. 2005; Perfecto and Vandermeer 2008). 
Agroforestry systems (the practice of integrating trees and other large woody perennials on farms and throughout the agricultural landscape) are increasingly recognized as a useful and promising land use strategy that diversifies production for greater social, economic and environmental benefits (Schroth et al. 2004; Jose 2009). Particular attention has been paid to coffee (Coffea arabica, C. canephora) and cacao (Theobroma cacao) agroforestry systems (e.g. Tscharntke et al. 2011), the largest legal international trade volume beside petroleum (Donald 2004). These systems can support high numbers of plant and animal species depending on the local diversity of shade trees (e.g. Perfecto et al. 1996; Rice and Greenberg 2000) and the respective landscape context (e.g. Fahrig et al. 2011), especially proximity to primary forest (e.g. Perfecto et al. 2007; Clough et al. 2009b).

Transformation of tropical landscapes into agricultural land also leads to changes in landscape composition and spatial configuration which affect the diversity and abundance of important functional groups like insectivorous birds and bats (e.g. Faria et al. 2006; Sekercioglu et al. 2006; Tscharntke et al. 2008,; Estrada-Villegas et al. 2010; Williams-Guillén et al. 2010). Consequently, extensively managed smallholder agroforests with a diverse shade tree cover can support substantially higher levels of species richness and functional diversity, which may enhance the impact of natural ecosystem services provided by these species (Tscharntke et al. 2005; Whelan et al. 2008; Kunz et al. 2011). The idea of integrating such smallholder agroforestry systems into conservation strategies of tropical landscapes has become even more attractive since it has been shown that the support of species-rich agroforests does not need to result in a decrease in agricultural output (Clough et al. 2011, Karp et al. 2013). In conclusion, agroforestry practices which facilitate such win-win situations both for human well-being and biodiversity in the tropics, represent a great chance for more sustainable development of human actions in the future. 


\section{Birds, Bats and arthropods in tropical agroforestry}

The suppression of pest insects in worldwide agroforestry systems by natural enemies is considered as an important and increasingly attractive alternative to the use of pesticides or other chemical compounds (e.g. Bianchi et al. 2006; Clough et al. 2009a). Birds and bats provide numerous valuable ecosystem services in tropical landscapes and are particularly effective in supressing the numbers of pest insects in tropical agroforestry (e.g. Greenberg et al. 2000; Tscharntke et al. 2008; Van Bael et al. 2008). They act as functionally diverse mobile links that actively move in the landscape and connect habitats in space and time through recolonization ability and larger resource accessibility (Lundberg and Moberg 2003; Sekercioglu 2006; Whelan 2008; Kunz et al. 2011). However, until a few years ago, their role in agroforestry has not been investigated separately, underestimating the importance of bats for the limitation of insects (e.g. Kalka and Kalko 2006; Kunz et al. 2011) and attributing observed effects to birds (e.g. Greenberg et al. 2000; Jhonson et al. 2010). Williams Guillén et al. (2008) and Kalka et al. (2008) were the first to separate the effects of birds and bats in Neotropical agroforestry systems and forests using experimental exclosures. Their results showed that both diurnal and nocturnal flying predators have large impacts on the limitation of arthropods, especially in agroforestry systems (Williams-Guillén et al. 2008).

These new findings left behind open questions as well as an evident need for more empirical field studies which consider the complexity of multitrophic interactions between natural enemies and arthropods both in space and time and their relation to functional diversity and crop yield. For example, predation by birds and bats might lead to reorganizations of the local food web structure by affecting predatory insects and spiders (e.g. Lundberg and Moberg 2003), with unexpected consequences for the agricultural output. These effects of birds and bats on arthropod supression, trophic cascades and crop productivity in tropical agroforestry systems have not been investigated in previous studies, partly because multitrophic interaction and effects of mesopredator release are difficult to study. Furthermore, reliable recommendations for agroforestry systems need to integrate knowledge on the relative importance of local and landscape management for biodiversity and its relation to ecosystem services (e.g. Tscharntke et al. 2005; Bos et al. 2007), which have not been quantified to date. These knowledge gaps and open questions are the focus of my thesis. 
Chapter II of this thesis shows the results of our full factorial exclusion experiment, which relates predation of birds and bats to changes in phytophagous insects, mesopredators, development and damage of cacao fruits, leaf herbivory and crop yield over local and landscape scales. It provides a detailed introduction into our field exclusion experiment and the effects of manipulated access of birds and bats to our 15 cacao agroforestry study sites which differed in local shade tree management and distance to primary forest. The effects of single or simultaneous bird and bat exclusions are related to an unmanipulated control treatment on each site. The results of this study highlight the importance of multitrophic interactions in agroforestry food webs as well as the tremendous economic impact of insectivorous birds and bats on crop yield production.

In Chapter III, we present our findings from a comprehensive assessment of the bird community related to field predation experiments performed along gradients of local shade tree cover and distance to forest margin in the agroforestry landscape. Our results show that species diversity did not drive predation success, but the abundance of the most common species (mainly the Indonesian endemic Zosterops chloris) and the proximity to nearby forests. We found that mist netted birds better reflect species identities (which better represented the active predator community) whereas point counts reach higher overall inventory completeness (and therefore better represent species diversity). This chapter shows that species diversity and ecosystem services should be quantified with suitable methods and that their conservation does not necessarily rely on the same management strategies, although forest proximity seems to be of overall importance for both diversity and provided ecosystem functions.

In Chapter IV, we focus on the role of an endemic bird species within the dynamic forest margin landscape of our study region. The Grosbeak Starling Scissirostrum dubium (Sturnidae) is highly adapted to forest margin areas with high anthropogenic impact but depends on the availability of old and large forest remnant trees as nesting sites. Its unique breeding behavior therefore makes the species sensitive to transformation and degradation of the natural forest margin zone. We used this species-specific example to investigate the importance of big trees in agroforestry landscapes and to demonstrate the consequences of the rapidly ongoing conversion of forested habitats at the margin of protected areas. 


\section{Experimental design and collection of data}

The main experimental approach of my thesis was a comprehensive exclusion experiment of birds and bats in cacao agroforestry systems which were selected in Central Sulawesi (Indonesia). Indonesia is the largest producer of cocoa in South-East Asia and the third largest producer worldwide (Moser et al. 2010). The country has 1.5 million hectares of cocoa plantations, mostly in the eastern Sulawesi island, with an extra 10,000 to 20,000 hectares of additional production due the last years (Wall Street Journal, 2011). Contrasting to its economic importance, the island of Sulawesi is the largest within the Indonesian biodiversity hotspot Wallacea with its highly endemic avifauna (Stattersfield et al. 1998) and an outstanding high proportion of endemic species from various other taxa (e.g. Lee et al. 2007). Together with the fact that previous studies on the importance of both birds and bats in tropical agroforestry landscapes were only available from the Neotropics, Sulawesi turned out to be an ideal study area to investigate the addressed questions of the importance of birds, bats and arthropods in tropical agroforestry landscapes.

In the following, four color plates illustrate important parts of our extensive field work such as the experimental study design (Plate 1), the quantification of cacao fruit development and crop yield (Plate 2), leaf herbivory and arthropod community (Plate $\mathbf{3}$ ) and the insectivorous bird community (Plate 4). 

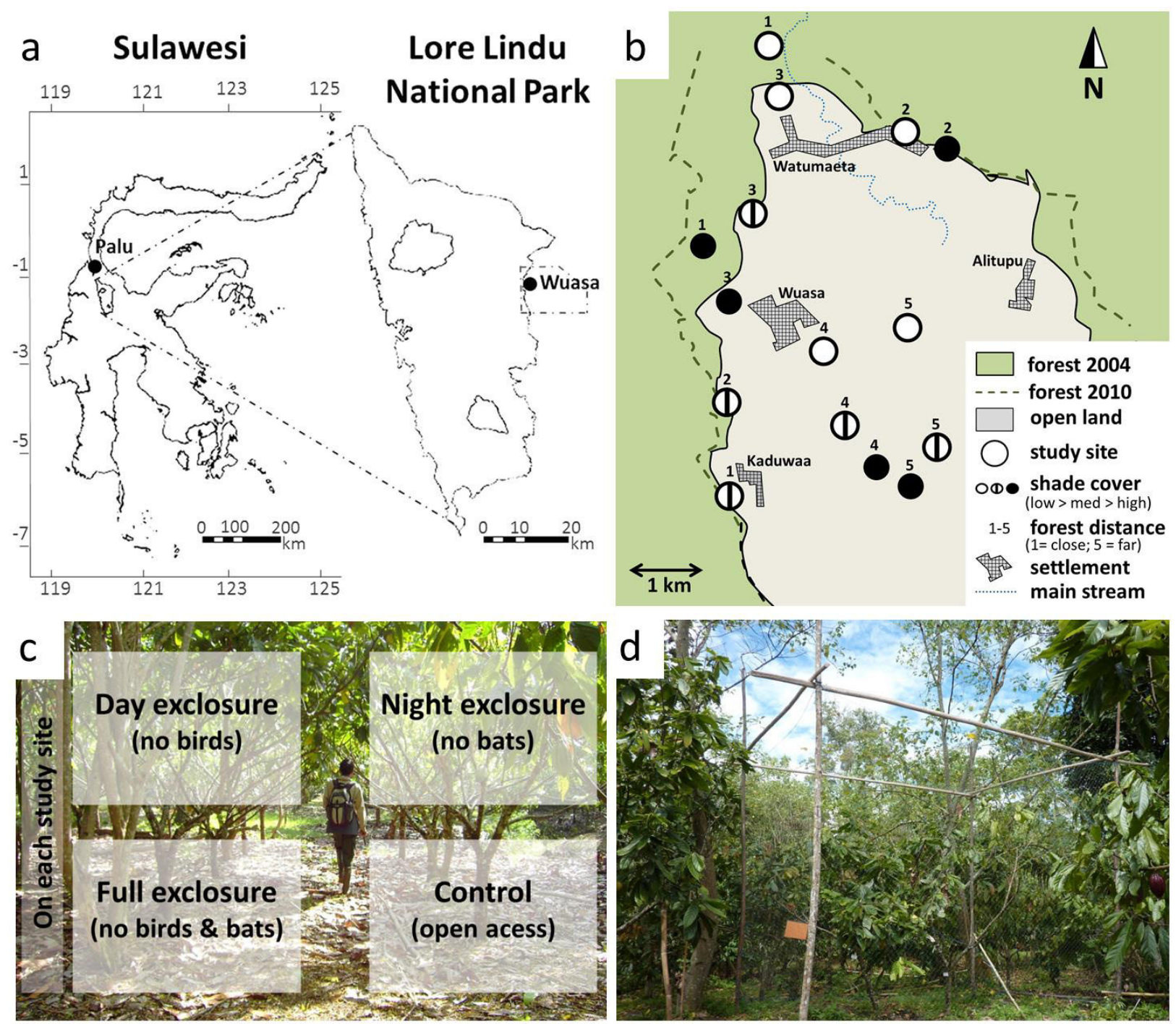

Plate 1: Study area and exclusion experiments. (a) Our study area was located at the eastern border of the Lore Lindu National Park in Central Sulawesi, Indonesia. (b) In our study area, we selected 15 cacao plantations with different local shade tree cover and distance to forest margin as our study sites. (c) On each study site, we established 4 exclosure treatments to manipulate the access of birds and bats. (d) Every exclosure treatment included 2 cacao trees and was built by bamboo constructions and nylon filament nets to exclude birds or bats (in the control treatment, no nets were used). 

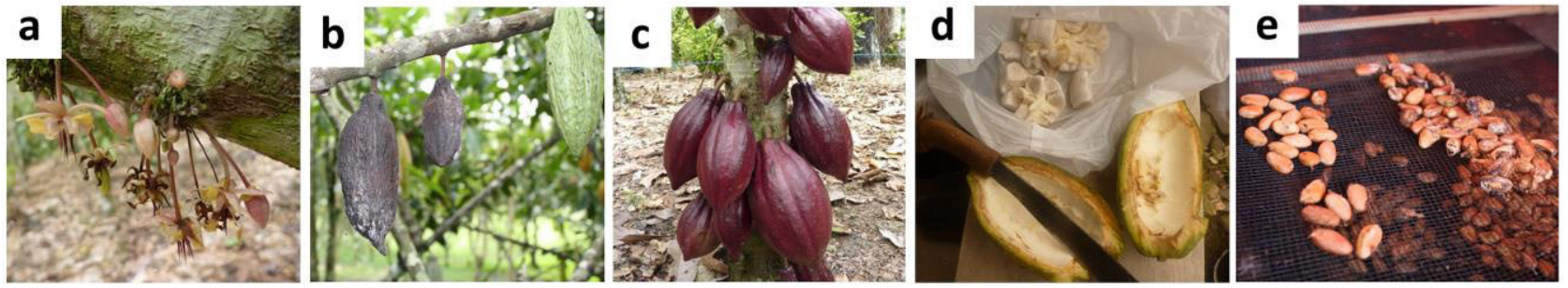

Plate 2: Quantification of cacao fruit development (per tree) and crop yield (per study treatment). (a) Counting of cacao flowers on each tree; (b) Counting of fruits with assessment of fruit pests and diseases until ripeness of fruits; (c) Harvest of ripe fruits; (d) Assessments of pests and diseases inside the harvested fruits plus quantification of fresh weight of cacao yield; (e) drying cacao beans and quantifying dry weight in addition to qualitative sorting (best beans vs. low quality beans).
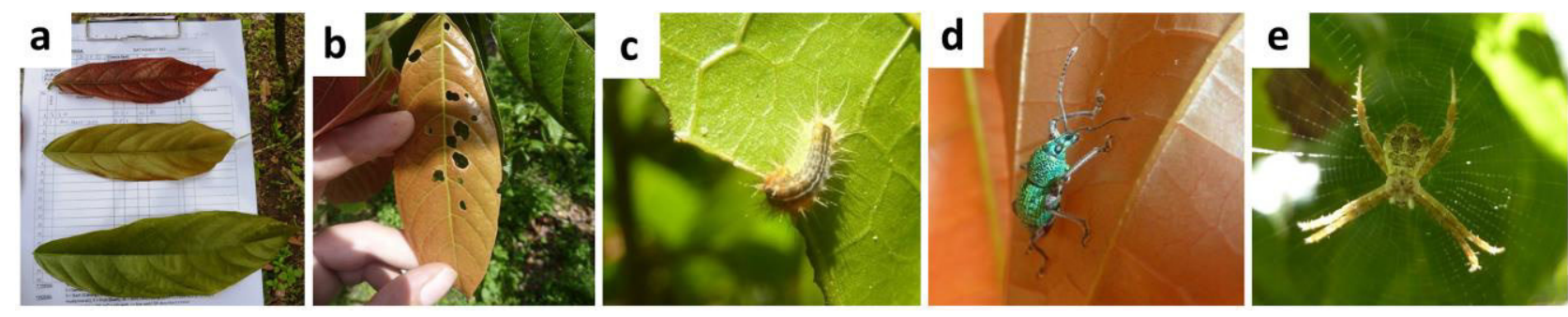

Plate 3: Quantification of leaf herbivory and the arthropod community on each study tree. (a) Leaf development was quantified for 4 weeks with selected groups of young leafs on every study tree; (b) in addition to leaf size and area measurement, we estimated leaf damage by phytophagous arthropods with highly standardized methods. In day-time and night-time arthropod surveys, we quantified the number of (c) all larvae, (d) adult arthropods, (e) spiders and other predatory arthropod groups on our study tress (such as ants). 

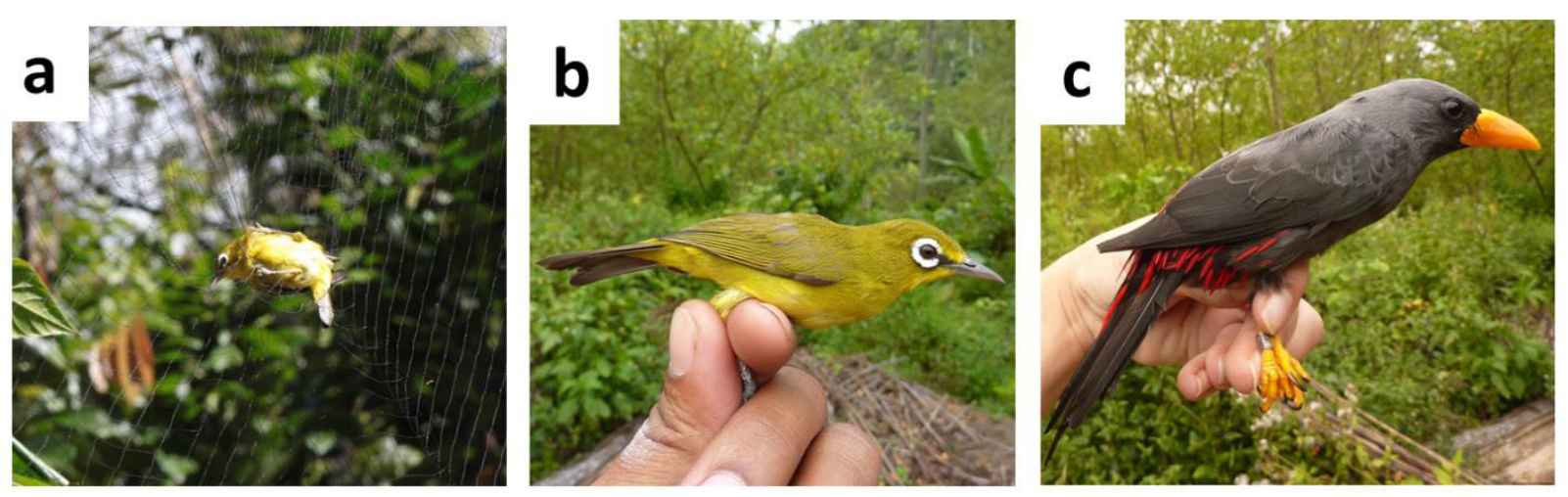

Plate 4: Assessment of the insectivorous bird community. We quantified the bird community on our study sites using point counts and (a) mist netting. In the following, we particularly focused on the role of abundant insectivorous bird species such as (b) Zosterops chloris in our analyses. In addition, we studied the nesting site requirements of (c) Scissirostrum dubium, an endemic Starling species which is well adapted to anthropogenic landscapes and requires proximity to natural forest resources such as large dead trees as nesting sites. 


\section{References}

Achard, F., Eva, H. D., Stibig, H. J., Mayaux, P., Gallego, J., Richards, T. and Malingreau, J. P. (2002) Determination of deforestation rates of the world's humid tropical forests. Science 297: 999-1002.

Bhagwat, S. A., Willis, K. J., Birks, H. J. B. and Whittaker, R. J. (2008) Agroforestry: a refuge for tropical biodiversity?. Trends in Ecology and Evolution 23: 261-267.

Bianchi, F. J. J. A., Booij, C. J. H. and Tscharntke, T. (2006) Sustainable pest regulation in agricultural landscapes: a review on landscape composition, biodiversity and natural pest control. Proceedings of the Royal Society B: Biological Sciences 273: 1715-1727.

Bos, M. M., Steffan-Dewenter, I. and Tscharntke, T. (2007) The contribution of cacao agroforests to the conservation of lower canopy ant and beetle diversity in Indonesia. Biodiversity and Conservation 16: 2429-2444.

Brooks, T. M., Mittermeier, R. A., da Fonseca, G. A., Gerlach, J., Hoffmann, M., Lamoreux, J. F., Mittermeier, C. G., Pilgrim, J. D. and Rodrigues, A. S. (2006) Global biodiversity conservation priorities. Science 313: 58-61.

Cincotta, R. P., Wisnewski, J. and Engelman, R. (2000) Human population in the biodiversity hotspots. Nature 404: 990-992.

Clough, Y., Faust, H. and Tscharntke, T. (2009a) Cacao boom and bust: sustainability of agroforests and opportunities for biodiversity conservation. Conservation Letters 2: 197-205.

Clough, Y., Dwi Putra, D., Pitopang, R. and Tscharntke, T. (2009b) Local and landscape factors determine functional bird diversity in Indonesian cacao agroforestry. Biological Conservation 142: $1032-1041$.

Clough, Y., Barkmann, J., Juhrbandt, J., Kessler, M., Wanger, T. C., Anshary, A., Buchori, D., Cicuzza, D., Darras, K., Dwi Putra, D. Erasmi, S., Pitopang, R., Schmidt, C., Schulze, C. H., Seidel, D., SteffanDewenter, I., Stenchly, K., Vidal, S., Weist M., Wielgoss A. C. and Tscharntke, T. (2011) Combining high biodiversity with high yields in tropical agroforests. Proceedings of the National Academy of Sciences 108: 8311-8316.

Daily, G. C. (2001) Ecological forecasts. Nature 411: 245-245.

Donald, P.F. (2004) Biodiversity impacts of some agricultural commodity production systems. Conservation Biology 18: 17-37.

Estrada-Villegas, S., Meyer, C. F. and Kalko, E. K. (2010) Effects of tropical forest fragmentation on aerial insectivorous bats in a land-bridge island system. Biological Conservation 143: 597-608.

Fahrig, L., Baudry, J., Brotons, L., Burel, F. G., Crist, T. O., Fuller, R. J., Sirami, C., Siriwardena, G. M. and Martin, J. L. (2011) Functional landscape heterogeneity and animal biodiversity in agricultural landscapes. Ecology Letters 14: 101-112.

Faria, D., Laps, R. R., Baumgarten, J. and Cetra, M. (2006) Bat and bird assemblages from forests and shade cacao plantations in two contrasting landscapes in the Atlantic Forest of southern Bahia, Brazil. Biodiversity and Conservation 15: 587-612. 
Fisher, B. and Christopher, T. (2007) Poverty and biodiversity: measuring the overlap of human poverty and the biodiversity hotspots. Ecological Economics 62: 93-101.

Foley, J. A., Defries, R., Asner, G. P., Barford, C., Bonan, G., Carpenter, S. R., Chapin, F. S., Coe, M. T., Daily G. C., Gibbs, H. K., Helkowski J. H., Holloway T., Howard, E. A., Kucharik C. J., Monfreda C.,

Patz J. A., Prentice I. C., Ramankutty N. and Snyder, P. K. (2005) Global consequences of land use. Science 309: 570-574.

Greenberg, R., Bichier, P., Angon, A. C., MacVean, C., Perez, R. and Cano, E. (2000) The impact of avian insectivory on arthropods and leaf damage in some Guatemalan coffee plantations. Ecology 81: 17501755.

Johnson, M. D., Kellermann, J. L. and Stercho, A. M. (2010) Pest reduction services by birds in shade and sun coffee in Jamaica. Animal Conservation 13: 140-147.

Jose, S. (2009) Agroforestry for ecosystem services and environmental benefits: an overview. Agroforestry System 76: 1-10.

Kalka, M. and Kalko, E. K. (2006) Gleaning bats as underestimated predators of herbivorous insects: diet of Micronycteris microtis (Phyllostomidae) in Panama. Journal of Tropical Ecology 22: 1-10.

Kalka, M.B., Smith A.R. and E.K.V. Kalko. (2008) Bats limit arthropods and herbivory in a tropical forest. Science 320: 71.

Karp, D. S., Mendenhall, C. D., Sandí, R. F., Chaumont, N., Ehrlich, P. R., Hadly, E. A. and Daily, G. C. (2013) Forest bolsters bird abundance, pest control and coffee yield. Ecology Letters (in press).

Keinan, A. and Clark, A. G. (2012) Recent explosive human population growth has resulted in an excess of rare genetic variants. Science 336: 740-743.

Koh, L. P. (2008) Birds defend oil palms from herbivorous insects. Ecological Applications 18: 821-825

Kunz, T. H., Braun de Torrez, E., Bauer, D., Lobova, T. and Fleming, T. H. (2011) Ecosystem services provided by bats. Annals of the New York Academy of Sciences 1223: 1-38.

Lawton, J. H., Bignell, D. E., Bolton, B., Bloemers, G. F., Eggleton, P., Hammond, P. M., Hodda, M., Holt, R. D., Larsenk, T. B., Mawdsley, N. A., Stork, N. E., Srivastava, D. S. and Watt, A. D. (1998) Biodiversity inventories, indicator taxa and effects of habitat modification in tropical forest. Nature 391: 72-76.

Lee, T. M., Sodhi, N. S. and Prawiradilaga, D. M. (2007) The importance of protected areas for the forest and endemic avifauna of Sulawesi (Indonesia). Ecological Applications 17: 1727-1741.

Lundberg, J. and F. Moberg. (2003) Mobile link organisms and ecosystem functioning: implications for ecosystem resilience and management. Ecosystems 6: 87-98.

McShane, T. O., Hirsch, P. D., Trung, T. C., Songorwa, A. N., Kinzig, A., Monteferri, B., Mutekanga, D., Van Thang, H., Dammert, J. L., Pulgar-Vidal, M., Welch-Devine, M., Brosius, J. P., Coppolillo, P. and O'Connor, S. (2011) Hard choices: Making trade-offs between biodiversity conservation and human well-being. Biological Conservation 144: 966-972.

Myers, N., Mittermeier, R. A., Mittermeier, C. G., Da Fonseca, G. A. and Kent, J. (2000) Biodiversity hotspots for conservation priorities. Nature 403: 853-858. 
Myers, N. (2003) Biodiversity hotspots revisited. BioScience 53: 916-917.

Moser, G., Leuschner, C., Hertel, D., Hölscher, D., Köhler, M., Leitner, D. Michalzik, B., Prihastanti, E., Tjitrosemito, S. and Schwendenmann, L. (2010) Response of cocoa trees (Theobroma cacao) to a 13month desiccation period in Sulawesi, Indonesia. Agroforestry Systems 79: 171-187.

Perfecto, I., Rice, R. A., Greenberg, R. and Van der Voort, M. E. (1996) Shade coffee: a disappearing refuge for biodiversity. BioScience 46: 598-608.

Perfecto, I., Armbrecht, I., Philpott, S. M., Soto-Pinto, L. and Dietsch, T. V. (2007) Shaded coffee and the stability of rainforest margins in northern Latin America. In Stability of Tropical Rainforest Margins (pp. 225-261). Springer Berlin Heidelberg.

Perfecto, I. and Vandermeer, J. (2008) Biodiversity conservation in tropical agroecosystems. Annals of the New York Academy of Sciences 1134: 173-200.

Rice, R. A. and Greenberg, R. (2000) Cacao cultivation and the conservation of biological diversity. AMBIO: A Journal of the Human Environment 29: 167-173.

Schroth, G. (Ed.). (2004) Agroforestry and biodiversity conservation in tropical landscapes. Island Press.

Schulze, C. H., Waltert, M., Kessler, P. J., Pitopang, R., Veddeler, D., Mühlenberg, M., Gradstein, S. R., Leuschner, C., Steffan-Dewenter, I. and Tscharntke, T. (2004) Biodiversity indicator groups of tropical land-use systems: comparing plants, birds and insects. Ecological Applications 14: 1321-1333.

Sekercioglu, C. H. (2006) Increasing awareness of avian ecological function. Trends in Ecology and Evolution 21: 464-471.

Stattersfield, A. J., Crosby, M. J., Long, A. J. and Wege, D. C. (2005) Endemic bird areas of the world: priorities for biodiversity conservation. BirdLife Conservation 550.

Tscharntke, T., Klein, A. M., Kruess, A., Steffan-Dewenter, I. and Thies, C. (2005) Landscape perspectives on agricultural intensification and biodiversity-ecosystem service management. Ecology Letters 8: 857-874.

Tscharntke, T., Sekercioglu, C. H., Dietsch, T. V., Sodhi, N. S., Hoehn, P. and Tylianakis, J. M. (2008) Landscape constraints on functional diversity of birds and insects in tropical agroecosystems. Ecology 89: 944-951.

Tscharntke, T., Clough, Y., Bhagwat, S. A., Buchori, D., Faust, H., Hertel, D., Hölscher, D., Juhrbandt, J., Kessler, M., Perfecto, I., Scherber, C., Schroth, G., Veldkamp, E. and Wanger, T. C. (2011) Multifunctional shade-tree management in tropical agroforestry landscapes-a review. Journal of Applied Ecology 48: 619-629.

Tscharntke, T., Clough, Y., Wanger, T. C., Jackson, L., Motzke, I., Perfecto, I., Vandermeer, J. and Whitbread, A. (2012) Global food security, biodiversity conservation and the future of agricultural intensification. Biological Conservation 151: 53-59.

Van Bael, S. A., Philpott, S. M., Greenberg, R., Bichier, P., Barber, N. A., Mooney, K. A. and Gruner, D. S. (2008) Birds as predators in tropical agroforestry systems. Ecology 89: 928-934.

Wall Street Journal (2011) Indonesia, Ghana may Fill Cocoa Void. Wall Street Journal, 2011, April 06, pp. n/a. 
Whelan, C. J., Wenny, D. G. and Marquis, R. J. (2008) Ecosystem services provided by birds. Annals of the New York Academy of Sciences 1134: 25-60.

Williams-Guillén, K., Perfecto, I. and Vandermeer, J. (2008) Bats limit insects in a neotropical agroforestry system. Science 320: 70-70.

Williams-Guillén, K. and Perfecto, I. (2010) Effects of Agricultural Intensification on the Assemblage of Leaf-Nosed Bats (Phyllostomidae) in a Coffee Landscape in Chiapas, Mexico. Biotropica 42: 605-613. 



\section{Chapter II}

Bats and birds increase crop yield in tropical agroforestry landscapes

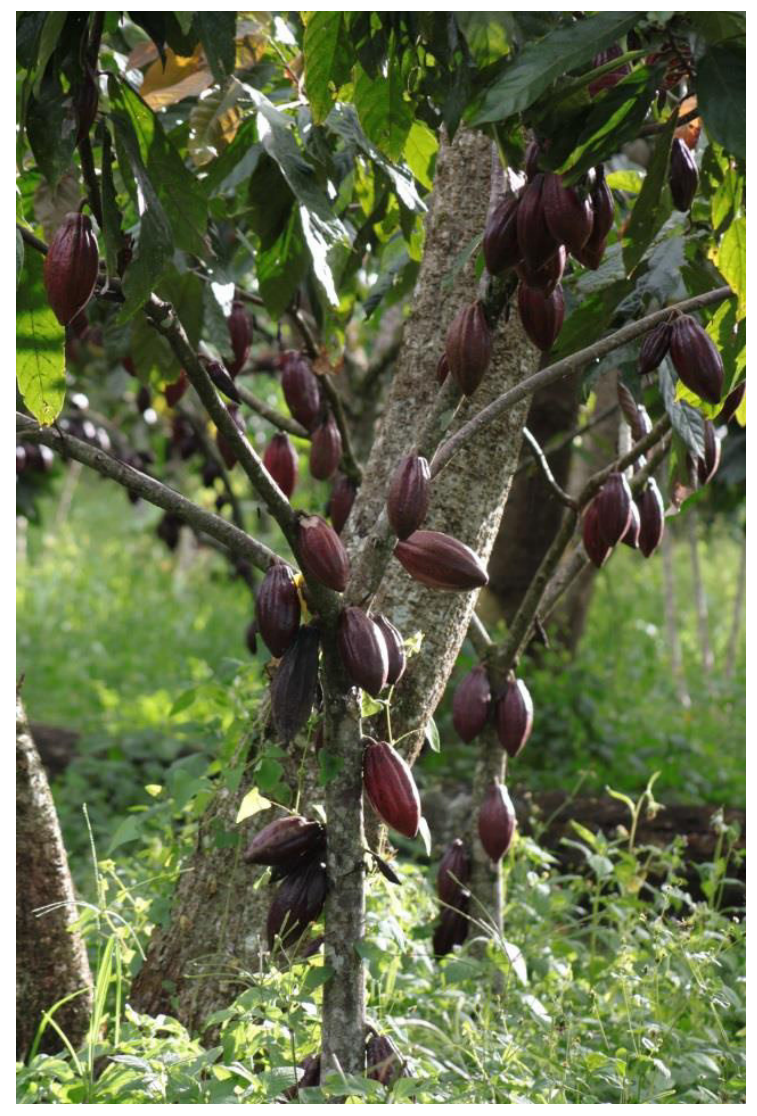




\section{Bats and birds increase crop yield in tropical agroforestry landscapes}

This article is published in Ecology Letters

Manuscript received: $\quad 25$ June 2013

First decision made: $\quad 19$ July 2013

Manuscript accepted: $\quad 10$ September 2013

Running title: Bats and birds increase tropical crop yield

Authors: Bea MAAS ${ }^{1}$, Yann CLOUGH ${ }^{1}$ and Teja TSCHARNTKE ${ }^{1}$

Affiliations:

${ }^{1}$ Agroecology, University of Goettingen, Grisebachstraße 6, 37077 Goettingen, Germany

\section{Keywords:}

Southeast Asia; exclosure field experiment; multitrophic interactions; Theobroma cacao; shade cover; land-use management; biological control; biodiversity conservation; mesopredators; ecosystem services 


\begin{abstract}
Human welfare is significantly linked to ecosystem services such as the suppression of pest insects by birds and bats. However, effects of biocontrol services on tropical cash crop yield are still largely unknown. For the first time, we manipulated the access of birds and bats in an exclosure experiment (day, night and full exclosures compared to open controls in Indonesian cacao agroforestry) and quantified the arthropod communities, the fruit development and the final yield over a long time period (15 months). We found that bat and bird exclusion increased insect herbivore abundance, despite the concurrent release of mesopredators such as ants and spiders, and negatively affected fruit development, with final crop yield decreasing by $31 \%$ across local (shade cover) and landscape (distance to primary forest) gradients. Our results highlight the tremendous economic impact of common insectivorous birds and bats, which need to become an essential part of sustainable landscape management.
\end{abstract}




\section{Introduction}

Ecosystem services such as biological control of pests contribute to human welfare, especially for the world's poor (Millennium Ecosystem Assessment 2005; Boyd \& Banzhaf 2007). Recent studies paid particular attention to the impacts of both diurnal and nocturnal flying predators in different tropical habitats (Kalka et al. 2008; Williams-Guillén et al. 2008; Morrison \& Lindell 2012), but there is no publication showing the influence of birds and bats on arthropod suppression and crop productivity. It has not yet been analyzed in a long-term experimental approach considering effects on arthropods and final yield across spatial scales. This is partly due to the complexity of predator-prey interactions, which are often non-linear, change in space and time, and include direct as well as indirect effects (e.g. Brown et al. 2001; Singer et al. 2012), making predictions difficult. For example, insectivorous birds, which decrease the numbers of leaf chewing insects can indirectly enhance forest tree growth by reduction of leaf damage (Marquis \& Whelan 1994), whereas intermediate densities of minor pests in other ecosystems can be favorable, if they inhibit infestation of major pests (Wielgoss et al. 2012).

Flying vertebrates like birds and bats are considered to be effective arthropod predators in the tropics (e.g. Whelan et al. 2008; Kunz et al. 2011; Morrison \& Lindell 2012), but can also impact predatory insects and spiders, releasing lower trophic levels from potential pest control (e.g. Lundberg \& Moberg 2003). Such mesopredator release (e.g. of predatory spiders and ants) could lead to reorganization of local food web structure and consequentially, unexpected changes in crop productivity, underlining the need for empirical studies that consider the complexity of interactions both in space and time with their relation to crop yield.

We conducted an extensive exclosure field experiment, including 15 months of continuous data collection to investigate the effects of biological control by birds and bats on diurnal and nocturnal insect communities, cacao fruit development, crop yield and leaf herbivory in Indonesian tropical cacao agroforests differing in local shade tree management and distance to primary forest. Such long-term empirical studies (conducted over a period of 12 months or more) better account for variation of environmental and seasonal fluctuations (e.g. Williams- 
Guillén et al. 2008; Singer et al. 2012), changing peaks of population densities and crop yield, which have never been considered in previous exclosure experiments. They also provide for larger sample sizes and higher completeness of species inventories (e.g. Novotný \& Basset 2000).

Landscape structure influences local communities and ecosystem services (e.g. Tscharntke et al. 2012), especially the biological control of insect pests (Bianchi et al. 2006) as well as species richness and diversity of birds and bats (Faria et al. 2006). Both distance to forest margin and available amount of shade trees are known to be critical variables in explaining the composition of bird (Clough et al. 2009) and bat (Faria et al. 2006) communities, in particular of forest species.

Last but not least, the majority of research on the functional role of birds and bats is available from the Neotropics (e.g. Van Bael et al. 2005; Kalka et al. 2008; Williams-Guillén et al. 2008; Morrison \& Lindell 2012), while knowledge from other tropical regions is urgently needed to understand global patterns of biodiversity-related ecosystem services.

We tested the hypotheses that (1) the absence of top predators (birds and bats) does not only influence the abundance of phytophagous insects and mesopredators (predatory ants and spiders) but also (2) affects cacao crop yield. Furthermore, we hypothesized that (3) these effects depend on shade tree availability in the cacao plantations (Clough et al. 2011; Tscharntke et al. 2012), and on the distance to the next closed forest block (Clough et al. 2009), a likely source of foraging insectivorous birds.

To our knowledge, we present the first results from a comprehensive exclosure experiment relating predation of birds and bats to changes in mesopredators (predatory insects and spiders), phytophagous insects, and the development and damage of fruits over more than one year. In particular, we quantified crop yield, the final ecosystem service integrating all intermediate services (Mace et al. 2012), and found that bats and birds induced crop yield increases consistently across local (shade cover) and landscape (distance to primary forest) gradients. 


\section{Material and Methods}

\section{Establishment of long-term exclosures}

All sites were situated at the northern tip of Napu Valley in Central Sulawesi, Indonesia $\left(1^{\circ}\right.$ $25^{\prime} 32^{\prime \prime} \mathrm{S}, 120^{\circ} 18^{\prime} 54^{\prime \prime} \mathrm{E}$ ). After an initial mapping of the study area, we selected 15 smallholder cacao plantations as sites for our exclosure experiments in March 2010 (Fig. 1).

Each site represented a unique combination of two gradients: (i) Local shade tree cover: With reference to Steffan-Dewenter et al (2007) and based on measurements in the field, we quantified local shade tree canopy cover in percent and classified it as low (0-25\%), medium (25-50\%) or high (more than 50\%). In all of our study sites, shade was predominately provided by planted legume shade trees (Erythrina sp. and Gliricidia sp.; $N=2148$; see Appendix Tab. S5), which are favored in many agroforestry systems (e.g. Tscharntke et al. 2011). Single shade tree species from the families Euphorbiaceae (e.g. candle nut tree) and Lauraceae (e.g. avocado) occurred in two thirds of the plots, but were much less common ( $N$ $=87$ and 86 , respectively). We used mean shade tree cover per site, which was calculated from two shade cover surveys in June 2010 and February 2011, using digital photographs of the treatment canopy at each site (Panasonic DMC-TZ7EG-K) and processing software Image J (Rasband 1997-2010).

(ii) Distance to primary forest: Distance to primary forest was determined using satellite pictures and GPS data (Garmin 12 Map) from the study area and measured as the distance (range: 0-3500 m) from the edge of the study site to the edge of the closed forest block. There were no secondary forest patches between the cacao plantations and the primary forest of the adjacent national park (Lore-Lindu National Park).

All cacao plantations were larger than 0.5 hectare (range: 0.5-1.5 ha) and at least $500 \mathrm{~m}$ apart from each other. They were managed by local farmers without applications of insecticides, herbicides or other chemical compounds. We rented 8 cacao trees per site during the period of the study (January 2010 until August 2011). Trained field assistants maintained the experimental plots (see Appendix Tab. S2). Study tree and site characteristics are listed in more detail in the Supporting Information (see Appendix Tab. S1). 


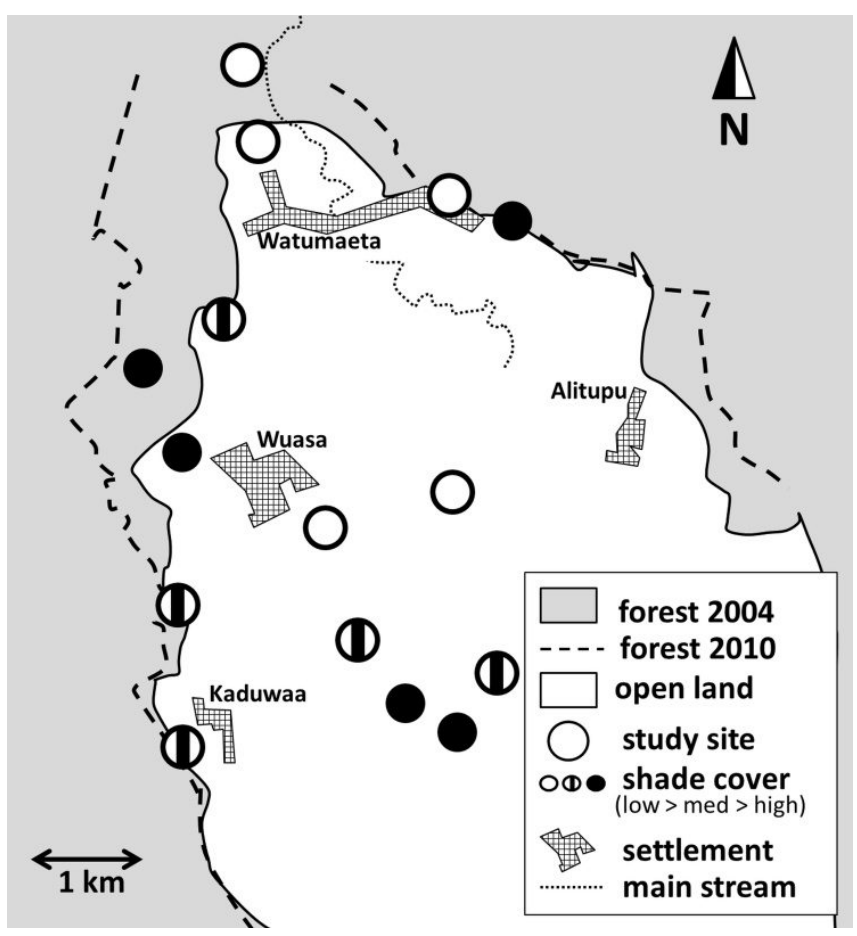

Fig. 1: Schematic map of study sites. Grey parts indicate the closest primary forest block of the Lore Lindu National Park in 2004. The dashed line represents the forest margin measured in our study (2010). White area represents the human dominated open land of the Napu valley (with all other habitat types, including agricultural systems). Our 15 cacao agroforestry study sites are plotted as circles, which indicate the amount of shade cover: 0-25 \% (empty); $25-50 \%$ (half filled) and more than 50\% (filled black).

In each cacao plantation, 4 exclosure treatments (Fig. 2) were established: (1) Day-time exclosure of birds (Day ex.); (2) Night-time exclosure of bats (Night ex.); (3) Total exclosure of both birds and bats (Full ex.); (4) Control treatment with no exclosure (Con). Each of the four exclosure treatments contained two 2.5-4 m high cacao trees. The foliage of the study trees and the exclosure net were always spaced 1-2 m. Except for the control, each treatment was surrounded by an exclosure cage built by a bamboo construction and commercial nylon monofilament with a mesh size of $2 \times 2 \mathrm{~cm}$ (following Van Bael et al. 2005; Kalka et al. 2008; Williams-Guillén et al. 2008). The exclosures prevented access by all bird and bat species but allowed access by arthropods, including large spiders and Lepidoptera (personal observation; see also Morrison \& Lindell 2012). The exclosure nets were opened and closed like curtains daily in the morning hours $(5: 30 \mathrm{am})$ and in the evening $(6: 30 \mathrm{pm})$ to avoid/allow access from all directions. The total exclosure was always closed and cleaned from fallen shade tree leaves if necessary. In total, 120 cacao trees from 60 exclosure treatments on 15 cacao plantation sites were included in our study. 


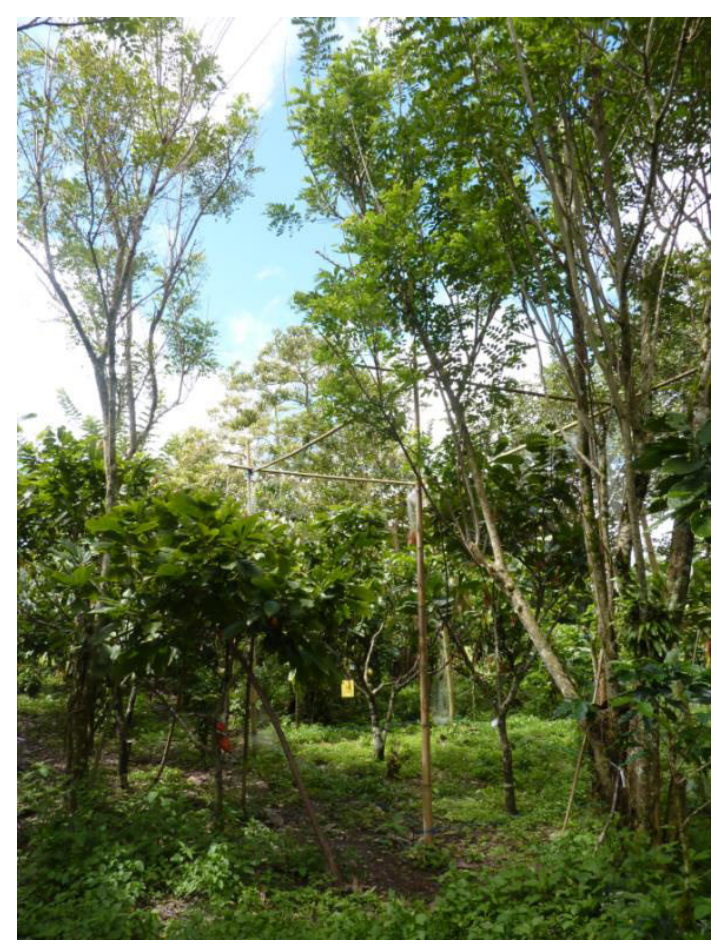

Fig. 2: One of the four exclosure treatments per site (Day, Night and Full Exclosure in addition to a non-caged Control) with two cacao trees (Theobroma cacao) within the exclosure construction of bamboo and nylon monofilament (mesh size: $2 \times 2 \mathrm{~cm}$ ).

After 8 weeks of training of Indonesian assistants and optimization of methods and survey schedules, we started our standardized, repeated surveys in May 2010 and finished in August 2011 (15 months of continuous data collection; see Appendix Tab. S2). Additional mist netting of birds (see Appendix Tab. S3) and data from bat mist netting $23 \mathrm{~km}$ apart from our study area (see Appendix Tab. S4) were used to identify excluded species and families. The most abundant insectivorous bird species excluded within our sites were: Diceaum aureolimbatum, D. celebicum, Nectarinia jugularis, Zosterops chloris and Z. atrifrons (see Appendix Tab. S3). Excluded insectivorous bat species from the western border of the Lore Lindu national park mostly belong to the genera Hipposideros, Myotis, Megaderma and Rhinolophus (Graf 2010, see Appendix Tab. S4).

\section{Arthropod communities}

Every month, B. M. observed the arthropod community of each study tree on each site twice: During daytime (7am until $1 \mathrm{pm})$ and during nighttime (8pm until 2am). We used a time standard of 25-minutes per survey round and tree to observe all insects and spiders on the different parts of the tree. Starting on the ground, we observed stem, branches and tree 
foliage visually and documented the observed arthropods with digital photographs (Panasonic DMC-TZ7EG-K). For each insect or spider, we noted as many attributes as possible and necessary for the best available identification (e.g. colour, morphological characteristics and body size). In the field, we identified insects and spiders at least to order level and estimated the size (in $\mathrm{mm}$ ). We recorded the respective position on the tree (branch, stem, fruit, flower or leaf) and activity (eating or hunting) of each observed individual. The number of insects that occurred in groups larger than 20 individuals was estimated and re-checked after the survey using the photographs. Final identification was done using various references (e.g. Zborowski \& Storey 2010) and photographic material from the surveys, which was archived after each survey.

For statistical analysis, we used seven groups of the most common arthropod groups that are expected to play an essential role within the multitrophic interactions on cacao trees (out of 7 target orders), either being at least partly phytophagous (Coleoptera imagines and Lepidoptera larvae), mesopredators (ants and spiders), phytophagous ant trophobionts (aphids), and/or mainly night active consumers (Orthoptera and Blattodea). Lepidopteran larvae were the only larvae group which was abundant enough (Tab. 1) to perform a separate analysis (in contrast to Coleoptera larvae). As flowers and fruits of cacao grow on the tree stem (cauliflore) and we were interested in quantifying fruit development, we analyzed arthropods on the stem of the cacao trees (including tree stem, branches, fruits and flowers) separately from those on the tree foliage (two different response variables). Each of these seven groups showed up with min. 250 individuals in at least one of the two tree parts.

\section{Cacao pests, fruit production, flowers and yield}

The cacao fruits were surveyed in two steps. First, every two weeks, the number of small, medium and large cacao fruits was counted (according to the methods of Wielgoss et al. 2012) and fruit pests were quantified, including feeding marks of Helopeltis sulawesii Stonedahl (Heteroptera, Miridiae) and cacao pod borer Conopomorpha cramerella Snellen (Lepidoptera: Gracillaridae) feeding symptoms as well as cherelle wilt (early abortion of small cacao fruits smaller than $5 \mathrm{~cm}$ ). 
In addition to the cacao fruits, we counted all cacao flowers (2011-2012) on each tree. Cacao flower and fruit survival strongly depend on multiple factors such as fruit abortion, diseases and pollination and are determined during the first few weeks of fruit development (Bos et al. 2007).

The total number of cacao flowers was used in our analyses. In a second step, all harvested cacao fruits were opened and diseases of the fruit content were recorded (e.g. cacao pod borer damage). Finally, the cacao seeds were dried in separate drying boxes for each treatment per site. The dry cacao seeds (kg/treatment) represent cacao yield in our analyses. Cacao yield was further sorted into first class and second class cacao beans to determine effects on the top quality yield. In total, we recorded 75576 cacao fruits of all size classes (including multiple counts of single fruits which developed during the survey and were therefore counted more than once). Altogether, 4071 cacao fruits were produced and harvested on all sites during our experiment.

\section{Herbivory}

On each study tree, leaf damage (in \%) caused by phytophagous insects (and not by fungi, virus infection, or sunburn) was quantified by a trained assistant. Every month, we marked a new group of 10 freshly developed (red colored and soft) cacao leaves on one or two branches of each study tree, and surveyed them three times (every 10 days). The selection of leaves was determined by the leaf production on the tree itself: very young cacao leaves have an intensive red color, in contrast to leaves older than a few days, which change their color increasingly to green, and are not of primary interest for herbivores (personal observation; see also Van Bael et al. 2005). We measured the leaves' lengths and widths (in $\mathrm{cm}$ ) to calculate the leaf area according to an algorithm developed by Marc Adams (personal communication: $\left.N=97, R^{2}=0.997\right)$ : Area $=(\text { Length*0. 4807 })^{2}$. For analyses we used the absolute leaf loss per tree calculated as the product of leaf area and leaf damage. In total, we investigated 34400 leaves in 30 rounds. 


\section{Statistical analysis}

We used linear mixed-effects models (Ime) with site as a random factor to test for the effects of vertebrate exclosure (treatments were grouped within site) on the observed parameters.

Adequacy of models checked graphically by plotting residuals against fitted values. The variables shade tree cover and distance to forest margin were centered by substracting the mean to improve the interpretation of multiplicative and interaction terms in the models. The distribution of the response variable was assumed to be normal (yield, number of fruit, leaf loss), overdispersed binomial (incidence of damage by pests and diseases) or rightskewed (arthropod counts and number of cacao flowers). The number of all arthropod counts and cacao flowers per treatment were log-transformed (natural logarithms) before analyses. Cacao fruit damage incidences were calculated as the relative proportion of pest infection relative to the total number of harvested cacao fruits $(N=4071)$ or proportion of cherelle wilt pods relative to the total fruit set including black cacao pods ( $N=10362)$. For the analyses of cacao yield, harvested cacao fruits and small cacao fruits, untransformed raw data were used. All data were aggregated at study site and study treatment level.

Exclosure treatment, mean shade cover (\%) and distance to forest (in meters) were used as fixed effects in all initial full models. To produce the final model, we took the models using Maximum Likelihood (ML) and dropped all three- and two-way interactions from the full model that did not reach statistical significance in the LRT (Likelihood Ratio Test). Significance of remaining interaction terms and explanatory variables not entering any interaction term was also assessed using LRT and a manual approach in which single terms were dropped one by one from the full model to investigate effects of the single terms.

To plot the effect of the exclosures relative to the control treatment, we calculated the difference between each study treatment (Day ex., Night ex. and Full ex.) and the control treatment. Coefficients and respective SE's between exclosure treatment and the tested parameters were determined from the models' summary statistics. Differences between groups were considered significant when $P<0.05$. All analyses were conducted using $R$ version 2. 15. 1 (R Core Team 2012). 


\section{Results}

\section{Responses of the arthropod community}

In total, we observed 47406 nocturnal and diurnal insects and spiders belonging to 16 orders and 65 families, from which 32537 individuals from seven target arthropod orders (from at least 46 families) were included in our analyses (Tab. 1).

Tab. 1: Total numbers (N) of the most common arthropod groups observed on (a) woody cacao tree parts (stem, branches, fruits and flowers) or (b) the cacao foliage. Differences between arthropod numbers in daytime and night-time surveys (I and II) are shown above the total count of arthropods (TOTAL). Short names of the groups relate to: Lepidoptera larvae (leplarv), Coleoptera imagines (coleo), wingless Formicidae (ants), Araneae (spiders), Aphididae (aphids), Orthoptera (ortho) and Blattodea (blatto).

\begin{tabular}{lccccccc}
\hline & \multicolumn{7}{c}{ Arthropod groups } \\
No. of individuals & leplarv & coleo & ants & spiders & aphids & ortho & blatto \\
\hline (a) woody parts & 486 & 1101 & 9711 & 3580 & 1343 & 97 & 374 \\
(b) tree foliage & 1973 & 2469 & 1047 & 1330 & 5704 & 250 & 18 \\
\hline (I) Day & 1665 & 2062 & 9367 & 3228 & 5352 & 108 & 162 \\
(II) Night & 794 & 1508 & 1391 & 1682 & 1695 & 239 & 230 \\
\hline TOTAL & 2459 & 3570 & 10758 & 4910 & 7047 & 347 & 392 \\
\hline
\end{tabular}

All arthropod groups responded with significant increases to the absence of birds, bats or both predators in the full exclosure and in at least one of the two cacao tree parts (foliage vs. woody parts). The following results from Post-Hoc tests are displayed in Fig. 3 and listed in detail in the Supplementary Material (see Appendix Tab. S5). On the woody parts of the cacao trees, where flowers and fruit develop, the abundance of the main chewing insect groups, the Coleoptera and larvae of Lepidoptera, increased in the full exclosure and the day exclosure relative to the control treatment $(P<0.05$, Tukey test; Fig. $3 / \mathrm{I}$ a and b). These groups were also often observed actively feeding on cacao flowers. Spiders increased also strongly on woody tree parts in all exclosure treatments $(P<0.05$, Tukey test; Fig. $3 / / \mathrm{d})$. Phloem-feeding aphids increased in the full exclosures on both tree positions $(P<0.05$, Tukey test; Fig. 3/I and II e). Interestingly, mainly night-active insects like Orthoptera and Blattodea increased only within the night exclosures and on both tree parts $(P<0.05$, Tukey test; Fig. $3 / \mathrm{l}$ and II $f$ and $g)$. 
(a)

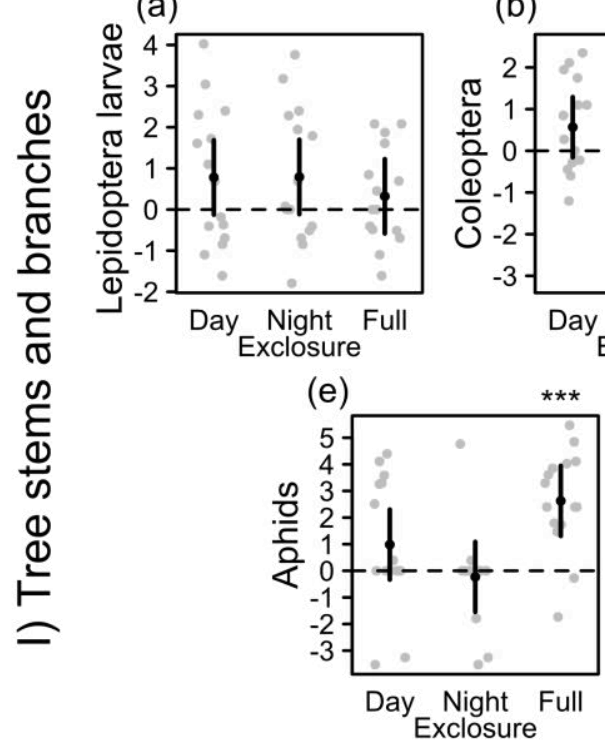

(c)

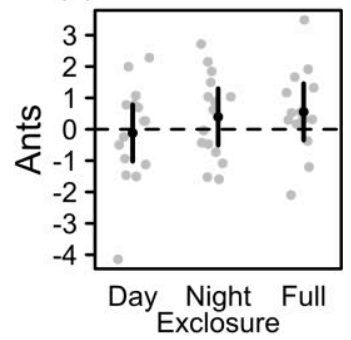

(d)

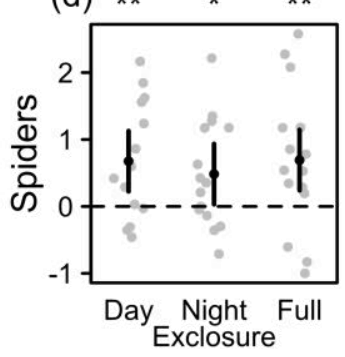

(a) *

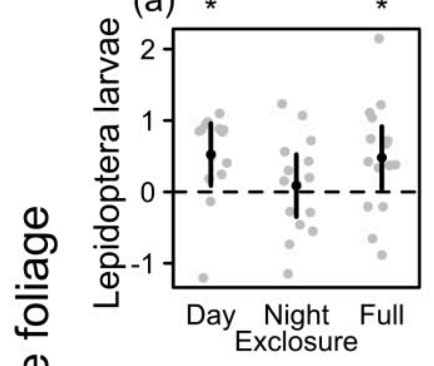

(e)

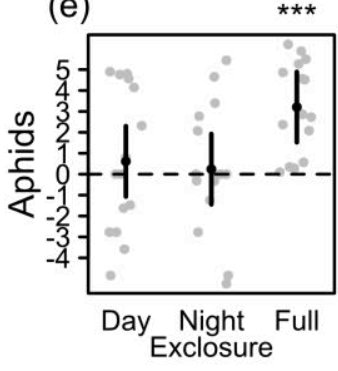

(b) $* * *$
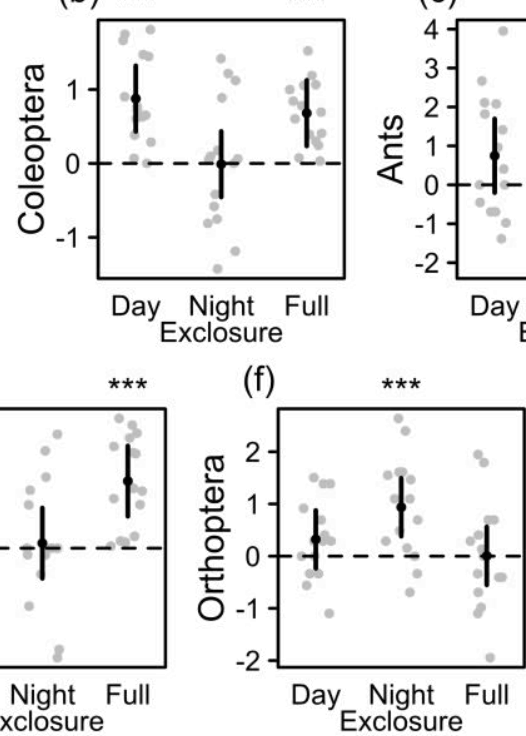

(c)

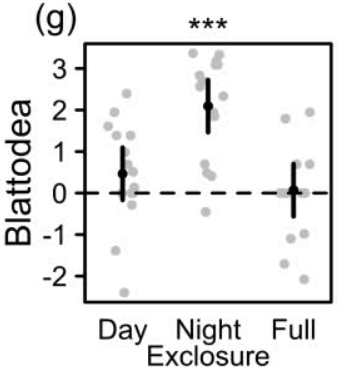

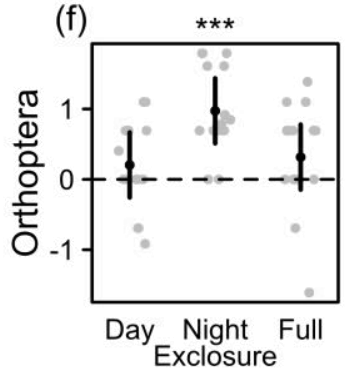

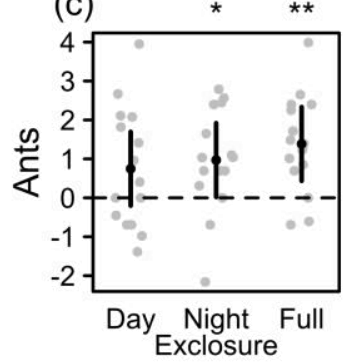

(g)

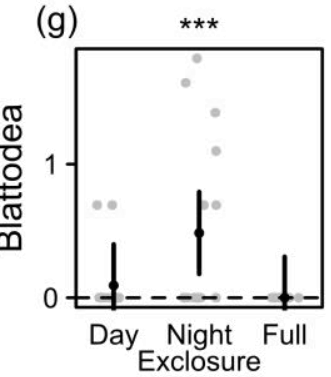

Fig. 3: Effects of daytime, night-time and full exclosures of birds and bats on abundances of seven arthropod groups (a-g) observed on (I) woody parts of the cacao trees (stem, branches, cauliflore fruits and flowers) or (II) on the cacao tree foliage. Observed abundance of all groups increased in the exclosure treatments relative to the unmanipulated control treatment (dashed line at zero level). For each exclosure treatment, the mean number of individuals is displayed in black ( $\pm 95 \%$ confidence intervals) and original data on study site-level (15 circles per treatment) are shown in grey. This allows a direct visual interpretation of treatment effects on single arthropod groups. All individual numbers were LOG transformed before analyses. Asterisk symbols represent statistical significance for $p$ values below $0.05,0.01$ and $0.001\left(*, * *\right.$ and $\left.{ }^{* * *}\right)$.

In contrast, predominantly day-active insects like Coleoptera and Lepidoptera larvae increased only in the day exclosures, and only in their main microhabitat, the tree foliage $(P<$ 0.05, Tukey test; Fig. 3/II a and b). 
Spiders were much less abundant on the tree foliage (only $27 \%$ of the whole spider sample) and increased there only within day exclosures, whereas ants in the tree foliage strongly increased in the night and under full exclosure of birds and bats $(P<0.05$, Tukey test; Fig. $3 /$ II c and d). Abundance of aphids, which were observed to attack young flowers and fruits and were attended by ants, were the only herbivore group that was negatively related to cacao yield $\left(F_{1,44}=7.459, P=0.009 ;\right.$ see Appendix Tab. S7).

\section{Cacao yield}

In total, we recorded 50114 small cacao fruits, 5648 medium-size fruits and 15743 large fruits (including multiple counts of fruits over different survey rounds) during 28 survey rounds on our study sites, resulting in a final count of 4071 ripe and harvested fruits. The number of harvested fruits represents the total amount of cacao fruit production in the exclosure cages. These fruits were used to determine the representative cacao yield per treatment and study site.

In the control treatments, a mean cacao yield (dry cacao beans) of $0.1 \mathrm{~kg}$ per treatment and month was obtained over the whole duration of the experiment. The total amount of cacao yield was closely related to the amount of selected first class cacao beans $\left(R^{2}=0.81, \mathrm{~d}\right.$. $\mathrm{f}$. $=$ $58, N=1680)$. The absence of birds and bats in the full exclosure $(P=0.004)$ and night exclosure $(P=0.032)$, but not in the day exclosure, caused a significant decrease of crop yield compared to the control treatment $(P<0.05$, Tukey test; Fig. 3a). The number of harvested cacao fruits was significantly reduced in all experimental treatments, compared to the mean productivity in the control treatment (all $P<0.05$, Tukey test; Fig. 4 a). 
(a)

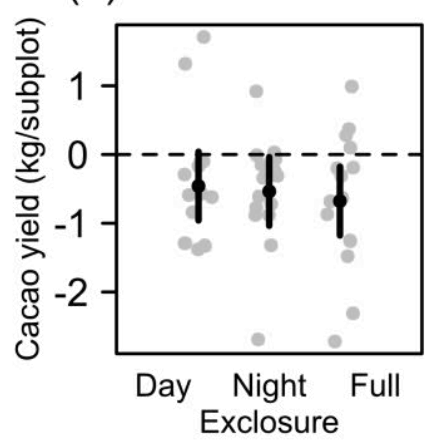

(b)

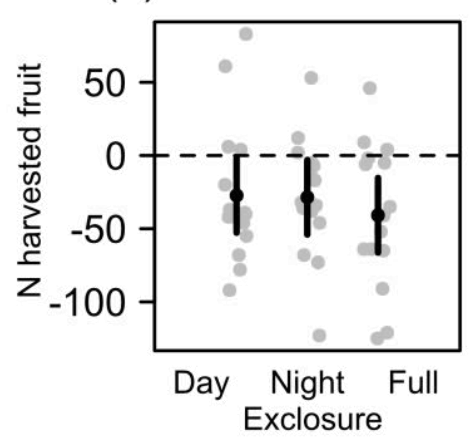

Fig. 4: Results from linear mixed effect models (Ime) and performed Tukey Test's for multiple comparisons of means. The amount of cacao yield (a) decreased as consequence of the exclosures of birds and bats in daytime, night-time and full exclosures from cacao trees. In case of the decreased number of harvested cacao pods (b) this difference was significant in all experimental treatments relative to the control. Asterisk symbols represent statistical significance for $\mathrm{p}$ values below $0.05,0.01$ and $0.001\left(*, * *\right.$ and $\left.{ }^{* * *}\right)$.

The negative effect of bird and bat exclosure was also significant for earlier stages of the cacao fruit development: the number of cacao flowers (log transformed) and small fruits decreased in day exclosures, or night and full exclosure treatments, respectively (see Appendix Fig. S1 and Tab. S6). We calculated the mean reduction of crop yield per site and year (July 2010 until June 2011) following bird and bat exclosure, and translated this loss to an economical value. Relative to the controls, the mean crop yield in the full exclosures was reduced by $31 \%$. Related to the mean size of one exclosure treatment within the cacao plantations $\left(16.43 \mathrm{~m}^{2}\right)$ and the mean yield outcome in the control (1051.73 $\mathrm{kg}$ yield per ha and year), this reduction equals approximately $326 \mathrm{~kg}$ yield per ha and year which are lost due to the absence of birds and bats. According to the current ICCO daily prizes of cacao beans (mean of $2.25 \mathrm{USD} / \mathrm{kg}$ in 2013) this reduction leads to an estimated economical loss of 730 USD per ha and year. The negative effects of bird and bat exclosure on crop yield remain across differences in local shade cover or distance to the nearest forest $(P>0.05)$.

\section{Fruit pests, leaf herbivory and spatial scales}

Neither the damage by the notorious pest species Helopeltis sulawesii and Conopomorpha cramerella, nor leaf herbivory were affected by the exclosure treatments in their abundance $(P>0.05$, see Appendix Fig. S1 and Tab S6). The negative effects of bird and bat exclosure on 
crop yield remain across differences in local shade cover or distance to the nearest forest $(P>$ 0.05). Lepidoptera larvae were the only arthropod group showing positive significant responses to the local and landscape gradients (leplarv: $F_{1,13}=4.686, P=0.05$ ). This group increased in abundance on sites that were both highly shaded and located at higher distances from the primary forest. All other observed arthropod groups (observed total numbers on both tree positions) occurred in similar abundances across both gradients $(P>0.05)$.

\section{Discussion}

Day and night exclosures of birds and bats in tropical cacao agroforestry did not only increase the abundance of phytophagous insects, ants and spiders, but also caused an economically important reduction in crop yield (31\% or 730 USD per ha and year), consistently across gradients of shade cover and distance to primary forest.

\section{Effects on the arthropod communities}

Bat and bird exclosures caused higher densities of phytophagous insects, despite increases in densities of mesopredators such as spiders and ants. Phytophagous insects (which occurred in high abundances) were expected to have a high impact on young leaves, cacao flowers and fruits. These effects were only partially detected. As expected, the number of leaf-eating chewing insects (Coleoptera and Lepidoptera larvae) increased in the day exclosures, whereas mainly night active groups such as Blattodea and Orthoptera increased in the night exclosures (Fig. 3).

Leaf damage did not significantly increase (contrary to our expectations), and was not directly related to insect abundances. Similarly, Williams-Guillén et al. (2008) did not find an effect of exclosures on leaf area losses in coffee agroforestry. We observed several arthropod groups (predominately larvae of Lepidoptera and few Coleoptera larvae) on cacao flowers during our insect surveys and assume that the herbivory on flowers may be of significant importance for the development of the crops, a mechanism which needs to be studied further in detail. 
Coleoptera and Lepidoptera (especially their larvae) are known to be effectively reduced in their abundance by birds with effects on host plants across different habitat types (Van Bael et al. 2005; Barber \& Wouk 2012; Morrison \& Lindell 2012). On the other hand, arthropod groups which might have been underrepresented in former studies due to several reasons such as polyphagy, sampling artifacts and genuine rarity (Novotný \& Basset 2000), showed strong responses within our exclosure treatments. In particular, Orthoptera form a substantial part of the diet of gleaning insectivorous bats (e.g. Belwood \& Morris 1987; Kalka \& Kalko 2006). In contrast to Coleoptera and Lepidoptera, Orthoptera feed on plant foliage throughout their life cycles; individuals are usually rare, but relatively large and high in biomass.

These increases in the abundance of phytophagous insects occurred despite a concurrent increase in mesopredator abundance in response to the exclosures. Prugh et al. (2009) and Brashares \& Prugh (2010) define 'mesopredator release' broadly, as the expansion in density or distribution of a middle-rank predator, resulting from a decline in the density or distribution of an apex predator.

Spiders, which greatly increased in both nocturnal and diurnal exclosures, are abundant predators that can reduce insect pest populations in terrestrial habitats and can curtail plant damage by lowering the numbers of herbivores (Van Bael et al. 2005; Sanders \& Veen 2011). Spiders were the second most observed arthropods in our samplings, which accords with other cacao studies from Sulawesi (Klein et al. 2002).

Night active arthropods strongly declined in abundance in the night-time exclosures which raises the question if and how activity patterns of diurnal and nocturnal predators (Meyer et al. 2004) and their prey are the result of a potential avoidance strategy.

Ants were the most abundant arthropod group observed and ants on the tree foliage responded to the absence of flying vertebrates with strong increases in the night-time and full exclosures. Ant species like Anoplolepis gracilipes, Crematogaster sp., and Monomorium floricola were very abundant in our study sites, and are potential predators of pests in cacao plantation (Rizali et al. 2012). Although ants are considered to be important mesopredators, especially in the tropics (e.g. Conner 2010), they can also provide disservices such as enhancement of their plant-sucking trophobionts (Wielgoss et al. , unpublished data). 
In our study, both ants and aphids (which were ant attended) increased in the exclosures. As aphids attacked flowers and young fruits, their damage might have been significant and may at least partly explain flower and young fruit losses. Further, the fact that aphid density was significantly related to the reductions in final yield pointed to a potentially major role of aphids in cacao yield reduction.

Interestingly, the well-known insect pests of cacao, the Helopeltis bugs and the cacao pod borer, were not affected by bat and bird exclosure. The main reason appeared to be that the cacao pod borer, which is a major cacao pest (Wielgoss et al. 2012), spends most of its immature stages hidden inside the cacao pod and therefore is not at all a conspicuous prey.

\section{Effects on cacao yield and fruit productivity}

Cacao crop yield was significantly reduced in the night-time exclosure and the full exclosure of flying vertebrates, where it decreased by $31 \%$ (Fig. 4). This impressive ecological impact of bats and birds (730 USD per ha and year), is an important argument for public policy makers, farmers and conservationists alike for sustainable management of this service, which is provided by common bird and bat species.

Furthermore, this service might even be enhanced by effective management focused on those bird and bat species that exhibit the greatest beneficial impact on cacao fruit development.

\section{Neotropics vs. Paleotropics}

This study presents the first results of bird and bat exclosures from a paleotropical system. Previous studies focused on the Neotropics (e.g. Van Bael et al. 2003; Kalka et al. 2008; Williams-Guillén et al. 2008; Morrison \& Lindell 2012), the natural origin of Theobroma cacao. Although cacao has been introduced to Indonesia, and now covers 1.5 million hectares of cacao production area (the largest in South-East Asia), it is likewise affected by ecological processes, diseases and pests.

Comparing Neotropics with Paleotropics, differences in species richness and species specialization are conspicuous. Williams-Guillén et al. (2008) reported more than 120 bird species and 45 bat species present in Mexican organic coffee plantations. Bird and bat mist 
netting in agroforestrsy systems in Sulawesi recorded 13 bat species (see Appendix Tab. S4) and 71 bird species (see Appendix Tab. S7). In general, the species richness of birds and bats in neotropical agroforestry is higher than in the Old World tropics, but the mean proportion of endemic species is highest in Southeast Asia (Sodhi et al. 2010). Ongoing conversion of agroforests into simplified agricultural systems can result in shifts towards less specialized bird communities with altered proportions of functional groups (e.g. loss of insectivorous bird species) and cause reduced avian ecosystem functions in these systems (Tscharntke et al. 2008; Sekercioglu 2012).

Migratory birds were found to be of high importance in Neotropical systems, where they showed the strongest correlation with reduced arthropod densities (Van Bael et al. 2008). The presence of migratory bird species might influence the effectiveness of arthropod suppression due to an increased diversity of the bird assemblage, which results in a higher probability of present insectivorous species (e.g. Van Bael et al. 2008). In our study, no migratory birds were recorded.

Contrary to Neotropical studies conducted on forest sites, which detected increased leaf herbivory in bird and bat exclosures in natural habitats (e.g. Van Bael et al. 2005; Kalka et al. 2008), no significant effect on leaf damage could be found in Mexican agroforestry (WilliamsGuillén et al. 2008). This is consistent with our findings, except for the dependency on seasonal effects found by Williams-Guillén et. al. (2008). Such differences in herbivory could be caused by changing food resource use of insects. Cacao insects feed on cacao flowers, whereas flower herbivory does not appear to be important in coffee. Generally, the ecology of cacao flowers as well as their pollination remain largely unstudied and should be included in future research.

Although ecosystem services in agroforestry might be often provided by common species, this does not decrease its potential to support also endangered natural forest species. Recommended management practices like increasing numbers of shade tree species (Clough et al. 2011), exposing roosting boxes (Morrison \& Lindell 2012) and planting fruit trees (Tscharntke et al. 2011) to augment resources for insectivorous birds and bats may become part of biodiversity-friendly management by smallholder farmers (Bhagwat et al 2008) and need to be realized in the near future to prevent losses of ecological services and high biodiversity. 


\section{Conclusions}

The functional importance of birds and bats for tropical agroforestry is demonstrated in our study by the effective suppression of arthropod densities and the impressive increase of cacao crop yield by almost a third. We provide new arguments for wildlife-friendly management of agroecosystems, which is not only important for sustaining rural livelihoods, but also for the potential conservation of endangered species. For a better understanding of the role of birds and bats in tropical agroforestry, further research on biotic interactions shaping their services (e.g. effects on predatory arthropods like ants and spiders) as well as on interactions with other ecosystem services (e.g. pollination) needs to be conducted. These studies should be performed on appropriate scales accounting for temporal (e.g. seasonal effects, migrations, annual breeding cycles) and spatial variation (e.g. local and landscape effects; elevational gradients). Taking into account larger spatial and temporal scales into management practices might even facilitate the beneficial impact of birds and bats on agroforestry crops. 


\section{Acknowledgements}

We thank our team of local farmers and field assistants for giving permission to conduct fieldwork on their land, for their outstanding commitment, hard work and good cooperation in the field. In this regard, special thanks goes to our main assistants Edi, Opu, Papa Ifer, Sinto and Robi which supported our study in all areas. We want to thank the officers of RISTEK Indonesia and all responsible authorities of Tadulako University (CTFM Office) and the city of Palu and Central Sulawesi (Kecamatan Lore Utara) for their great help and support. Dr. Shahabuddin Saleh, our study counterpart, provided very helpful support, for which we are very grateful. We thank Christopher J. Whelan and two anonymous reviewers for their constructive comments on the manuscript. The identification of arthropod families and species was supported by the great help of Kathrin Stenchly (spiders), Arno Wielgoss (ants) and Marc Adams (larvae, beetles and other arthropod groups). The research project was partly funded by a scholarship of the German National Academic Foundation (Studienstiftung des deutschen Volkes) and benefited from financial support from the German Science Foundation (DFG Grant CL-474/1-1 to YC).

\section{References}

Barber, N. a \& Wouk, J. (2012). Winter predation by insectivorous birds and consequences for arthropods and plants in summer. Oecologia, 170, 999-1007.

Belwood, J. \& Morris, G. (1987). Bat predation and its influence on calling behavior in neotropical katydids. Science, 238, 64-67.

Bhagwat, S.A., Willis, K.J., Birks, H.J.B. \& Whittaker, R.J. (2008). Agroforestry: a refuge for tropical biodiversity? Trends Ecol. Evol., 23, 261-7.

Bianchi, F. J. J. A., Booij, C. J. H., \& Tscharntke, T. (2006). Sustainable pest regulation in agricultural landscapes: a review on landscape composition, biodiversity and natural pest control. P. Roy. Soc. BBiol. Sci., 273, 1715-1727.

Bos, M. M., Steffan-Dewenter, I., \& Tscharntke, T. (2007). Shade tree management affects fruit abortion, insect pests and pathogens of cacao. Agr. Ecosyst. Environ., 120, 201-205.

Boyd, J. \& Banzhaf, S. (2007). What are ecosystem services? The need for standardized environmental accounting units. Ecol. Econ., 63, 616-626. 
Brashares, J.S., Prugh, L.R., Stoner, C.J. \& Epps, C. (2010). Ecological and conservation implications of mesopredator release. In: Trophic cascades: predators, prey, and the changing dynamics of nature. Island Press, Washington, DC., pp. 221-240.

Brown, J.H., Whitham, T.G., Morgan Ernest, S.K. \& Gehring, C.A. (2001). Complex species interactions and the dynamics of ecological systems: long-term experiments. Science, 293, 643-650.

Clough, Y., Barkmann, J., Juhrbandt, J., Kessler, M., Wanger, T.C., Anshary, A., et al. (2011). Combining high biodiversity with high yields in tropical agroforests. PNAS, 108, 8311-8316.

Clough, Y., Dwi Putra, D., Pitopang, R. \& Tscharntke, T. (2009). Local and landscape factors determine functional bird diversity in Indonesian cacao agroforestry. Biol. Conserv., 142, 1032-1041.

Conner, L., Rutledge, J.C. \& Smith, L.L. (2010). Effects of Mesopredators on Nest Survival of ShrubNesting Songbirds. J. Wildl. Manag. 74, 73-80.

Faria, D., Laps, R. R., Baumgarten, J., \& Cetra, M. (2006). Bat and bird assemblages from forests and shade cacao plantations in two contrasting landscapes in the Atlantic Forest of southern Bahia, Brazil. Biodivers. Conserv. 15, 587-612.

Graf, S. (2010). Diversity and habitat use of understorey bats in forest and agroforestry systems at the margin of Lore Lindu National Park (Central Sulawesi, Indonesia). Diploma thesis, University of Vienna.

Kalka, M. \& Kalko, E.K. V. (2006). Gleaning bats as underestimated predators of herbivorous insects: diet of Micronycteris microtis (Phyllostomidae) in Panama. J. Trop. Ecol., 22, 1-10.

Kalka, M.B., Smith, A.R. \& Kalko, E.K. V. (2008). Bats limit arthropods and herbivory in a tropical forest. Science, 320, 71-71.

Klein, A., Steffan-Dewenter, I. \& Tscharntke, T. (2002). Predator-prey ratios on cocoa along a land-use gradient in Indonesia. Biodivers. Conserv., 11, 683-693.

Kunz, T. H., Braun de Torrez, E., Bauer, D., Lobova, T., \& Fleming, T. H. (2011). Ecosystem services provided by bats. Ann. NY Acad. Sci., 1223, 1-38.

Lundberg, J. \& Moberg, F. (2003). Mobile link organisms and ecosystem functioning: implications for ecosystem resilience and management. Ecosystems, 6, 87-98.

Mace, G., Norris, K. \& Fitter, A. (2012). Biodiversity and ecosystem services: a multilayered relationship. Trends Ecol. Evol., 27, 19-26.

Marquis, R. \& Whelan, C. (1994). Insectivorous birds increase growth of white oak through consumption of leaf-chewing insects. Ecology, 75, 2007-2014.

Meyer, C., Schwarz, C. \& Fahr, J. (2004). Activity patterns and habitat preferences of insectivorous bats in a West African forest-savanna mosaic. J. Trop. Ecol., 20, 397-407.

Millennium Ecosystem Assessment. (2005). Ecosystems and human well-being: Synthesis. Island Press, Washington, DC.

Morrison, E.B. \& Lindell, C.A. (2012). Birds and bats reduce insect biomass and leaf damage in tropical forest restoration sites. Ecol. Appl., 22, 1526-1534. 
Novotný, V., \& Basset, Y. (2000). Rare species in communities of tropical insect herbivores: pondering the mystery of singletons. Oikos, 89, 564-572.

Prugh, L.R., Stoner, C.J., Epps, C.W., Bean, W.T., Ripple, W.J., Laliberte, A.S., et al. (2009). The Rise of the Mesopredator. BioScience, 59, 779-791.

R Development Core Team, 2007. R: A Language and Environment for Statistical Computing. R Foundation for Statistical Computing, Vienna, Austria. <http:// www.r-project.org>.

Rasband, W. (1997-2010). ImageJ 1.43u. National Institutes of Health, Bethesda, Maryland, USA.

Rizali, A., Clough, Y., Buchori, D., Hosang, M.L.A., Bos, M.M. \& Tscharntke, T. (2012). Long-term change of ant community structure in cacao agroforestry landscapes in Indonesia. Insect Conserv. Diver.

Sanders, D. \& Veen, F. van. (2011). Ecosystem engineering and predation: the multi-trophic impact of two ant species. J. Anim. Ecol., 80, 569-576.

Sekercioglu, C. H. (2012). Bird functional diversity and ecosystem services in tropical forests, agroforests and agricultural areas. J. Ornithol., 153, 153-161.

Singer, M.S., Farkas, T.E., Skorik, C.M. \& Mooney, K.A. (2012). Tritrophic Interactions at a Community Level : Effects of Host Plant Species Quality on Bird Predation of Caterpillars. Am. Nat., 179, 000-000.

Sodhi, N. S., Posa, M. R. C., Lee, T. M., Bickford, D., Koh, L. P., \& Brook, B. W. (2010). The state and conservation of Southeast Asian biodiversity. Biodiv. Conserv., 19, 317-328.

Steffan-Dewenter, I., Kessler, M., Barkmann, J., Bos, M.M., Buchori, D., Erasmi, S., et al. (2007). Tradeoffs between income, biodiversity, and ecosystem functioning during tropical rainforest conversion and agroforestry intensification. P. Natl. Acad. Sci. USA, 104, 4973-4978.

Tscharntke, T., Sekercioglu, C. H., Dietsch, T. V., Sodhi, N. S., Hoehn, P., \& Tylianakis, J. M. (2008). Landscape constraints on functional diversity of birds and insects in tropical agroecosystems. Ecology, $89,944-951$

Tscharntke, T., Clough, Y., Bhagwat, S.A., Buchori, D., Faust, H., Hertel, D., et al. (2011). Multifunctional shade-tree management in tropical agroforestry landscapes - a review. J. Appl. Ecol., 48, 619-629.

Tscharntke, T., Tylianakis, J. M., Rand, T. A., Didham, R. K., Fahrig, L., Batáry, P.et al. (2012). Landscape moderation of biodiversity patterns and processes-eight hypotheses. Biol. Rev., 87, 661-685.

Van Bael, S. A., Brawn, J. D., \& Robinson, S. K. (2003). Birds defend trees from herbivores in a Neotropical forest canopy. P. Natl. Acad. Sci. USA, 100, 8304-8307.

Van Bael, S. A. \& Brawn, J. D. (2005). The direct and indirect effects of insectivory by birds in two contrasting Neotropical forests. Oecologia, 145, 658-668.

Van Bael, S. A. V., Philpott, S. M., Greenberg, R., Bichier, P., Barber, N. A., Mooney, K. A. \& Gruner, D. S. (2008). Birds as predators in tropical agroforestry systems. Ecology, 89, 928-934. 
Vandermeer, J., Perfecto, I. \& Philpott, S. (2010). Ecological complexity and pest control in organic coffee production: uncovering an autonomous ecosystem service. BioScience, 60, 527-537.

Whelan, C. J., Wenny, D. G., \& Marquis, R. J. (2008). Ecosystem services provided by birds. Ann. NY. Acad. Sci., 1134(1), 25-60.47.

Wielgoss, A., Clough, Y., Fiala, B., Rumede, A. \& Tscharntke, T. (2012). A minor pest reduces yield losses by a major pest: plant-mediated herbivore interactions in Indonesian cacao. J. Appl. Ecol., 49, 465-473.

Williams-Guillén, K., Perfecto, I. \& Vandermeer, J. (2008). Bats limit insects in a neotropical agroforestry system. Science, 320, 70-70.

Zborowski, P., \& Storey, R. (2010). Field Guide to Insects in Australia. Reed New Holland. 


\section{Appendix - Chapter II - Bats and birds increase tropical crop yield}

Table S1 - Study site and tree characteristics

We measured all study trees at the beginning of our study (June 2010) and 6 months later in February 2011. An overview of the mean study tree sizes $(a, b)$, distance to the closest primary forest $(c)$, mean shade cover (d) and the dominant legume shade tree species (e: $B=$ Gliricidia sp.; $\mathrm{A}=$ Erythrina sp.; mean height of $8 \mathrm{~m} ; N=2148$ ) for each study site are shown in the table. The cacao tree diameter ( $\mathrm{dbh}$ ) was measured below the first branching of the cacao trees (mean height $=85 \mathrm{~cm}, N=120$ ). Tree size parameters $\mathrm{a}$ and $\mathrm{b}$ do not change the results of the final models from Table $\mathrm{S} 6$ if added as additional covariable.

\begin{tabular}{lccccc}
\hline & $\begin{array}{c}\text { a } \\
\text { mean tree } \\
\text { height }\end{array}$ & b & c & d & e \\
mean tree & distance to next & mean shade & dominant shade \\
site ID & $(\mathrm{cm})$ & dbh $(\mathrm{cm})$ & primary forest $(\mathrm{m})$ & $\begin{array}{c}\text { cover }(\%) \\
\text { tree species }\end{array}$ \\
\hline 1 & 246.63 & 5.70 & 0 & 0.66 & $\mathrm{~B}$ \\
2 & 315.81 & 8.73 & 200 & 0.74 & $\mathrm{~B}$ \\
3 & 311.25 & 7.40 & 480 & 0.50 & $\mathrm{~A}$ \\
4 & 308.94 & 10.51 & 1100 & 0.03 & $\mathrm{~B}$ \\
5 & 380.81 & 12.15 & 3000 & 0.06 & $\mathrm{~B}$ \\
6 & 260.69 & 6.20 & 2300 & 0.65 & $\mathrm{~B}$ \\
7 & 304.19 & 8.64 & 450 & 0.46 & $\mathrm{~A}$ \\
8 & 285.69 & 8.00 & 380 & 0.20 & $\mathrm{~B}$ \\
9 & 265.50 & 7.50 & 1200 & 0.50 & $\mathrm{~B}$ \\
10 & 322.25 & 8.45 & 800 & 0.63 & $\mathrm{~B}$ \\
11 & 271.06 & 7.62 & 3000 & 0.21 & $\mathrm{~B}$ \\
12 & 244.31 & 6.59 & 2700 & 0.53 & $\mathrm{~A}$ \\
13 & 268.44 & 6.74 & 1800 & 0.20 & $\mathrm{~B}$ \\
14 & 300.94 & 7.67 & 1800 & 0.28 & $\mathrm{~B}$ \\
15 & 297.56 & 7.51 & 0 & 0.02 & \\
\hline
\end{tabular}


Table S2 - Detailed information on the research assistant team

In total, 46 local assistants regularly assisted the first author (B.M.) in the field. B.M. was present in the field during the whole period of the study. All major parts of the field work were within her responsibility, and coordinated by her. In the field, there were basically two types of field work: physical work (construction; maintenance; transportation) and scientific work (preparation, collection and processing of data). The first type was conducted by a large number of local field assistants and workers, including the cacao plantation owners themselves. Scientific work was exclusively planned and supervised by the first author. B.M. did preliminary investigations for all datasets and trained scientific head assistants as long as necessary in each case (2-8 weeks). All head assistants were either well experienced scientific field work assistants (with minimum 6 years of experience in other biological research projects; e.g. SFB552/"STORMA" by the DFG), or biology master students from the Tadulako University in Palu. After weeks of training, coordination and supervision by B.M., they collected data in the field (e.g. leaf measurements; counting of fruits; weighing seeds) in groups of at least two persons per task. During the whole period of field work, all tasks were supervised by the first author and regular trainings occurred to test the accuracy of the measurements in the field and the technical devices used in our study. The head assistants did not change during the study. Except three persons assisting for a shorter period, the field work team consisted of the same persons during the whole experiment.

\begin{tabular}{ll}
\hline field work & Short description of tasks and field work \\
\hline Manual & All tasks supervised and coordinated by the first author and \\
& scientific-assistants: Construction and maintenance of treatments; \\
& Daily opening and closing of exclosure cages; Pruning and mowing in \\
& treatments; Transportation of field equipment and other logistic \\
& tasks; Assisting in data collection \\
\hline Scientific & Data measurements (after previous training periods): Head \\
& assistants helped with coordination of local workers, and were \\
& responsible in one major data project each (fruit development data \\
& and leaf herbivory data); Master students assisted during insect \\
& surveys (all identifications confirmed by B.M.), and helped with entry \\
& of first data. Bird mist netting was done in cooperation with a \\
& scientific bird expert (Dadang Dwi Putra). \\
\hline
\end{tabular}


Table S3 - Insectivorous bird species

Most common excluded insectivorous bird species were determined by repeated mist netting surveys on our 15 study sites (monthly mist netting per site in September 2010 and between February and June 2011; total of 7 mist netting runs per site). Short method description: We used 8 mist nets per study site (each net $6 \times 3 \mathrm{~m}$ in size with $6 \mathrm{~mm}$ mesh size) and situated them along a continuous net line $(48 \mathrm{~m})$ in the middle of the study site. From 06 h00 until 17h00, nets were checked every 60 minutes (every 30 minutes only under cold weather conditions). All captured birds were identified, banded with uniquely numbered metal rings and measured following the Level 1 standard of the revised field method manual published by Bairlein et al. (1995) ${ }^{1}$. The ten most common bird species are listed according to the total number of individuals captured (excluding re-captures) and with their habitat affiliations and distribution (endemic v. widespread species). In total, we observed 71 bird species belonging to 37 families within the 15 studied cacao agroforestry systems.

\begin{tabular}{lccc}
\hline Species name & Habitat affiliation & Endemic/Widespread & Total number \\
\hline Zosterops chloris & GEN & W & 626 \\
Dicaeum celebicum & GEN & E & 167 \\
Dicaeum aureolimbatum & GEN & E & 61 \\
Zosterops atrifrons & GEN & W & 48 \\
Nectarinia jugularis & OL & W & 25 \\
Halcyon chloris & OL & W & 20 \\
Scissirostrum dubium & GEN & E & 19 \\
Aplonis minor & GEN & W & 13 \\
Nectarinia aspasia & GEN & W & 9 \\
Dicaeum nehrkoni & FO & E & 9 \\
\hline
\end{tabular}

*Habitat affiliation: GEN (generalistic); OL (open land) and FO (forest) habitat.

${ }^{1}$ Bairlein, F., Jenni, L., Kaiser, A., Karlsson, L., Noordwijk, A., Peach, W. and Walinder, G. (1995). European-African songbird migration network: manual of field methods. Vogelwarte Helgoland, Wilhelmshaven. 
Table S4 - Insectivorous bat species

List of the insectivorous bat species captured in a mist netting study of Graf $(2010)^{2}$. The study was conducted in the Kulawi valley, situated at the western border of the Lore Lindu National Park in Central Sulawesi (approximately $23 \mathrm{~km}$ apart from our study area in Napu valley). Insectivorous bat species (Microchiroptera) were captured along a habitat gradient (natural forests, selectively logged forests and agroforestry systems) and belonged to 4 families and 7 species.

\begin{tabular}{ll}
\hline Family & Species \\
\hline Rhinolophidae & Rhinolophus borneensis (Peters, 1861) \\
Rhinolophidae & Rhinolophus euryotis (Temminck, 1835) \\
Hipposideridae & Hipposideros cervinus (Gould, 1863) \\
Verspertilionidae & Myotis ater (Peters, 1866) \\
Verspertilionidae & Myotis horsfieldii (Temminck, 1840) \\
Verspertilionidae & Myotis muricola (Gray, 1864) \\
Megadermatidae & Megaderma spasma (Linnaeus, 1758) \\
\hline
\end{tabular}

${ }^{2}$ Graf, S. (2010). Diversity and habitat use of understorey bats in forest and agroforestry systems at the margin of Lore Lindu National Park (Central Sulawesi, Indonesia). Diploma thesis, University of Vienna. 
Table S5 - Arthropod responses to bird/bat exclosures

Results from final linear mixed effect (Ime) models (with treatment) fit by REML (Restricted Maximum Likelihood) and Post Hoc tests (Tukey's Test) for the total number of each investigated arthropod group (log transformed) both on (A) woody tree parts and on the (B) tree foliage. The table results from the summary statistics of the final Ime model (value and Standard Error SE) and the Tukey's Post Hoc test of significance ( $P$-value, upper and lower bound of Confidence Interval $\mathrm{Cl}$ ) for both tree positions.

\begin{tabular}{|c|c|c|c|c|c|c|c|c|c|}
\hline \multirow{3}{*}{$\begin{array}{l}\text { Group } \\
\text { name }\end{array}$} & \multirow{3}{*}{$\begin{array}{l}\text { Exclosure } \\
\text { treatment }\end{array}$} & \multirow{2}{*}{\multicolumn{2}{|c|}{ final model }} & \multicolumn{3}{|c|}{ A) WOODY TREE PARTS } & \multicolumn{3}{|c|}{ B) TREE FOLIAGE } \\
\hline & & & & & Tukey's Te & & & Tukey's Te & \\
\hline & & value & SE & $p$ & Cl_upper & Cl_lower & $\mathrm{p}$ & $\mathrm{Cl}$ _upper & Cl_lower \\
\hline \multirow{4}{*}{$\begin{array}{l}\text { Lepidoptera } \\
\text { larvae }\end{array}$} & Control & 1.039 & 0.307 & - & 0 & 0 & - & 0 & 0 \\
\hline & Day ex. & 0.779 & 0.386 & 0.110 & 1.687 & -0.128 & 0.013 & 0.960 & 0.088 \\
\hline & Night ex. & 0.792 & 0.386 & 0.103 & 1.699 & -0.115 & 0.935 & 0.524 & -0.348 \\
\hline & Full ex. & 0.322 & 0.386 & 0.740 & 1.229 & -0.585 & 0.026 & 0.917 & 0.045 \\
\hline \multirow[t]{4}{*}{ Coleoptera } & Control & 2.208 & 0.249 & - & 0 & 0 & - & 0 & 0 \\
\hline & Day ex. & 0.567 & 0.320 & 0.186 & 1.319 & -0.185 & 0.0001 & 1.322 & 0.431 \\
\hline & Night ex. & 0.146 & 0.320 & 0.941 & 0.898 & -0.606 & 0.100 & 0.435 & -0.456 \\
\hline & Full ex. & 0.794 & 0.320 & 0.036 & 1.546 & 0.041 & 0.0009 & 1.126 & 0.234 \\
\hline \multirow{4}{*}{$\begin{array}{l}\text { Formicidae } \\
\text { (adult } \\
\text { wingless } \\
\text { ants) }\end{array}$} & Control & 4.470 & 0.293 & - & 0 & 0 & - & 0 & 0 \\
\hline & Day ex. & 0.119 & 0.384 & 0.980 & 0.783 & -1.022 & 0.160 & 1.698 & -0.204 \\
\hline & Night ex. & 0.393 & 0.384 & 0.608 & 1.296 & 1.296 & 0.044 & 1.921 & 0.020 \\
\hline & Full ex. & 0.555 & 0.384 & 0.336 & 1.458 & 1.458 & 0.002 & 2.335 & 0.434 \\
\hline \multirow[t]{4}{*}{ Arachnida } & Control & 3.478 & 0.155 & - & 0 & 0 & - & 0 & 0 \\
\hline & Day ex. & 0.676 & 0.193 & 0.001 & 1.129 & 0.226 & 0.011 & 1.083 & 0.114 \\
\hline & Night ex. & 0.484 & 0.193 & 0.033 & 0.937 & 0.937 & 0.061 & 0.952 & -0.017 \\
\hline & Full ex. & 0.692 & 0.193 & 0.001 & 1.145 & 0.239 & 0.079 & 0.930 & -0.039 \\
\hline \multirow[t]{4}{*}{ Aphididae } & Control & 0.775 & 0.392 & - & 0 & 0 & - & 0 & 0 \\
\hline & Day ex. & 0.984 & 0.554 & 0.193 & 2.303 & -0.336 & 0.725 & 2.302 & -1.072 \\
\hline & Night ex. & 0.228 & 0.554 & 0.957 & 1.091 & -1.548 & 0.975 & 1.927 & -1.447 \\
\hline & Full ex. & 2.626 & 0.554 & 0.0001 & 3.945 & 1.306 & 0.0001 & 4.895 & 1.521 \\
\hline \multirow[t]{4}{*}{ Orthoptera } & Control & 0.365 & 0.138 & - & 0 & 0 & - & 0 & 0 \\
\hline & Day ex. & 0.205 & 0.195 & 0.596 & 0.668 & -0.258 & 0.387 & 0.879 & -0.235 \\
\hline & Night ex. & 0.974 & 0.195 & 0.001 & 1.437 & 0.511 & 0.0002 & 1.494 & 0.381 \\
\hline & Full ex. & 0.316 & 0.195 & 0.254 & 0.779 & -0.146 & 0.999 & 0.563 & -0.551 \\
\hline \multirow[t]{4}{*}{ Blattodea } & Control & 0.713 & 0.209 & - & 0 & 0 & - & 0 & 0 \\
\hline & Day ex. & 0.465 & 0.283 & 0.202 & 1.096 & -0.167 & 0.818 & 0.397 & -0.212 \\
\hline & Night ex. & 2.095 & 0.283 & 0.001 & 2.726 & 1.463 & 0.0006 & 0.790 & 0.180 \\
\hline & Full ex. & 0.070 & 0.283 & 0.988 & 0.702 & -0.561 & 1.000 & 0.305 & -0.305 \\
\hline
\end{tabular}


Table S6 - Cacao fruit development and leaf herbivory

Results from final linear mixed effect (Ime) models (withtreatment) fitted by REML (Restricted Maximum Likelihood) and Post Hoc tests (Tukey's Test) for different stages of the cacao harvesting process (yield in $\mathrm{kg} /$ treatment; $\mathrm{N}$ of harvested fruits; $\mathrm{N}$ of small fruits; log transformed $\mathrm{N}$ of cacao flowers) and the percentage of leaf damage due to herbivores. The table shows results from the summary statistics of the final Ime model (value and Standard Error SE) and the Tukey's Post Hoc test of significance ( $P$-value, upper and lower bound of Confidence Interval $\mathrm{Cl}$ ).

\begin{tabular}{lcccccc}
\hline \multirow{2}{*}{ Variable } & \multicolumn{2}{c}{ final model } & & \multicolumn{1}{c}{ Tukey's Test } & \\
& $\begin{array}{c}\text { Exclosure } \\
\text { treatment }\end{array}$ & value & SE & $p$ & Cl_upper & Cl_lower \\
\hline Cacao & Control & 1.940 & 0.198 & - & 0 & 0 \\
yield & Day ex. & -0.459 & 0.213 & 0.081 & 0.042 & -0.959 \\
& Night ex. & -0.536 & 0.213 & $\mathbf{0 . 0 3 2}$ & -0.035 & -1.037 \\
& Full ex. & -0.677 & 0.213 & $\mathbf{0 . 0 0 4}$ & -0.177 & -1.178 \\
\hline Fruits & Control & 92.000 & 9.275 & - & 0 & 0 \\
(harv.) & Day ex. & -27.267 & 10.869 & $\mathbf{0 . 0 3 3}$ & -1.736 & -52.792 \\
& Night ex. & -28.533 & 10.869 & $\mathbf{0 . 0 2 4}$ & -3.003 & -54.059 \\
& Full ex. & -40.800 & 10.869 & $\mathbf{0 . 0 0 1}$ & -15.270 & -66.325 \\
\hline Fruits & Control & 1185.000 & 175.640 & - & 0 & 0 \\
(small) & Day ex. & -306.867 & 204.891 & 0.307 & 174.415 & -788.281 \\
& Night ex. & -578.067 & 204.891 & $\mathbf{0 . 0 1 3}$ & -96.785 & -1059.481 \\
& Full ex. & -514.133 & 204.891 & $\mathbf{0 . 0 3 3}$ & -32.851 & -995.548 \\
\hline Flowers & Control & 8.521 & 0.160 & - & 0 & 0 \\
(log) & Day ex. & -0.405 & 0.153 & $\mathbf{0 . 0 1 2}$ & -0.046 & -0.765 \\
& Night ex. & -0.234 & 0.153 & 0.355 & 0.216 & -0.503 \\
& Full ex. & -0.143 & 0.153 & 0.136 & 0.126 & -0.593 \\
\hline Leaf & Control & 407.112 & 39.175 & - & 0 & 0 \\
Damage & Day ex. & 11.880 & 55.402 & 0.993 & 142.021 & -118.257 \\
(\%) & Night ex. & 0.976 & 55.402 & 0.993 & 131.118 & -129.161 \\
& Full ex. & 11.703 & 55.402 & 1.000 & 141.845 & -118.434 \\
\hline & & & & & &
\end{tabular}


Table S7 - Yield vs. pest insect abundances

Relationship between total cacao yield (dry weight of harvest outcome) and the total number of herbivore arthropods resulting from linear mixed effect models (Ime). Significant relationships in bold.

\begin{tabular}{lcc}
\hline Herbivore group & \multicolumn{2}{c}{ Ime model } \\
\hline & F-value $(1,44)$ & $p$-value \\
Lepidoptera larvae & 0.037 & 0.848 \\
Coleoptera & 0.512 & 0.478 \\
Aphids & 7.459 & $\mathbf{0 . 0 0 9}$ \\
Orthoptera & 0.572 & 0.454 \\
\hline
\end{tabular}


Figure S1 - Cacao fruit development, leaf herbivory and fruit pests

Effects of the experimental exclosures (Day, Night and Full exclosure of birds and bats) on (a) the number of small cacao fruits, (b) number of cacao flowers (LOG), (c) the total leaf loss area (in $\mathrm{cm}^{2}$ ) and the percentages of the notorious cacao fruit pests (d) cocoa pod borer (Conopomorpha cramerella), (e) mirid damage (Helopeltis sulawesii) and (f) early fruit abortion (cherrele wilt). Each exclosure treatment effect is shown relative to the unmanipulated control treatment (dashed line at zero level). The mean value of each parameter is displayed in black ( $\pm 95 \%$ confidence intervals) and original data on study sitelevel (15 circles per treatment) are displayed as grey filled circles. This allows a direct visual interpretation of treatment effects on (a) - (f). Asterisk symbols represent statistical significance for $\mathrm{p}$-values below $0.05\left(^{*}\right)$.

(a)
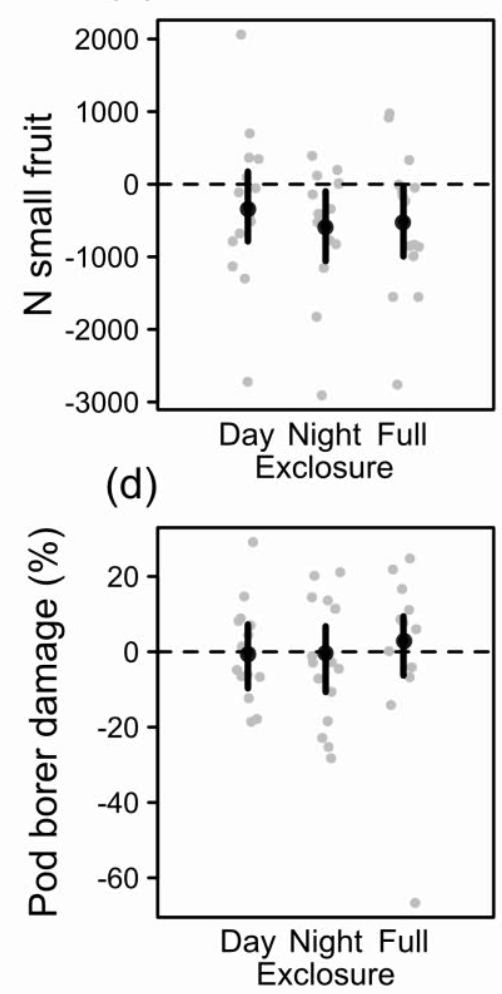

(b)

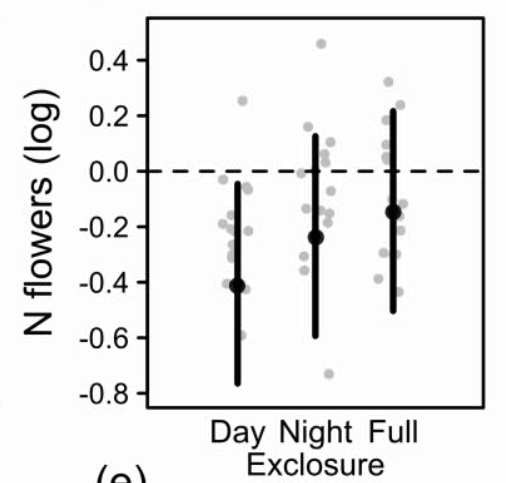

(e)

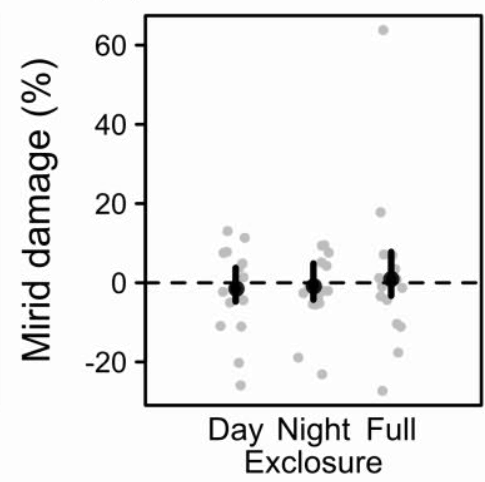

(c)

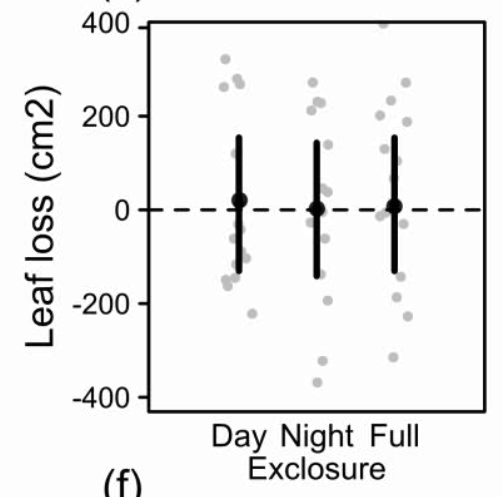

(f)

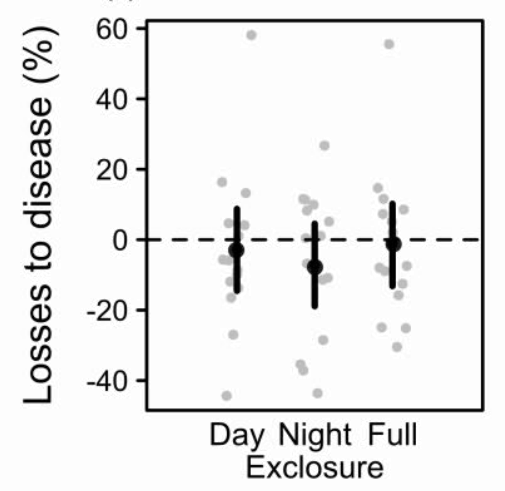


Chapter III

Avian species identity drives predation success in tropical cacao agroforestry

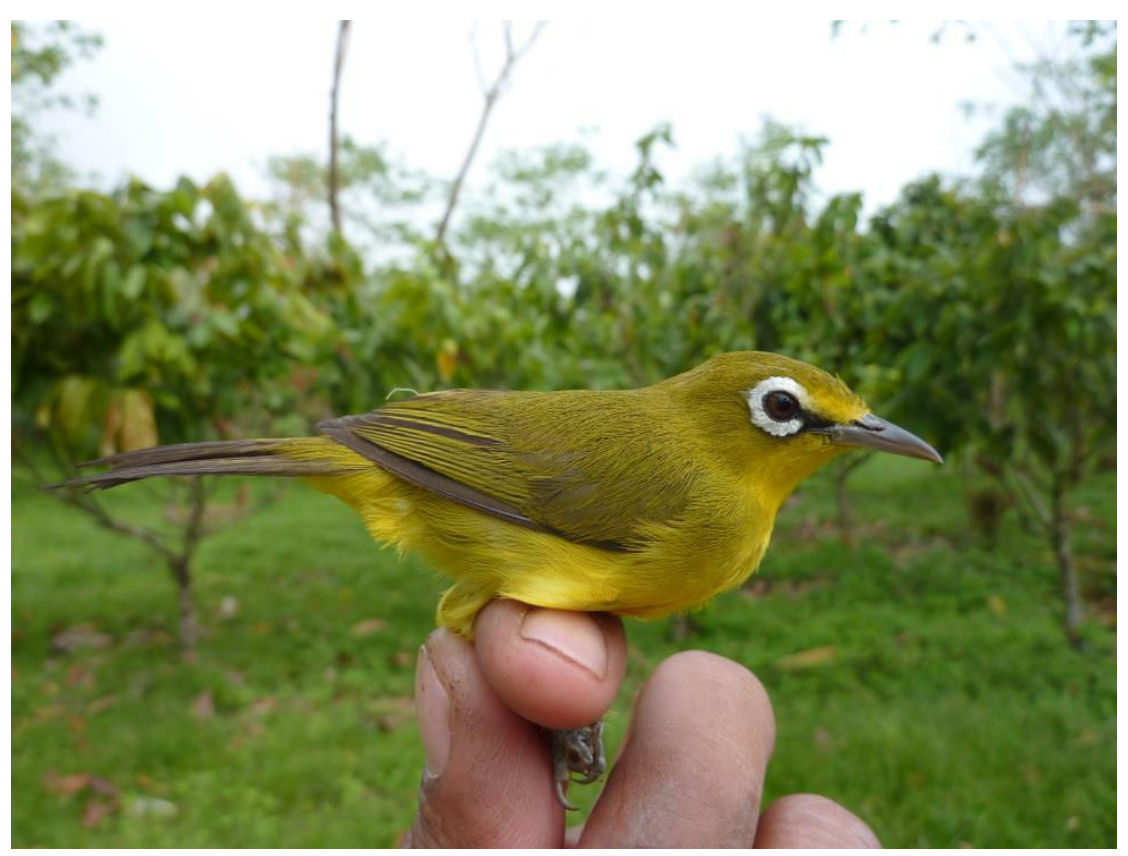




\section{Avian species identity drives predation success in tropical cacao agroforestry}

This article is submitted to Journal of Applied Ecology

Submission date: 31 March 2014

Running title: Avian predator identity vs. diversity

Authors: Bea MAAS ${ }^{1}$, Teja TSCHARNTKE ${ }^{1}$, Saleh SHAHABUDDIN ${ }^{2}$, Dadang DWI PUTRA ${ }^{3}$ and Yann CLOUGH ${ }^{1,4}$

\section{Affiliations:}

${ }^{1}$ Agroecology, University of Goettingen, Goettingen, Germany

${ }^{2}$ Faculty of Agriculture, University of Tadulako, Palu 94118, Indonesia

${ }^{3}$ Celebes Bird Club c/o Balai Penelitian dan Pengembangan Zoologi, Puslitbang Biologi - LIPI, Cibinong, Indonesia

${ }^{4}$ Centre for Environmental and Climate Research, Faculty of Science, Lund University, Sölvegatan 37, SE-223 62 Lund, Sweden

Keywords: biodiversity-friendly; biological control; Central Sulawesi; ecosystem service management; forest proximity; landscape gradient; predation experiment; shade tree management; species-specific functions; Zosterops chloris 


\section{Summary}

1. Avian ecosystem services such as the suppression of arthropods are considered being of high ecological and economic importance in a range of ecosystems, especially in tropical agroforestry. But how bird predation success is concretely affected by the diversity and composition of the bird community, as well as local and landscape factors, is poorly understood.

2. We quantified arthropod predation in relation to the identity and diversity of insectivorous birds, using artificial prey experiments on 15 smallholder cacao plantations, differing in local shade management and distance to primary forest. To sample birds, both mist netting (targeting on active understory insectivores) and point counts (higher completeness of species inventories) were used.

3. Bird predation success in differently managed cacao agroforestry systems was not related to local shade tree management or overall species diversity, but to the activity of insectivorous bird species and the proximity to primary forest. Insectivore activity was best predicted by mist netting based data, not point counts. We identified the Indonesian endemic Lemon-bellied White-eye (Zosterops chloris) as the main driver of predation on artificial prey.

4. Synthesis and applications. The suppression of arthropods by insectivorous birds is one of the most important ecosystem services provided in agricultural systems, where it has the potential to reduce herbivore damage on plants and yields. Targeted management of this service represents a biodiversity-friendly and profitable alternative to the use of pesticides and other chemical compounds, but requires evidence based knowledge. Avian predation success seems to be driven by common insectivorous species, rather than by local shade management and overall bird species diversity. Forest proximity is important for enhancing predator density, thus contributing both to conservation of biodiversity and human wellbeing in tropical agroforestry landscapes. 


\section{Introduction}

Top down control of arthropod densities by insectivorous birds is a highly valuated service in a range of different ecosystems (Sekercioglu 2006), especially in tropical agroforestry landscapes (e.g. Van Bael et al. 2008; Perfecto et al. 2004; Philpott et al. 2009). Insectivorous birds and their contributions to ecosystem functioning are increasingly well studied (e.g. Tscharntke et al. 2008), facilitate remarkable increases in crop yields (Karp et al. 2013; Maas, Clough \& Tscharntke 2013) and may serve as a viable alternative to pesticides or other chemical compounds in tropical agroforestry (e.g. Bianchi et al. 2006). However, the drivers of bird predation success and the importance of diversity and composition of the local bird community (with respect to local and landscape factors) are currently poorly understood.

Avian predation success is often linked to the high functional diversity and mobility of bird species (e.g. Philpott et al. 2009). But this services is likely influenced by multiple factors (Van Bael et al. 2008; Mace, Norris \& Fitter 2012), including variation in resource availability (e.g. Clough et al. 2009), habitat complexity (e.g. Philpott et al. 2009) and diversity of predator assemblages (e.g. Schmitz 2007). A key question in the study of avian ecosystem functioning is the relative importance of bird species diversity compared to species identities and functional groups. Philpott et al. (2009) conducted a meta-analysis of studies on birds in agroforestry, concluding that distinct traits (body mass, foraging strategy, foraging strata and diet) associate bird assemblages with increased contribution to ecosystem service or function. Contrastingly, high levels of bird species diversity are considered to secure the provision of ecosystem services and positively affect plant productivity (Tscharntke et al. 2008; Sekercioglu et al. 2012). Most likely, avian predation pressure on arthropods does not only depend on local insectivore density, but is affected by predator satiation, intraguild predation, and intra- and interspecific competition (Schmitz 2007). However, there is consensus that at least some minimum number of species is essential for efficient ecosystem functioning under constant conditions and that a larger number of species is probably essential for maintaining the stability of ecosystem processes in changing environments (Loreau et al. 2001). Including avian ecosystem services into biodiversity-friendly management of tropical agroforestry landscapes may thus not only provide a promising conservation strategy, but also enhance human well-being through supporting food-security and ecosystem resilience (Fischer, Lindenmayer \& Manning 2006; Tscharntke et al. 2012). 
The need for such alternatives to intensified agroforestry management persists (Mace, Norris \& Fitter 2012), but requires an improved understanding of avian predation services. To date, the importance of overall bird species diversity and species-specific functions for the provision and management of ecosystem services in agroforestry landscapes has not been quantified. Avian predation should be understood in relation to the local management of different farming systems as well as the landscape structure or availability of natural forest. Tropical agroforestry systems are increasingly recognized as a useful and promising land use strategy that diversifies production for greater social, economic and environmental benefits (Schroth 2004; Jose 2009). Particular attention has been paid to cacao (Theobroma cacao), the largest legal international trade volume beside petroleum (Donald 2004). Cacao plantations can support high biodiversity levels depending on the local shade tree availability (e.g. Clough et al. 2011) and the respective landscape context (e.g. Tscharntke et al. 2008; Fahrig et al. 2011). However, results showing local and landscape effects on insectivorous birds are still biased, neglecting the Paleotropics, where few studies are currently available (e.g. Maas, Clough \& Tscharntke 2013). To provide reliable recommendations on the impact of avian predators on arthropods, studies under varying field conditions are needed (Philpott et al. 2009).

Few studies have been published that quantify predation activity of birds in tropical habitats using predation field experiments (e.g. Loiselle \& Farji-Brener 2002; Koh \& Menge 2006; Posa, Sodhi \& Koh 2007; Fáveri, Vasconcelos \& Dirzo 2008). Only one of them investigated agroecosystems (Howe, Lövei \& Nachman 2009) and none was yet conducted in tropical Asia. Consequently, a distinct link between predation activity (measured in a standardized field experiment) and the role that birds play in suppressing phytophagous arthropods is still missing in tropical agroforestry research (e.g. Perfecto et al. 2004; Philpott et al. 2009).

From a practical point of view, the choice of adequate sampling method or a combination of methods is essential for the accurate assessment of relative bird species abundances and avian activity in the field (Derlindati \& Caziani 2005). Mist nets and point counts have been widely used in the study of Neotropical birds, and a combination of the two techniques might be the most effective methodological approach for monitoring bird assemblages (e.g. Wang and Finch 2002). Although point counts of birds have been used extensively in tropical agroforestry (e.g. Van Bael et al. 2008; Waltert, Mardiastuti \& Mühlenberg 2004; Maas et al. 2009), they strongly depend on the researcher's training in identification of species (e.g. 
Blake \& Loiselle 2001), although they have the advantage to provide more complete assessments of bird communities. Mist nets are considered as a simple assessment method of birds with data representing species activity rather than abundance (Remsen \& Good 1996), typically confined to the understory (Sodhi et al. 2002), thus excluding most canopy birds. Therefore, point count sampling seems more suitable for a more general 'diversity assessment' of birds whereas mist netting is a good method for the 'functional characterization' of a certain bird community. With respect to these different community parameters, potentially reflected by point counts (abundances) and mist nets (activity), we conducted both methods on our study sites and applied them simultaneously.

Regarding our main focus on the importance of avian diversity and predator identity for predation success on phytophagous insects in relation to local management and landscape context of cacao agroforestry systems, we asked the following questions:

(1) Do species richness, abundance and predation success of the bird community depend on:

(a) local shade management and/or (b) distance to primary forest (landscape context)?

(2) Is the combination of sampling methods (point counts and mist netting) adequate to relate bird community patterns to predation activity in agroforestry systems?

(3) With focus on practical implications: Which bird species contribute most to insect predation in shaded agroforestry as measured by a standardized predation field experiment? We selected 15 cacao agroforestry systems which were located along independent gradients of local shade cover and distance to primary forest as our study sites. Thus, we were able to control for local and landscape effects on avian predation success which we tested in a standardized predation field experiment, using plasticine caterpillars as artificial prey for birds. Different community measures and sampling methods were chosen to assess diversity of species and functions within the insectivorous bird community. Based on our results, we aimed to identify local and landscape features as well as those bird species, which drive avian predation success in tropical agroforestry to contribute to practical implications for smallholder farmers in these landscapes. We expected common open land insectivores (Maas et al. 2009) to play a major role in predation of artificial arthropod prey. 


\section{Materials and methods}

\section{Study Sites}

Our study was conducted in Central Sulawesi which is not only the biggest cacao producer in Indonesia (third largest cacao producer worldwide) but is also the largest island within the Indonesian biodiversity hotspot Wallacea.

We selected 15 smallholder cacao plantations which were situated the eastern margin of Lore Lindu National Park, as our study sites. The Lore Lindu National Park is covers an area of 218,000 ha, largely dominated by montane and submontane forests (The Nature Conservancy 2002). The forest margin landscape is characterized by a mosaic of secondary forests and a rapidly increasing number of land use systems with coffee, maize and rice representing the main cultivated crops besides the dominant cacao (e.g. Maas et al. 2009). Due to its proximity to the equator, the seasonality is not very marked. Precipitation levels vary considerably with elevation and topography, and climatic stations are few, but mean annual precipitation can be estimated to be around 2000-3000 mm per year (Kessler et al. 2005). The park contains 227 bird species of which 77 are endemic (Coates, Bishop \& Gardner 1997).

In 2010, our study sites were selected. The 15 smallholder cacao plantations were 0.5 - 1.5 ha in size, at least $500 \mathrm{~m}$ apart from each other and managed without any use of pesticides, herbicides or other chemical compounds. Every selected plantation represented a unique combination of local shade tree availability (local management gradient) and distance to the next closed primary forest block of the park (landscape context gradient) to allow for a comparison of different management regimes and a separation of their effects on the bird community. We quantified local shade tree canopy cover (Fig. 1) in percent and classified it as low (0-25\%), medium (25-50\%) or high (more than 50\%). For statistical analyses, we used mean shade tree cover per site, which was calculated from two shade cover surveys in June 2010 and February 2011, using digital photographs (Panasonic DMC-TZ7EG-K) and Image J processing software (Rasband 1997-2010). Distance to primary forest was determined using satellite pictures and GPS data (Garmin $12 \mathrm{Map}$ ) from the study area and measured as the distance (range: 0-3500 $\mathrm{m}$ ) from the edge of the study site to the edge of the closed forest block. For the selection of study sites, we selected cacao plantations on five different 
distances to the primary forest edge (Fig. 1), with three plantations in each class and not being correlated to the shade cover gradient.

In September 2010 and from February until June 2011, we conducted monthly point count and mist netting sampling of birds on each of the 15 study sites (total of 7 visits per site). Both sampling methods were always conducted on the same date in each plantation and performed by two authors (B.M. and D.D.P.) who are very experienced in acoustical and visual identification of the studied bird species (Maas et al. 2009) as well as with the applied capture-recapture methods. In addition, an artificial prey experiment was performed to investigate the predation activity within the plots between June and July 2011.

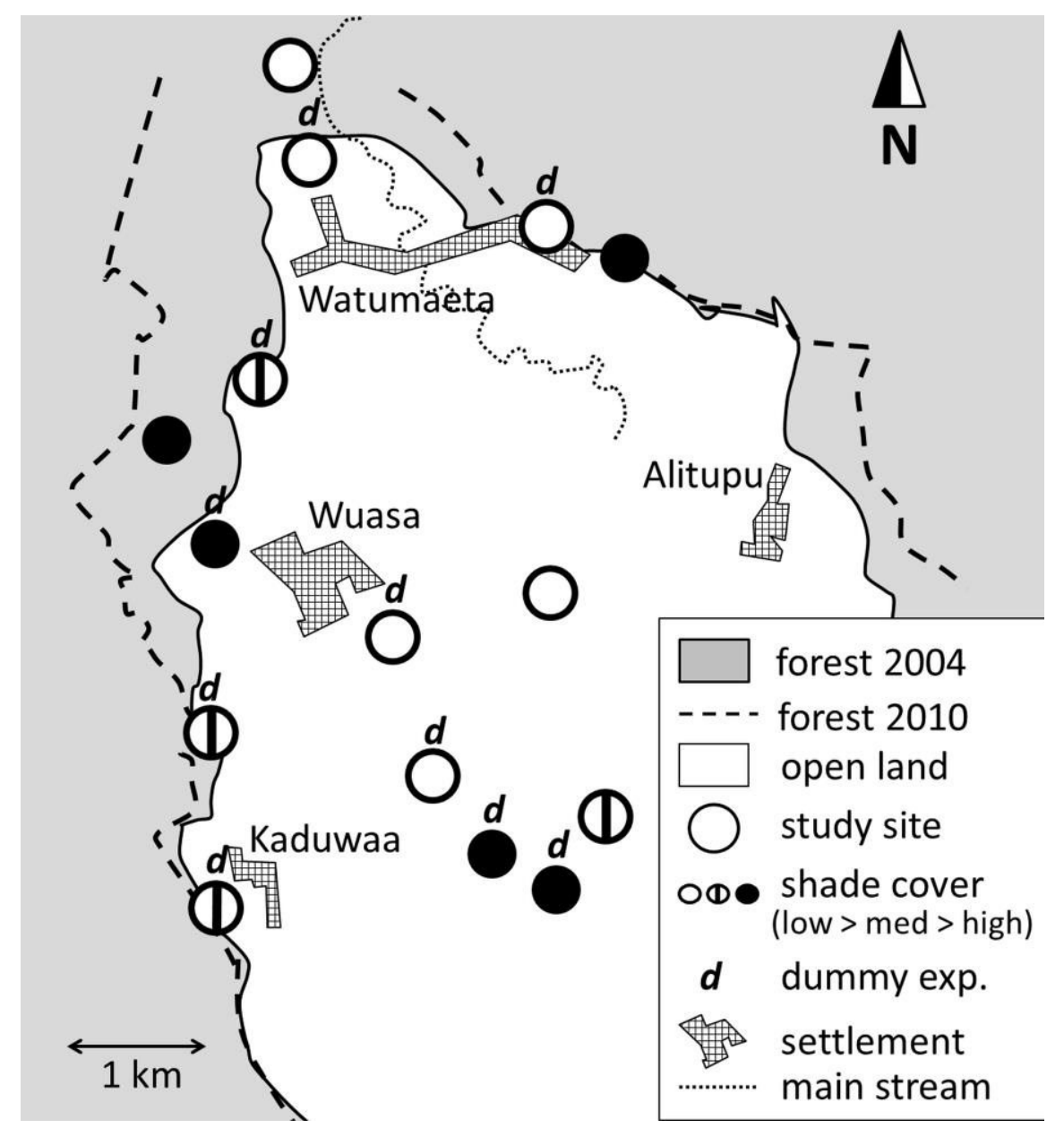

Fig. 1. Schematic map of study area and study sites in Central Sulawesi (Indonesia). Grey areas indicate the closest primary forest block of the Lore Lindu National Park in 2004. Dashed lines represent the forest margin measured in 2010. White parts indicate settlement and land use areas. The 15 cacao agroforestry study sites are plotted as circles, which indicate the amount of shade cover: 0-25\% (empty); $25-50 \%$ (half filled) and more than $50 \%$ (filled black). Circles with the letter ' $d$ ' on the top represent the sites were the predation field experiment ('dummy exp.') with artificial prey was conducted 


\section{Mist Netting}

For every monthly mist netting survey per study site, we established continuous net lines of $48 \mathrm{~m}$ length in total (each with 8 songbird mist nets of $6 \times 3 \mathrm{~m}$ and $16 \mathrm{~mm}$ mesh size per line). Lowest net height was $1.5 \mathrm{~m}$ above ground and opened nets reached up to $4.5-5 \mathrm{~m}$ into the canopy of cacao and shade trees. This vertical orientation was chosen to cover the parts of the cacao canopy with the highest bird activity. Two weeks of preliminary experiments (August 2010), showed that most of the bird species were moving closely above or below the cacao tree canopy of the agroforestry system but not near to the ground. The mist netting lines were always readily prepared before $05 \mathrm{~h} 00$ and checked for the first time at $06 \mathrm{~h} 00$. From then on, we checked the net line every 60 minutes except for some cases with extreme weather conditions (e.g. high temperatures due to intensive direct sunlight or cold temperatures due to heavy rain events) were we checked every half an hour. Captured birds were identified and banded with uniquely numbered metal rings (provided by LIPI/Indonesia and Vogelwarte Helgoland/Germany). We measured every individual following the Level 1 standard provided in the bird ringing manual of Coiffait, Clar \& Robinson (2008) and took additional photographs. Recaptures of individuals within identical mist netting rounds were discarded from the statistical analyses.

\section{Point Counts}

From a fixed central location within each study site, we detected all birds visually and acoustically within a radius of $50 \mathrm{~m}$ for 20 minutes per survey. We experienced this time standard to be appropriate for agricultural systems in a former study (Maas et al. 2009) and carefully tried to ensure, that the same individual was not counted more than once. All observations beyond $50 \mathrm{~m}$, including those individuals that flew over the canopy, were discarded from analysis. Point count sampling was performed between 07h00 and 10h00 parallel to the mist netting surveys and with a total of seven visits per site.

\section{Artificial prey experiment}

To investigate the predation activity by insectivorous birds in cacao agroforestry systems, we performed a predation field experiment using artificial prey (plasticine caterpillars) to imitate natural prey of avian predators (Lepidopteran larvae). Comparable methods are explained in 
detail in Howe, Lövei \& Nachman (2009). We conducted the experiment on 10 of our 15 study sites (Fig. 1).

In total, we visited each study site four times (4 replicates) between June and July 2011 to perform the predation experiment. On each site, we randomly chose 5 cacao trees which were at least separated by two other cacao trees within the site. For every cacao tree, we prepared 7 plasticine caterpillars which were fixed on the trees in the early morning (between $05 \mathrm{~h} 00$ and $06 \mathrm{~h} 00$ ), checked for predation marks in the evening hours (between $17 \mathrm{~h} 00$ and 18h00) and kept over the night on the study site to account for night predation activity. On the next morning (between $05 \mathrm{~h} 00$ and $06 \mathrm{~h} 00$ ), the caterpillars from the last day were checked again for predation marks and subsequently removed from the cacao trees which completed one survey unit for the respective study site. A dummy caterpillar was $2 \mathrm{~cm}$ long and had a diameter of $0.4 \mathrm{~cm}( \pm 1 \mathrm{~mm})$. The dummy caterpillar lengths derived from an insect data set taken from the same study sites in August 2010 which included 72 Lepidoptera larvae with a mean length of $1.38 \mathrm{~cm}( \pm 0.72 \mathrm{SD})$. We oversized the caterpillars approximately by their standard deviation in order to increase the attraction of potential predators such as birds, bats and predatory arthropods. All produced plasticine caterpillars were green, which was naturally very common on our sites and considered to imitate attractive prey (e.g. Fáveri, Vasconcelos \& Dirzo 2008; Howe, Lövei \& Nachman 2009). The artificial caterpillars ("dummies") were fixed on different positions of the study trees: (a) one dummy on the first branching of the cacao tree, (b) three dummies on a main tree branch distanced $20 \mathrm{~cm}$ from each other and (c) three dummies on the center of single and healthy cacao leafs.

All dummies were fixed at the tree using a drop of commercially available power glue (of neutral smell). We distinguished between marks of birds, predatory insects (typical mandibles), snails, rodents and unidentified predators (see Fig. 2). The design of the study was inspired by the few number of published studies on rapid predation assessment using caterpillar dummies in tropical habitats (Loiselle \& Farji-Brener 2002; Koh \& Menge 2006; Posa, Sodhi \& Koh 2007). Howe, Lövei \& Nachman (2009) provide a detailed description of such artificial prey experiments. 

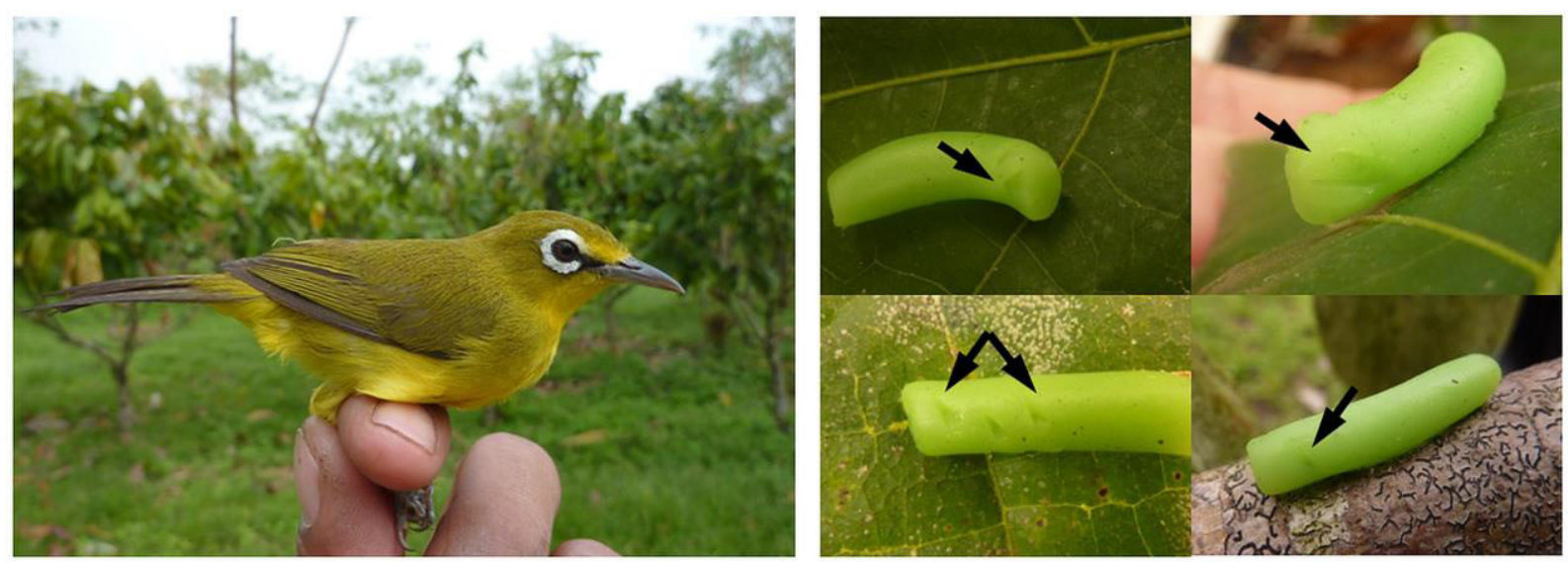

Fig. 2. The common Lemon-bellied White-eye (Zosterops chloris) and typical dummy-predation marks of birds. Zosterops chloris was the most commonly observed insectivorous species in the cacao agroforestry sites and turned out to contribute most to the predation on artificial prey (right). Bird predation marks (indicated by black arrows) were frequently detected. Photo credits: B. Maas

\section{Statistical analyses}

Birds assessed during point count and mist netting surveys were assigned to their individual guild affiliations (habitat and feeding guilds) and distribution (endemic vs. widespread) before analyses. Total species richness and completeness of our bird samples were estimated using the abundance-based ACE species richness estimator (e.g. Chazdon et al. 1998). For details on all estimators, including equations of the nonparametric statistics, see Colwell (2013). We used the software EstimateS version 9.1.0 (Colwell 2013) to calculate species accumulation curves. Samples were randomized 100 times. Bird species richness was estimated separately for point counts, mist netting and the total bird count (including both methods) per site. We compared species diversity among different survey methods with Fisher's alpha, which incorporates species richness and evenness of species abundance into a single measure (Magurran 2004).

All main statistical analyses were performed using $R$ version 2.15.1 (R Core Team 2012) with additional functions provided by the R packages 'vegan' (Oksanen et al. 2007), for calculation of diversity indices and the bird community analyses and 'MuMIn' (Barton 2011), for the multi-model selection of species specific analyses. Number of bird species (species richness) as well as the number of individuals (abundance) were log-transformed before analyzes. The variables shade tree cover and distance to forest margin were centered by substracting the mean to improve the interpretation of multiplicative and interaction terms in the models. 
Correlation analyses of insectivorous birds (log transformed abundance and species richness), local shade tree cover, distance to forest and predation activity (sum of bird marks per site), was performed with linear regression models (calculation of $P$ and $F$ values and adjusted R2). We fitted models of dummy caterpillar predation (sum of recorded bird marks), local and landscape gradient (local shade and distance to forest margin) by generalized least squares (GLS) using restricted maximum likelihood (REML) and power variance function, which accommodated variability between study sites (Pinheiro \& Bates 2000).

Because our study is focused on the importance of insectivorous bird species in tropical agroforestry landscapes, we made separate statistical analyses for this feeding guild. We also assigned those species to the analyses, which are not predominately feeding on insect prey but are considered to be insectivorous to a certain extent (e.g. sunbirds, flower peckers). To investigate species specific effects, we included the 7 most abundant ( $\min . \quad N=30$ ) insectivorous bird species in a model simplification approach based on Akaike Information Criterion corrected for small sample size (AICC) with predation activity (sum of bird marks per site) added as fixed effect. $\triangle \mathrm{AICC}$ is calculated as the difference between each model's AICC and the lowest AICC with a $\triangle \mathrm{AICC}<2$ interpreted as substantial support (model belongs to the best models) and higher values interpreted as less or no support that the model belongs to the best set (Burnham \& Anderson 2002).

\section{Results}

In total, we observed 69 bird species belonging to 36 families within the 15 smallholder cacao agroforestry systems (Table S1). From this overall number of observed bird species, 38 species were caught with mist nets and 57 species were recorded with repeated point counts (Table S2D). The majority of all birds was represented by insectivorous species ( $N=50$; 71.43\%; Table S2A). Bird species with no specific habitat preference account for the half (Table S2B) while open land species make up 30\% and forest species $17 \%$ of the whole bird community. Almost a third of the species $(N=19 ; 27.14 \%)$ were endemic whereas the remaining 50 species (71.43\%) were widespread (Table S2C). 


\section{Insectivorous bird community}

We focused on the 50 insectivorous bird species recorded during our study. Species richness as well as species diversity (Fisher's alpha) was higher in species point counts than in simultaneous mist netting samples (Table 1). The completeness of the insectivorous species inventory was relatively high both for the single survey methods mist netting ( $\mathrm{MN}=81.36 \%$ ) and point counts ( $P C=88.69 \%$ ), as well as for the total of the two methods ( $A L L=86.94 \%)$.

Tab. 1: Results from EstimateS for insectivorous bird species $(N=50)$. For the total bird count $(A L L)$ as well as for the single methods mist netting $(\mathrm{MN})$ and point counts $(\mathrm{PC})$, we show the observed species (spp. obs.), the estimated species richness (ACE estimate) and the completeness of inventories (\%). Species diversity is represented by Fisher's alpha

\begin{tabular}{lclll}
\hline method & $\begin{array}{c}\text { spp. } \\
\text { obs. }\end{array}$ & $\begin{array}{l}\text { ACE } \\
\text { estimate }\end{array}$ & $\begin{array}{l}\text { compl. } \\
(\%)\end{array}$ & $\begin{array}{l}\text { Fisher's } \\
\text { alpha }\end{array}$ \\
\hline ALL & 50 & 57.51 & 86.94 & 8.45 \\
MN & 31 & 38.10 & 81.36 & 5.98 \\
PC & 40 & 45.10 & 88.69 & 7.03 \\
\hline
\end{tabular}

The abundance of insectivorous species significantly decreased with increasing distance to primary forest $(P<0.05$; Table 2a; Fig. 3a) but was not significantly related to local shade cover in the study sites $(P>0.05$; see Table $2 a)$. Species richness was not significantly related to both gradients (Table $2 b$ ).

Tab. 2: Effects of local shade and landscape context (distance to primary forest) on insectivorous birds. Correlation analysis for distance to primary forest (in $\mathrm{m}$ ) and local shade cover (decimal values) on (a) abundance and (b) species richness of insectivorous bird species. Results shown for different sampling methods $(\mathrm{MN}=$ mist netting; $\mathrm{PC}=$ point counts $)$ and the total count of bird species $(\mathrm{ALL})$. Significant effects $(P<0.05)$ are indicated by *

\begin{tabular}{llllllll}
\hline & & \multicolumn{3}{l}{ (a) Species abundances } & \multicolumn{3}{l}{ (b) Species richness } \\
\cline { 3 - 8 } & & $R^{2}$ & $P$ & $\mathrm{~F}_{(1,13)}$ & $R^{2}$ & $P$ & $\mathrm{~F}_{(1,13)}$ \\
\hline Forest & ALL & 0.502 & $\mathbf{0 . 0 0 2}$ & 15.110 & -0.054 & $0-606$ & 0.279 \\
& MN & 0.208 & 0.05 & 4.681 & 0.056 & 0.199 & 1.824 \\
& PC & 0.456 & $\mathbf{0 . 0 0 3}$ & 12.910 & -0.041 & 0.517 & 0.443 \\
\hline Shade & ALL & -0.066 & 0.720 & 0.135 & -0.006 & 0.358 & 0.910 \\
& MN & -0.018 & 0.401 & 0.754 & 0.005 & 0.321 & 1.066 \\
& PC & -0.077 & 0.944 & 0.005 & 0.057 & 0.197 & 1.848 \\
\hline
\end{tabular}




\section{Bird Predation activity}

To quantify the avian predation activity in our cacao agroforestry sites, we dispersed a total of 2800 dummy caterpillars on the ten selected experimental sites and controlled them for predation marks after daytime predation activity (of birds) and night-time predation (of bats, rodents). Only 6 dummy caterpillars were lost, 29 dummies were found on the ground and recorded and the rest (99\%) remained on the study trees. From all predation marks that could be identified in the field $(N=182)$, birds caused $45 \%(N=81)$, snails $40 \%(N=74)$ and rodents $15 \%(N=27)$.
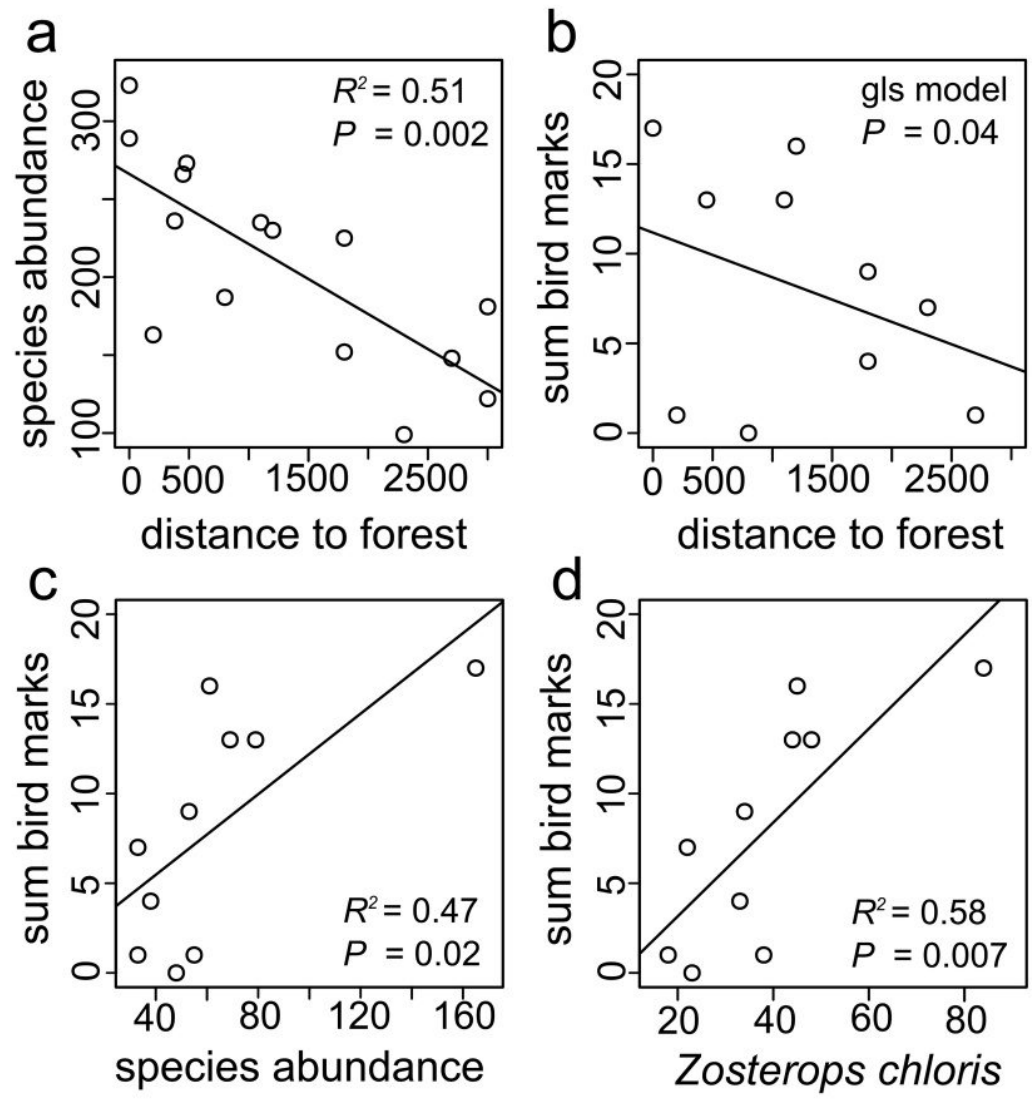

Fig. 3. Bird predation activity (bird marks) vs. distance to forest, species richness and species identity. Upper plots show the relationship between distance to forest margin and (a) total abundance of insectivorous birds (log) or (b) predation activity (sum of bird marks per site).

The lower plots show the quantified between predation activity against (c) total insectivorous bird species abundance and (d) total abundance of the most common insectivorous species (Zosterops chloris). For (a - c), Pvalues and Adjusted R-Squares from the linear model are shown; (b) is fitted by a generalized least squares which accommodate for equal variances 
Bird predation marks were positively correlated to bird abundances of mist netting surveys $\left(F_{1,8}=8.94 ; P=0.017\right.$; Fig. $\left.3 b\right)$ but showed no significant relationship to bird abundances of point count data $\left(F_{1,8}=1.304 ; P=0.287\right)$ or the total record of both methods $\left(F_{1,8}=4.22 ; P=\right.$ 0.074). Bird species richness did not significantly influence the number of bird predation marks on dummy caterpillars (all $P>0.05$ ). The number of bird predation marks fitted by generalized least squares significantly depended on distance to forest margin, with decreasing sums of marks on increasing distances ( $d f=10 ; P=0.04 ;$ Fig. $3 c$ ), but with nonsignificant relation to local shade cover $(\mathrm{df}=10 ; P=0.350)$.

\section{Species specific analysis}

To identify the importance of single species identities for predation success, we computed model selection for the 7 most common insectivorous bird species (Table 3). The best model with a $\triangle \mathrm{AICC}$ below 2 and the highest AICc weight included Zosterops chloris (Zosteropidae), the most abundant insectivorous bird species recorded in all survey methods (ALL, MN and PC; Table 3 and Fig. 2). All other bird species included in the model simplification approach resulted in both high $\triangle \mathrm{AICC}$ values (3.88 and higher) and low AICC weights (0.09 and lower), which excludes them from the set of best models for all abundant insectivorous bird species. Correlation analyses of Zosterops chloris and the total number of bird predation marks shows a strong positive relationship $\left(F_{1,8}=13.43 ; P=0.007\right.$; Fig. $\left.3 d\right)$ between these two variables.

Table 3. Model selection (based on $\triangle \mathrm{AICC}$ and AICc weight) for common insectivorous bird species. The 7 most common species sorted by frequencies in the total bird count (ALL). Total number of recorded individuals is provided for mist netting $(\mathrm{MN})$ and point count $(\mathrm{PC})$ surveys. All seven species were included in the model simplification for which results are presented by AICC, $\triangle \mathrm{AICC}$ and $\mathrm{AICC}$ weight

\begin{tabular}{lllllll}
\hline Species name & ALL & MN & PC & AICc & $\Delta$ AICc & AICc weight \\
\hline Zosterops chloris & 1431 & 626 & 805 & 64.77 & 0.00 & 0.57 \\
Dicaeum celebicum & 609 & 167 & 442 & 69.67 & 4.91 & 0.05 \\
Aplonis minor & 176 & 13 & 163 & 68.65 & 3.88 & 0.08 \\
Dicaeum aureolimbatum & 175 & 61 & 114 & 69.10 & 4.34 & 0.06 \\
Zosterops atrifrons & 150 & 48 & 102 & 70.12 & 5.35 & 0.04 \\
Scissirostrum dubium & 119 & 19 & 100 & 70.33 & 5.57 & 0.04 \\
Nectarinia jugularis & 98 & 25 & 73 & 68.49 & 3.72 & 0.09 \\
\hline
\end{tabular}




\section{Discussion}

Our study provides first empirical evidence that predation success of insectivorous birds in tropical agroforestry landscapes is driven by the activity of the most common insectivorous bird species (in our case Zosterops chloris), rather than by bird species richness.

In accordance with previous findings from Central Sulawesi (Clough et al. 2009), increasing forest proximity was positively related to the abundance of insectivorous birds, but not to overall species richness. Local shade management did not influence predation success or activity of insectivorous birds.

Reliable recommendations for practical agroforestry management using common bird species and their provided services need a quantitative assessment of bird predation effects (Van Bael et al. 2008). The conduction of different sampling methods in relation to the analysis of avian predation success and predator diversity showed that only mist-netting was suitable to characterize the activity of insectivorous birds in the cacao canopy and understory layer. In contrast, overall species richness was better assessed with point counts, in agreement with other studies in which both methods were used (e.g. Blake \& Loiselle 2001; Wang \& Finch 2002; Derlindati \& Caziani 2005).

The application of a standardized field predation experiment (e.g. Howe, Lövei \& Nachman 2009), in combination with mist netting as a targeted method for quantifying insectivores, offered the possibility to examine the relative importance of species identity vs. complementarity in a species rich bird community, which is an important addition to previous studies (Philpott et al. 2009), and provides valuable findings for smallholder farmers who desire to take advantage of ecosystem services in an agricultural landscapes.

Highly abundant groups of arthropods, such as caterpillars (Lepidopteran larvae), are known to be effectively reduced by insectivorous birds in different types of agroforestry systems, resulting in higher amounts of crop yield (Mols \& Visser 2002; Maas et al. 2013). Similarly high predation rates on larvae were observed in shaded coffee agroecosystems (Perfecto et al. 2004), with small foliage-gleaning insectivores being more important for arthropod suppression than community diversity (Philpott et al. 2009). This relationship was simulated in our standardized field predation experiment, which allows considering different insectivore foraging patterns (leaf gleaning vs. perching species) and standardized positioning of the artificial prey, making a comparison of different study sites possible. 
Our findings confirmed our expectation that common open land insectivores, in our case the endemic Lemon-bellied White-eye (Zosterops chloris), drive avian predation success in cacao agroforestry. Zosterops chloris occurs both in land use systems and forest habitats (Maas et al. 2009), usually lives in small flocks and forages at all levels in the vegetation (Coates, Bishop \& Gardner 1997). Although the species is currently not important from a conservational viewpoint, it provides a major contribution to the highly valuated ecosystem service of arthropod suppression. To enhance the density of Zosterops chloris in the humandominated agricultural landscape, the proximity of forest area is important. In this case, the conservation of forest habitat will contribute both to the protection of endangered biodiversity (species richness and functional richness or rare species) and human well-being by enhancing ecosystem services.

Similar recommendations could apply to tropical coffee agroforestry, where especially common bird species played an important role for arthropod suppression and provided enhanced services in the proximity of forest stretches (Karp et al. 2013).

Although the integration of natural services into land use systems holds a great potential for human welfare and biodiversity (Jose et al. 2009), it is not common to this day. Improved knowledge on the impact of bird species diversity and single species identities on arthropod predation is needed to reveal the importance of species identities (common vs. rare species) and landscape management (local management vs. landscape structure) for avian predation success.

Endemic species are often associated to forest areas and are of major importance as indicators of landscape conversion in South-East Asia (Maas et al. 2009; Sodhi et al. 2010). Although the Sulawesi endemic Zosterops chloris represents the most common insectivore species in our study area, its abundance and predation activity is likely to depend on the proximity of natural forest. This pattern might not be transferable to other tropical land use areas, where less common or even rare bird species might be of higher importance for the provision of ecosystem services.

Previous results from Indonesian agroforestry systems have shown that combining complex habitat structure, biodiversity and high crop yields in tropical agroforests can be realized without adding pressure on natural habitats (Clough et al. 2011). Agroforestry systems with a low-intensity management (little use of pesticides) and a complex vegetation structure (shade tree abundance and diversity) host large numbers of potential insect prey (Bos, 
Steffan-Dewenter \& Tscharntke 2007) and therefore are likely to be highly attractive as foraging sites for insectivorous birds (Clough et al. 2009).

In conclusion, our results emphasize that enhancing avian ecosystem services by taking into account the importance of forest proximity and species identities, can be of advantage both for human well-being and biodiversity, thus representing a win-win situation for both sides. Cacao smallholders in Central Sulawesi, having plantations close to the closed primary forest block might therefore profit from enhanced densities of the Lemon-bellied White-eye and the high predation pressure that it imposes upon phytophagous arthropods.

Policy-makers and land owners, especially agroforestry smallholders, should pay attention to the economic impact of avian arthropod suppression on crop productivity (Karp et al. 2013; Maas, Clough \& Tscharntke 2013) and start to integrate ecosystem services in the management of agricultural landscapes in the tropics. To achieve this, more research on the relation of species identities, species diversity, landscape management and ecosystem services is needed that provides evidence based knowledge and the possibility to conduct awareness training in regions were birds provide valuable ecosystem services. This way, the study of avian predation success and its drivers can contribute to increased valuation by rural populations and farmers, which is crucial for the integration of biodiversity and ecosystem functions in tropical agricultural landscapes (Schroth 2004).

\section{Acknowledgements}

We thank all local farmers and field assistants for giving permission to conduct fieldwork on their land, for their outstanding commitment, hard work and good cooperation in the field. In this regard, special thanks goes to our assistants Sissi and Papa Ifer who assisted with hard work on our mist netting surveys and predation experiments. We thank the officers of RISTEK Indonesia and all responsible authorities of Tadulako University (CTFM Office) and the city of Palu and Central Sulawesi (Kecamatan Lore Utara) for their great help and support. The research project was partly funded by a scholarship of the German National Academic Foundation (Studienstiftung des deutschen Volkes) and benefited from financial support from the German Science Foundation (DFG Grant CL-474/1-1 to YC). 


\section{References}

Barton, K. (2011) MuMIn, Multi-model inference. R package version 1.0. 0. Vienna, Austria, $R$ Foundation for Statistical Computing. See http,//CRAN. R-project. org/package= MuMIn.

Bianchi, F.J.J.A., Booij, C.J.H. \& Tscharntke, T. (2006) Sustainable pest regulation in agricultural landscapes: a review on landscape composition, biodiversity and natural pest control. Proceedings of the Royal Society B: Biological Sciences, 273, 1715-1727.

Blake, J.G., \& Loiselle, B.A. (2001) Bird assemblages in second-growth and old-growth forests, Costa Rica, perspectives from mist nets and point counts. The Auk, 118, 304-326.

Bos, M.M., Steffan-Dewenter, I., \& Tscharntke, T. (2007) The contribution of cacao agroforests to the conservation of lower canopy ant and beetle diversity in Indonesia. Biodiversity and Conservation, 16, 2429-2444.

Burnham, K.P., \& Anderson, D.R. (2002) Model selection and multi-model inference, a practical information-theoretic approach. Springer.

Chazdon, R.L., Colwell, R.K., Denslow, J.S., \& Guariguata, M.R. (1998) Statistical methods for estimating species richness of woody regeneration in primary and secondary rain forests of northeastern Costa Rica.

Clough, Y., Dwi Putra, D., Pitopang, R., \& Tscharntke, T. (2009) Local and landscape factors determine functional bird diversity in Indonesian cacao agroforestry. Biological Conservation, 142, 1032-1041.

Clough, Y., Barkmann, J., Juhrbandt, J., Kessler, M., Wanger, T. C., Anshary, A., Buchori, D., Cicuzza, D., Darras, K., Dwi Putra, D. Erasmi, S., Pitopang, R., Schmidt, C., Schulze, C.H., Seidel, D., SteffanDewenter, I., Stenchly, K., Vidal, S., Weist M., Wielgoss A.C. \& Tscharntke, T. (2011) Combining high biodiversity with high yields in tropical agroforests. Proceedings of the National Academy of Science, 108, 8311-8316.

Coates, B.J., K.D. Bishop, \& Gardner, D. (1997) A field guide to the birds of Wallacea. Dove Publications, Alderley, Queensland, Australia.

Coiffait, L., Clark, J., \& Robinson, R. (2008) Bird ringing, a concise guide. Thetford, British Trust for Ornithology.

Colwell, R.K. (2013) EstimateS, Statistical estimation of species richness and shared species from samples. Version 9. User's Guide and application published at, http,//purl.oclc.org/estimates.

Derlindati, E.J., \& Caziani, S.M. (2005) Using canopy and understory mist nets and point counts to study bird assemblages in Chaco forests. The Wilson Bulletin, 117, 92-99.

Donald, P.F. (2004) Biodiversity impacts of some agricultural commodity production systems. Conservation Biology, 18, 17-37.

Fahrig, L., Baudry, J., Brotons, L., Burel, F.G., Crist, T.O., Fuller, R.J., Sirami, C., Siriwardena, G.M. and Martin, J.L. (2011) Functional landscape heterogeneity and animal biodiversity in agricultural landscapes. Ecology Letters, 14, 101-112.

Fáveri, S.B., Vasconcelos, H.L., \& Dirzo, R. (2008) Effects of Amazonian forest fragmentation on the interaction between plants, insect herbivores, and their natural enemies. Journal of Tropical Ecology, $24,57-64$. 
Fischer, J., Lindenmayer, D. B., \& Manning, A. D. (2006). Biodiversity, ecosystem function, and resilience: ten guiding principles for commodity production landscapes. Frontiers in Ecology and the Environment, 4, 80-86.

Howe, A., Lövei, G.L., \& Nachman, G. (2009) Dummy caterpillars as a simple method to assess predation rates on invertebrates in a tropical agroecosystem. Entomologia Experimentalis et Applicata, 131, 325-329.

Jose, S. (2009) Agroforestry for ecosystem services and environmental benefits, an overview. Agroforestry Systems, 76, 1-10.

Karp, D.S., Mendenhall, C.D., Sandí, R.F., Chaumont, N., Ehrlich, P.R., Hadly, E.A., \& Daily, G.C. (2013) Forest bolsters bird abundance, pest control and coffee yield. Ecology Letters, 16, 1339-1347.

Kessler, M., Kessler, P.J., Gradstein, S.R., Bach, K., Schmull, M., \& Pitopang, R. (2005) Tree diversity in primary forest and different landuse systems in Central Sulawesi, Indonesia. Biodiversity and Conservation, 14, 547-560.

Koh, L.P., \& Menge, D.N. (2006) Rapid Assessment of Lepidoptera Predation Rates in Neotropical Forest Fragments. Biotropica, 38, 132-134.

Loiselle, B.A., \& Farji-Brener, A.G. (2002) What's Up? An Experimental Comparison of Predation Levels between Canopy and Understory in a Tropical Wet Forest. Biotropica, 34, 327-330.

Loreau, M., Naeem, S., Inchausti, P., Bengtsson, J., Grime, J.P., Hector, A. et al. \& Wardle, D. A. (2001) Biodiversity and ecosystem functioning, current knowledge and future challenges. Science, 294, 804808.

Maas, B., Putra, D.D., Waltert, M., Clough, Y., Tscharntke, T. \& Schulze, C.H. (2009) Six years of habitat modification in a tropical rainforest margin of Indonesia do not affect bird diversity but endemic forest species. Biological Conservation, 142, 2665-2671.

Maas, B., Clough, Y., \& Tscharntke, T. (2013) Bats and birds increase crop yield in tropical agroforestry landscapes. Ecology Letters, 16, 1480-1487.

Mace, G.M., Norris, K., \& Fitter, A.H. (2012) Biodiversity and ecosystem services, a multilayered relationship. Trends in Ecology and Evolution, 27, 19-26.

Magurran, A.E. (2004) Measuring biological diversity. Blackwell Science, Oxford, United Kingdom.

Mols, C.M., \& Visser, M.E. (2002) Great tits can reduce caterpillar damage in apple orchards. Journal of Applied Ecology, 39, 888-899.

Oksanen, J., Kindt, R., Legendre, P., O'Hara, B., Stevens, M. H. H., Oksanen, M. J., and Suggests, M.A.S.S. (2007) The vegan package. Community ecology package. Disponível em, http,//www. Rproject. org. Acesso em, 1001, 2008.

Perfecto, I., Vandermeer, J.H., Bautista, G.L., Nunez, G.I., Greenberg, R., Bichier, P., \& Langridge, S. (2004) Greater predation in shaded coffee farms, the role of resident neotropical birds. Ecology, 85, 2677-2681.

Philpott, S.M., Soong, O., Lowenstein, J.H., Pulido, A.L., Lopez, D.T., Flynn, D.F., \& DeClerck, F. (2009) Functional richness and ecosystem services, bird predation on arthropods in tropical agroecosystems. Ecological Applications, 19, 1858-1867. 
Pinheiro, J.C., \& Bates, D.M. (2000) Nonlinear Mixed-Effects Models, Basic Concepts and Motivating Examples. Mixed-Effects Models in S and S-PLUS, 273-304.

Posa, M.R.C., Sodhi, N.S., \& Koh, L.P. (2007) Predation on artificial nests and caterpillar models across a disturbance gradient in Subic Bay, Philippines. Journal of Tropical Ecology, 23, 27-33.

R Development Core Team, (2007) R, A Language and Environment for Statistical Computing. R Foundation for Statistical Computing, Vienna, Austria. <http,//www.r-project.org>.

Rasband, W. (1997-2010) ImageJ 1.43u. National Institutes of Health, Bethesda, Maryland, USA.

Remsen Jr, J.V., \& Good, D.A. (1996) Misuse of data from mist-net captures to assess relative abundance in bird populations. The Auk, 381-398.

Sekercioglu, C.H. (2006) Increasing awareness of avian ecological function. Trends in Ecology and Evolution, 21, 464-471.

Sekercioglu, C. H. (2012). Bird functional diversity and ecosystem services in tropical forests, agroforests and agricultural areas. Journal of Ornithology., 153, 153-161.

Schmitz, O.J. (2007) Predator diversity and trophic interactions. Ecology, 88, 2415-2426.

Schroth, G. (Ed.). (2004) Agroforestry and biodiversity conservation in tropical landscapes. Island Press.

Sodhi, N.S. (2002) A comparison of bird communities of two fragmented and two continuous Southeast Asian rainforests. Biodiversity and Conservation, 11, 1105-1119.

Sodhi, N.S., Koh, L.P., Clements, R., Wanger, T.C., Hill, J.K., Hamer, K.C. et al. \& Lee, T. M. (2010) Conserving Southeast Asian forest biodiversity in human-modified landscapes. Biological Conservation, 143, 2375-2384.

Tscharntke, T., Sekercioglu, C.H., Dietsch, T. V., Sodhi, N.S., Hoehn, P., \& Tylianakis, J.M. (2008) Landscape constraints on functional diversity of birds and insects in tropical agroecosystems. Ecology, 89, 944-951.

Tscharntke, T., Clough, Y., Bhagwat, S.A., Buchori, D., Faust, H., Hertel, D., Hölscher, D., Juhrbandt, J., Kessler, M., Perfecto, I., Scherber, C., Schroth, G., Veldkamp, E. \& Wanger, T.C. (2011) Multifunctional shade-tree management in tropical agroforestry landscapes-a review. Journal of Applied Ecology, 48, 619-629.

Tscharntke, T., Clough, Y., Wanger, T.C., Jackson, L., Motzke, I., Perfecto, I., Vandermeer, J. and Whitbread, A. (2012) Global food security, biodiversity conservation and the future of agricultural intensification. Biological Conservation, 151, 53-59.

The Nature Conservancy (2002) Lore Lindu National Park Draft Management Plan 2002-2027, vol. 1. The Nature Conservancy, Arlington, Virginia, USA.

Van Bael, S.A., Philpott, S.M., Greenberg, R., Bichier, P., Barber, N.A., Mooney, K.A., \& Gruner, D.S. (2008) Birds as predators in tropical agroforestry systems. Ecology, 89, 928-934.

Waltert, M., Mardiastuti, A., and Mühlenberg, M. (2004) Effects of landuse on bird species richness in Sulawesi, Indonesia. Conservation Biology, 18, 1339-1346.

Wang, Y., \& Finch, D.M. (2002) Consistency of mist netting and point counts in assessing landbird species richness and relative abundance during migration. The Condor, 104, 59-72. 


\section{Appendix - Chapter III - Avian predator identity vs. diversity}

\section{Table S1}

Results from EstimateS for all recorded bird species $(\mathbf{N}=\mathbf{6 9})$ recorded on 15 study sites. For the total bird count (ALL) as well as for the single methods mist netting (MN) and point counts (PC), we show the observed species (spp. obs.), the estimated species richness (ACE estimator) and the completeness of inventories (Compl.). Species diversity is represented by Fisher's alpha. Additionally, Shannon and Simpson index as well as Pilou's index (J) for eveness are shown.

\begin{tabular}{llllllll}
\hline & Total & ACE & Compl. & Fisher's & Shannon & Simpson & J \\
method & no. spp. & estimate & (\%) & alpha & index & index & eveness \\
\hline ALL & 69 & 87.45 & 78.90 & 12.32 & 2.21 & 4.33 & 0.62 \\
MN & 38 & 46.23 & 82.20 & 7.66 & 1.71 & 2.76 & 0.59 \\
PC & 57 & 72.47 & 78.65 & 10.66 & 2.36 & 5.41 & 0.67 \\
\hline
\end{tabular}




\section{Table S2}

Species guild composition of all recorded bird species (sorted by family names; $N=69$ ) from our cacao agroforestry sites. Species were assigned to different (A) feeding guilds ( $G=$ granivorous; $\mathrm{I}=$ insectivorous; $\mathrm{N}=$ nectarivorous; $\mathrm{P}=$ predatory and $\mathrm{O}=$ omnivorous); $(\mathrm{B})$ habitat affiliations (FO= forest species; GEN= generalists using both forest and open land habitats and $\mathrm{OL}=$ open land species); their respective $(\mathrm{C})$ distribution $(\mathrm{E}=$ endemic; $\mathrm{W}=$ widespread) and $(C)$ the survey method with which they were recorded ( $\mathrm{MN}=$ mist netting; $P C=$ point counts or both: $P C+M N)$.

\begin{tabular}{|c|c|c|c|c|}
\hline $\begin{array}{l}\text { Bird species } \\
\text { (sorted by family names) }\end{array}$ & $\begin{array}{c}\text { A } \\
\text { Feeding } \\
\text { guild }\end{array}$ & $\begin{array}{c}\text { B } \\
\text { Habitat } \\
\text { affiliation }\end{array}$ & $\begin{array}{c}\text { C } \\
\text { Distribution }\end{array}$ & $\begin{array}{c}\text { D } \\
\text { Survey method }\end{array}$ \\
\hline \multicolumn{5}{|l|}{ Acanthizidae } \\
\hline Gerygone sulphurea & 1 & GEN & W & $\mathrm{PC}+\mathrm{MN}$ \\
\hline \multicolumn{5}{|l|}{ Accipitriidae } \\
\hline Spizaetus lanceolatus & $P$ & GEN & $\mathrm{E}$ & PC \\
\hline \multicolumn{5}{|l|}{ Alcedinidae } \\
\hline Halcyon chloris & 1 & OL & w & $\mathrm{PC}+\mathrm{MN}$ \\
\hline Halcyon sancta & 1 & FO & w & $\mathrm{MN}$ \\
\hline \multicolumn{5}{|l|}{ Apodidae } \\
\hline Collocalia esculenta & 1 & GEN & W & $\mathrm{PC}+\mathrm{MN}$ \\
\hline Collocalia vanikorensis & 1 & GEN & w & PC \\
\hline \multicolumn{5}{|l|}{ Ardeidae } \\
\hline Ardea purpurea & $\mathrm{P}$ & $\mathrm{OL}$ & w & PC \\
\hline Ardeola speciosa & $P$ & $\mathrm{OL}$ & w & PC \\
\hline Eggreta intermedia & $P$ & OL & w & PC \\
\hline Arthamidae & & & & PC \\
\hline Arthamus leucorhynchus & 1 & $\mathrm{OL}$ & w & PC \\
\hline \multicolumn{5}{|l|}{ Campephagidae } \\
\hline Coracina leucopygia & 1 & OL & $\mathrm{E}$ & PC \\
\hline Coracina morio & 1 & FO & $\mathrm{E}$ & PC \\
\hline Coracina temminckii & 1 & GEN & $\mathrm{E}$ & PC \\
\hline Lalage leucopygialis & 1 & GEN & $\mathrm{E}$ & PC \\
\hline \multicolumn{5}{|l|}{ Columbidae } \\
\hline Chalcophaps indica & 0 & FO & w & $\mathrm{PC}+\mathrm{MN}$ \\
\hline Macropygia amboinensis & $\mathrm{F}$ & GEN & w & $\mathrm{MN}$ \\
\hline Ptilinopus melanospila & $\mathrm{F}$ & GEN & w & PC \\
\hline Ptilinopus superbus & $\mathrm{F}$ & FO & w & PC \\
\hline \multicolumn{5}{|l|}{ Corvidae } \\
\hline Corvus enca & 1 & GEN & W & PC \\
\hline \multicolumn{5}{|l|}{ Cuculidae } \\
\hline Cacomantis sepulcralis & 1 & FO & w & $\mathrm{PC}+\mathrm{MN}$ \\
\hline Centropus bengalensis & 1 & $\mathrm{OL}$ & w & PC \\
\hline
\end{tabular}


Chrysococcyx russatus

Cuculatus sparverioides

Cuculus saturatus

Phaenicophaeus calyorhynchus

Dicaeidae

Dicaeum aureolimbatum

Dicaeum celebicum

Dicaeum nerhkorni

\section{Estrilididae}

Lonchura malacca

Lonchura molucca

Lonchura punctulata

\section{Falconiidae}

Falco molucensis

Hemiprocnidae

Hemiprocne longipennis

Hirundinidae

Hirundapus caudacutus

Hirundo rustica

Hirundo tahitica

Meropidae

Merops ornatus

Monarchidae

Hypothymis azurea

Motacillidae

Motacilla cinerea

Motacilla flava

Muscicapidae

Cyornis rufigastra

Eumyias panayensis

Ficedula hyperythra

\section{Nectariniidae}

Aethopyga siparaja

Antreptes malacensis

Antreptes siparaja

Nectarinia aspasia

Nectarinia jugularis

\section{Oriolidae}

Oriolus chinensis

Pachycephalidae

Pachycephala sulfuriventer

Passeridae

Passer montanus

\section{Petroicidae}

Culicicapa helianthea

Phasianidae

\begin{tabular}{|c|c|c|c|}
\hline 1 & GEN & W & $\mathrm{MN}$ \\
\hline I & GEN & w & $\mathrm{MN}$ \\
\hline I & GEN & W & $\mathrm{MN}$ \\
\hline 1 & GEN & $E$ & $\mathrm{MN}$ \\
\hline 1 & GEN & $E$ & $\mathrm{PC}+\mathrm{MN}$ \\
\hline 1 & GEN & $E$ & $\mathrm{PC}+\mathrm{MN}$ \\
\hline 1 & FO & $E$ & $\mathrm{PC}+\mathrm{MN}$ \\
\hline G & $\mathrm{OL}$ & W & $\mathrm{MN}$ \\
\hline G & $\mathrm{OL}$ & W & $\mathrm{MN}$ \\
\hline G & $\mathrm{OL}$ & w & $\mathrm{MN}$ \\
\hline$P$ & GEN & W & PC \\
\hline I & GEN & W & PC \\
\hline I & GEN & W & PC \\
\hline 1 & $\mathrm{OL}$ & w & $P C$ \\
\hline 1 & $\mathrm{OL}$ & & $\mathrm{PC}+\mathrm{MN}$ \\
\hline I & GEN & W & $\mathrm{MN}$ \\
\hline I & GEN & W & PC \\
\hline I & $\mathrm{OL}$ & W & $\mathrm{PC}+\mathrm{MN}$ \\
\hline I & $\mathrm{OL}$ & w & PC \\
\hline I & GEN & W & $\mathrm{PC}+\mathrm{MN}$ \\
\hline 1 & FO & w & $\mathrm{PC}+\mathrm{MN}$ \\
\hline I & FO & w & $\mathrm{MN}$ \\
\hline I & GEN & W & $\mathrm{PC}+\mathrm{MN}$ \\
\hline I & GEN & w & $\mathrm{PC}+\mathrm{MN}$ \\
\hline 1 & GEN & w & PC \\
\hline 1 & GEN & w & $\mathrm{PC}+\mathrm{MN}$ \\
\hline I & $\mathrm{OL}$ & w & $\mathrm{PC}+\mathrm{MN}$ \\
\hline I & GEN & W & PC \\
\hline I & FO & $E$ & $\mathrm{MN}$ \\
\hline G & $\mathrm{OL}$ & W & PC \\
\hline I & GEN & W & $\mathrm{MN}$ \\
\hline
\end{tabular}


Turnix suscitator

\section{Picidae}

Dendrocopos temminckii

\section{Picnonotidae}

Pycnonotus aurigaster

\section{Psittacidae}

Loriculus exilis

Loriculus stigmatus

Trichoglossus flavoviridis

Trichoglossus ornatus

\section{Ralidae}

Amaurornis isabellinus

Gallirallus torquatus

\section{Rhipiduridae}

Rhipidura teysmannii

\section{Strigidae}

Ninox punctulata

\section{Sturnidae}

Aplonis minor

Scissirostrum dubium

\section{Sylviidae}

Cisticola exilis

\section{Timaliidae}

Trichastoma celebense

\section{Turnicidae}

Turnix suscitator

\section{Zosteropidae}

Zosterops atrifrons

Zosterops chloris

\begin{tabular}{|c|c|c|c|}
\hline $\mathrm{O}$ & $\mathrm{OL}$ & W & $\mathrm{MN}$ \\
\hline I & GEN & $\mathrm{E}$ & PC \\
\hline I & $\mathrm{OL}$ & W & PC \\
\hline $\mathrm{N}$ & FO & $\mathrm{E}$ & PC \\
\hline $\mathrm{N}$ & GEN & $E$ & PC \\
\hline$N$ & FO & W & PC \\
\hline$N$ & GEN & $E$ & PC \\
\hline $\mathrm{O}$ & $\mathrm{OL}$ & $E$ & PC \\
\hline $\mathrm{O}$ & $\mathrm{OL}$ & W & PC \\
\hline & & $E$ & \\
\hline I & FO & $E$ & $\mathrm{MN}$ \\
\hline I & GEN & $E$ & $\mathrm{MN}$ \\
\hline 1 & GEN & W & $\mathrm{PC}+\mathrm{MN}$ \\
\hline 1 & GEN & $\mathrm{E}$ & $\mathrm{PC}+\mathrm{MN}$ \\
\hline 1 & $\mathrm{OL}$ & W & PC \\
\hline 1 & GEN & $E$ & PC \\
\hline 0 & OL & W & \\
\hline 1 & GEN & W & $\mathrm{PC}+\mathrm{MN}$ \\
\hline I & GEN & w & $\mathrm{PC}+\mathrm{MN}$ \\
\hline
\end{tabular}




\section{Table S3}

Correlation analysis of effects of primary forest (in $\mathrm{m}$ ) and local shade cover (decimal values) on (a) abundance and (b) species richness of all recorded bird species $(N=69)$ for the different sampling methods ( $\mathrm{MN}=$ mist netting; $\mathrm{PC}=$ point counts) as well as their total count of bird species $(A L L)$. Significant effects $(P<0.05)$ are printed in bold.

\begin{tabular}{llllllll}
\hline & & \multicolumn{3}{l}{ (a) Species abundances } & \multicolumn{3}{l}{ (b) Species richness } \\
\cline { 3 - 8 } & & $\mathrm{R}^{2}$ & $\mathrm{P}$ & $\mathrm{F}_{(1,13)}$ & $\mathrm{R}^{2}$ & $\mathrm{P}$ & $\mathrm{F}_{(1,13)}$ \\
\hline Forest & $\mathrm{ALL}$ & 0.495 & $\mathbf{0 . 0 0 2}$ & 14.72 & -0.050 & 0.574 & 0.332 \\
& $\mathrm{MN}$ & 0.196 & 0.056 & 4.404 & 0.066 & 0.182 & 1.985 \\
& $\mathrm{PC}$ & 0.448 & $\mathbf{0 . 0 0 4}$ & 12.38 & -0.041 & 0.512 & 0.454 \\
\hline Shade & $\mathrm{ALL}$ & -0.071 & 0.794 & 0.071 & -0.064 & 0.697 & 0.158 \\
& $\mathrm{MN}$ & 0.023 & 0.423 & 0.683 & -0.008 & 0.363 & 0.890 \\
& $\mathrm{PC}$ & -0.076 & 0.935 & 0.007 & -0.057 & 0.628 & 0.246 \\
\hline
\end{tabular}




\section{Table S4}

Correlation analysis of effects of primary forest (in $\mathrm{m}$ ) and local shade cover (decimal values) on (a) abundance and (b) species richness of all recorded bird species $(N=69)$ for the different habitat affiliations (FO, GEN, OL) and distributions (endemic vs. widespread; see Table A2)

\begin{tabular}{llllllll}
\hline & & \multicolumn{3}{l}{ (a) Species abundances } & \multicolumn{3}{l}{ (b) Species richness } \\
\cline { 3 - 8 } & & $\mathrm{R}^{2}$ & $\mathrm{P}$ & $\mathrm{F}_{(1,13)}$ & $\mathrm{R}^{2}$ & $\mathrm{P}$ & $\mathrm{F}_{(1,13)}$ \\
\hline Forest & FO & 0.211 & $\mathbf{0 . 0 4 8}$ & 4.748 & 0.196 & 0.056 & 4.409 \\
& GEN & 0.532 & $\mathbf{0 . 0 0 1}$ & 16.91 & -0.005 & 0.354 & 0.924 \\
& OL & 0.208 & 0.05 & 4.669 & 0.148 & 0.087 & 3.438 \\
& end. & 0.700 & $<0.0001$ & 33.61 & 0.265 & $\mathbf{0 . 0 2 9}$ & 6.054 \\
& wide. & 0.089 & 0.148 & 2.371 & -0.068 & 0.747 & 0.109 \\
\hline Shade & FO & -0.036 & 0.486 & 0.514 & -0.039 & 0.504 & 0.473 \\
& GEN & -0.076 & 0.939 & 0.006 & 0.049 & 0.212 & 1.725 \\
& OL & -0.075 & 0.894 & 0.019 & -0.033 & 0.468 & 0.558 \\
& end. & -0.073 & 0.837 & 0.044 & -0.050 & 0.575 & 0.330 \\
& wide. & -0.055 & 0.615 & 0.266 & -0.076 & 0.917 & 0.011 \\
\hline
\end{tabular}





\section{Chapter IV}

Logging of large dead forest remnant trees at tropical forest margins causes a local population collapse of the endemic Grosbeak Starling

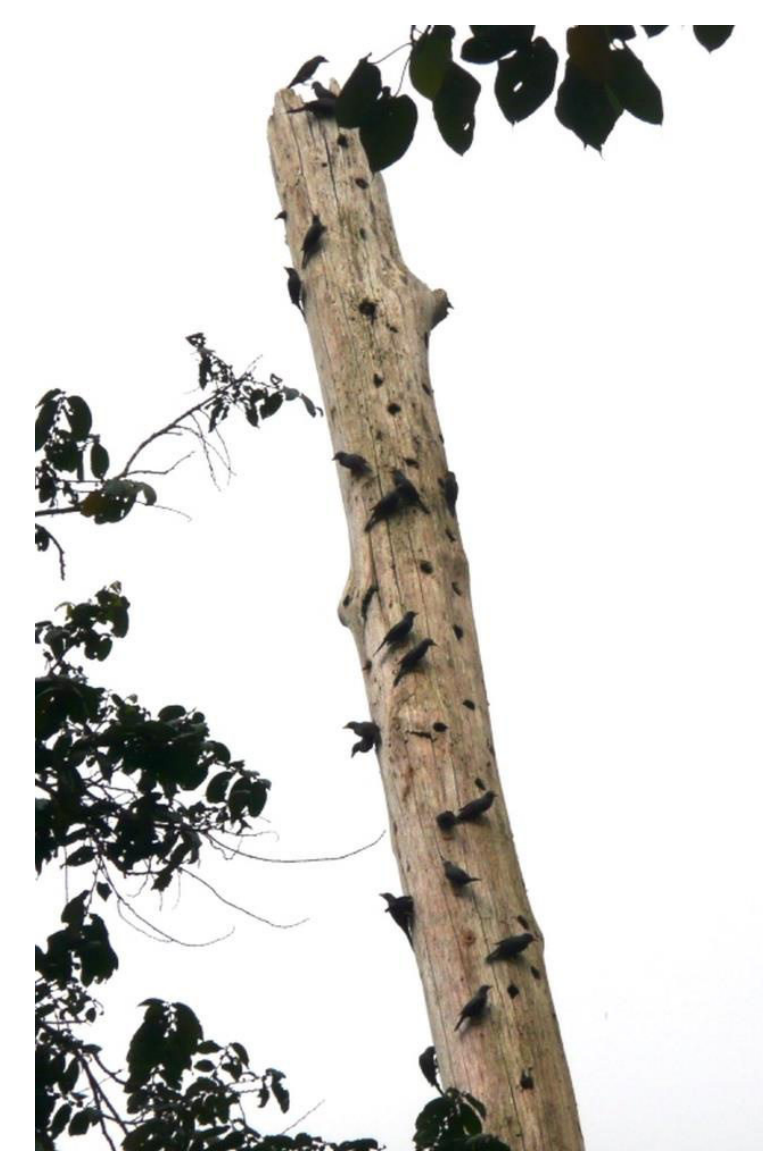




\section{Logging of large dead forest remnant trees at tropical forest margins causes a local population collapse of the endemic Grosbeak Starling}

This article is under review in Biological Conservation

Date of submission: 24 March 2014

Running title: Rapid local decline of the endemic Grosbeak Starling

Authors: Bea MAAS ${ }^{1}$, Teja TSCHARNTKE ${ }^{1}$ and Christian H. SCHULZE ${ }^{2}$

Affiliations:

${ }^{1}$ Agroecology, University of Goettingen, Grisebachstraße 6, 37077 Goettingen, Germany

${ }^{2}$ Department of Botany and Biodiversity Research, University of Vienna, Rennweg 14, A1030 Vienna, Austria

\section{Keywords:}

Scissirostrum dubium; Central Sulawesi; deforestation; habitat fragmentation; land use intensification; forest margin species; critical decline; Paleotropics 


\begin{abstract}
Large and isolated native forest trees often act as last refuges for rare forest species in highly fragmented land use areas. This is of particular importance in tropical forest margin areas where remnant forest trees are being cleared at an alarming rate. Drivers and consequences of such remnant tree losses are still poorly documented. Here, we report the rapid collapse of a local forest margin tree occurrence closely associated to colonies of the endemic Grosbeak Starling (GBS) in Central Sulawesi. GBS is the only starling that depends on large and dead remnant forest trees as nesting sites, which it excavates on its own. Its local distribution area at the eastern border of the Lore Lindu National Park is mainly made up by secondary forests, annual crops and a large number of shaded agroforestry systems, with Erythrina shade trees being the most common species. In 2008, we mapped all potential breeding trees of GBS in this area (ca. $45 \mathrm{~km}^{2}$ ) along with tree characteristics and the local population density of GBS. After a re-mapping of all colony trees in 2010, we observed a dramatic loss of all formerly recorded nesting sites (92\%) attended by a remarkable decline of the local GBS population. Analyses of colonized GBS trees showed that tree diameter (min $\mathrm{dbh}$ of $43.3 \mathrm{~cm}$ ) and the number of breeding holes were closely correlated. Logging left only $8 \%$ of the colonized trees in the two-year period of observation. In conclusion, our study highlights the critical role of rapid forest tree declines associated to native forest species diversity.
\end{abstract}




\section{Introduction}

Deforestation degrades habitats and isolates populations, thereby substantially reducing biodiversity and leading to mass extinctions (Brook et al. 2003; Cardillo et al. 2006; Gardner et al. 2009). Southeast Asia, almost entirely considered as a biodiversity hotspot and harboring an exceptionally high number of endemic species, is threatened by the globally highest rate of human-caused habitat loss (e.g. Myers et al. 2000, Sodhi et al. 2004 and 2010b). But still, the ecological impacts of deforestation are poorly understood in many regions of Southeast Asia (Sodhi et al. 2005), including the island of Sulawesi, where new species are still being discovered (e.g. Madika et al. 2001).

Sulawesi is the largest island within the Indonesian biodiversity hotspot Wallacea characterized by a highly endemic avifauna (Stattersfield et al. 1998) and an outstanding high proportion of endemic species from various other taxa (e.g. Lee et al. 2007). However, a large number of its species suffers from the lack of protected areas and conservation funding as well as from intense human encroachment (e.g. Whitten et al. 1987; Sodhi et al. 2010a). Large remnant rainforest trees are important structural elements for the diversity and composition of bird assemblages in human modified habitats (Abrahamczyk et al. 2008). The Sulawesi endemic Grosbeak Starling (GBS) Scissirostrum dubium (Sturnidae) mainly occurs along forest margin habitats and in lightly wooded areas (Coates et al. 1997) due to its dependency on large and isolated trees as nesting and foraging sites. GBS is the only starling able to excavate its own nesting-holes in tall and dead trees in the manner of a woodpecker (Craig \& Feare 2009; Fig.1). It only colonizes dead, often heavily rotten, large trees which remain at forest margin areas or in the agricultural landscapes, where it forages in small groups along the forest margin area and inside the agricultural landscape consuming fruits of numerous fruiting trees (e.g. Fabaceae, Moraceae, Myrtaceae) as well as insects and seeds (Maas et al., unpublished results). Large remnant trees at the forest margin and in the adjacent cultivated area are increasingly threatened by land use intensification and ongoing tree removal. GBS colony trees are occupied by highly social flocks of $20-150$ birds (Coates et al. 1997) which can merge to "super-colonies" of several neighbored trees and more than 1000 individuals. Considering its ecology and behavior, GBS originally seems to be a forest species that has adapted to forest margin habitats very well. But tolerance towards 
anthropogenic activities turns into a disadvantage for those species which are hunted, traded or removed from their colony trees (Sodhi et al. 2011, Wilcove et al. 2013, Maas et al., unpublished results).

Given the rapid and ongoing conversion of natural habitats into land use systems, particularly in more densely populated areas, within Sulawesi, an improvement of forest management and conservation practices is overdue to prevent endangered and endemic species from extinction (e.g. Sodhi et al. 2005, 2010a). This includes an improved understanding of largely unknown species and their habitat requirements. Regarding GBS, this information is very limited (see Coates et al. 1997; Craig \& Feare 2009).

In 2008 and 2010, we studied a population of GBS along the eastern border of Lore Lindu National Park (Central Sulawesi) with two main objectives. (1) Mapping of dead trees and GBS colonies in the forest margin zone in 2008 was used to identify important characteristics of nesting trees. (2) Based on the mapping of colonies we assessed the species' local population density. (3) A second mapping of colonized GBS trees in 2010 was used to reevaluate the species' current conservation status and conclude with recommendations for possible conservation measures.

\section{Materials and methods}

\section{Study Area}

Our study was conducted in Central Sulawesi, Indonesia, approximately $75 \mathrm{~km}$ southeast of the province capital Palu, at the eastern margin of Lore Lindu National Park (LLNP; Fig. 2). The area was declared a UNESCO Man and Biosphere Reserve in 1977, the national park was established in 1993 and covers an area of 229,000 ha (Adiwibowo 2005). LLNP is an exceptionally species-rich area harboring approximately $78 \%$ of Sulawesi's endemic birds (Coates et al. 1997).

The forest margin landscape outside the closed block of near-primary forest is characterized by a mosaic of secondary forests and a rapidly increasing number of land-use systems with cocoa, coffee, maize and rice as the main crops (Schulze et al. 2004, Maas et al. 2009). Our study area comprises the elevational range of the lower montane forest zone (Whitten et al. 1987) with a mean annual precipitation of over $3,000 \mathrm{~mm}$ (Schweithelm et al. 1992). GBS 
colonies were mapped at the northern tip of Napu Valley between 1,100 and 1,200 m ASL in an area of approximately $45 \mathrm{~km}^{2}$.

\section{Data collection}

During the first year of our study, data recordings (first tree mapping, tree measurements and observation of colony trees and GBS) were done between 22 August and 22 September 2008. All colony trees found in 2008 were re-visited between 1 April and 5 May 2010. Daily mapping hours were between $06 \mathrm{~h} 00$ and $19 \mathrm{~h} 00$ in both years.

\section{Tree mapping}

For mapping of the colony trees, we used a geo-referenced map of the study area (Bakosurtanal 1991), GPS data (Garmin 12 Map) and a digital rangefinder to measure and estimate distances (Nikon Laser 800S). We divided the study area into grids of $50 \times 50 \mathrm{~m}$ and mapped all dead trees with a dbh (diameter at breast height) larger than $20 \mathrm{~cm}$ and being taller than 2 meter by checking every grid. Every recorded tree $(N=547)$ obtained an individual number, a GPS position and was plotted on the map. In addition, we systematically searched for colonized trees along 22 forest transects being $300 \mathrm{~m}$ long and $200 \mathrm{~m}$ wide (buffer zone of $100 \mathrm{~m}$ left and right from each transect). For each dead tree ( $N=547)$ we recorded tree height (estimated using a digital rangefinder), dbh, distance to primary forest (GPS data), last logging event for the respective location ( 3 classes: less than 5 years ago, 510 years ago or more than 10 years ago), the habitat type (agricultural system, primary and secondary forest; see App. T1) and the number of breeding holes made by GBS. Because trees showing breeding holes are not necessarily occupied (meaning active use of the tree as nesting or roosting site) by GBS, we also noted which of the trees with visible breeding holes $(\mathrm{N}=24)$ were visited by GBS ( $N=20$ from 24$)$ in 2008. A tree was identified as occupied when GBS activity at the breeding holes was recorded during our mapping or the following tree observations. All potential colony trees were mapped and measured in 2008. In 2010, we focused on the re-assessment of colony trees from 2008.

In addition to the mapping of potential GBS colony trees, we mapped the forest margin along 158 GPS points in 2008 and re-mapped it in 2010 by taking additional data at those spots, were the forest margin had changed. All tree mapping data were analyzed using ArcGIS (ESRI, 2005). 


\section{Mapping and observation of GBS colonies}

For occupied trees (GBS individuals observed; Fig. 1) we determined the number of GBS individuals per tree in two steps. First, we counted the number of available breeding holes on each tree. In a second step, we observed every occupied tree for 6 hours (divided into 2 or 3 observation units) and determined the number of actively used breeding holes. These observations also served to obtain additional information on behavior, breeding activity and foraging times and were conducted by a team of experienced ornithologists (first author and experienced local guide) who adjusted their observations at the end of each observation unit. Each occupied breeding hole was used by two adult GBS individuals (and occasionally their chicks). Accordingly, the number of actively occupied breeding holes by two provides a conservative figure of GBS population size, only including adult GBS individuals that regularly returned to their breeding holes. Due to the long observation period of each tree, we can ensure that vacant breeding holes were not occupied by GBS. The population size was always recorded per tree, also if the colony occupied more than one tree at one place ("super colony"), because GBS pairs were not observed to use more than one breeding hole. Tree species were identified by the first author and an experienced local guide (App. T1).

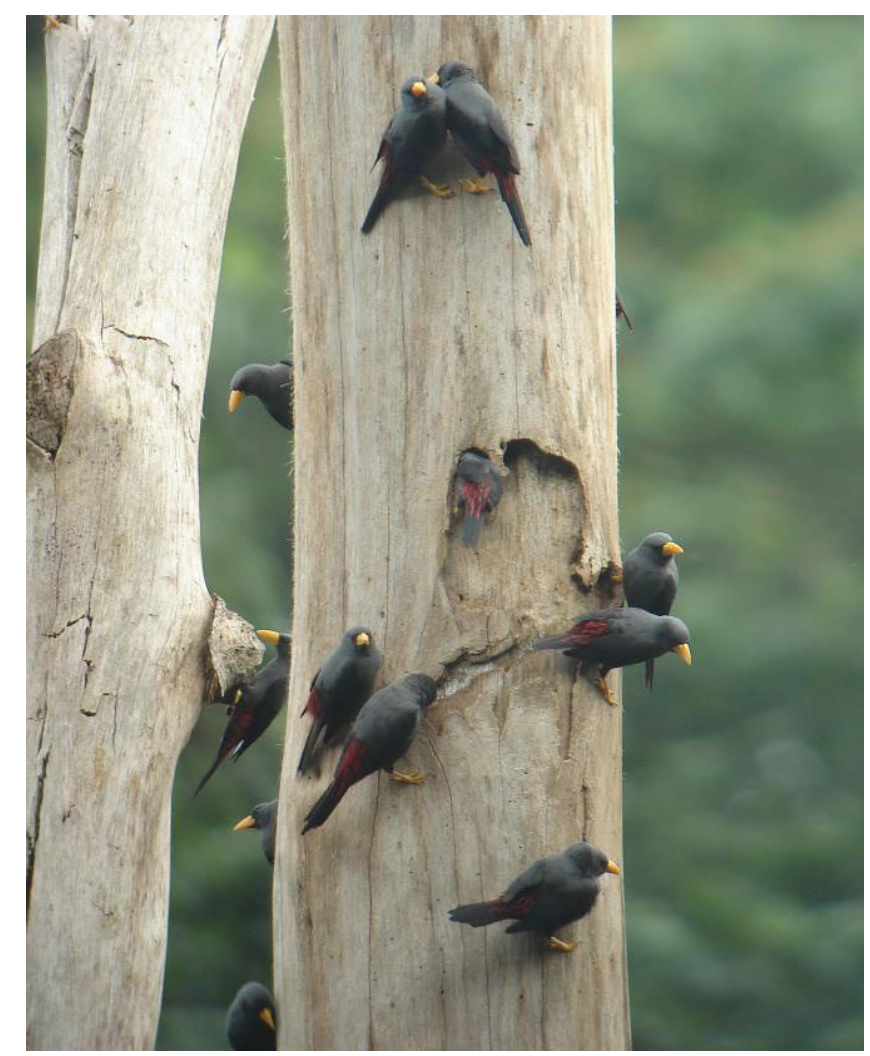

Fig. 1: A colony of Grosbeak Starlings in Napu Valley at the eastern margin of Lore Lindu National Park, Central Sulawesi. Photo: Christian H. Schulze 


\section{Statistical analyses}

To investigate the importance of measured tree parameters for tree colonization by GBS, we calculated Pearson correlations to relate tree height $(\mathrm{m})$ and tree $\mathrm{dbh}(\mathrm{cm})$ to the number of GBS breeding holes (log transformed) per tree. The distribution of the response variable was either assumed to be approximated by normal (tree height, tree $\mathrm{dbh}$ ) or overdispersed Poisson (number of breeding holes) distribution. In the last case, variables were logtransformed. In addition, the tree parameters were divided into classes (5 dbh classes with $50 \mathrm{~cm}$ intervals and 7 tree height classes with $5 \mathrm{~m}$ intervals) and tested them against the respective percentage of trees colonized within the intervals using Spearman rank correlations. Tree occupation by GBS was displayed within a bubble plot with colony size as weighted variable (colony size intervals of 20 individuals) against both tested tree parameters (tree height and tree $\mathrm{dbh}$ ) on the plot axes. All statistical tests and two-dimensional plots were computed using STATISTICA version 7.1 (StatSoft Inc., 2005).

\section{Sulawesi}

LLNP

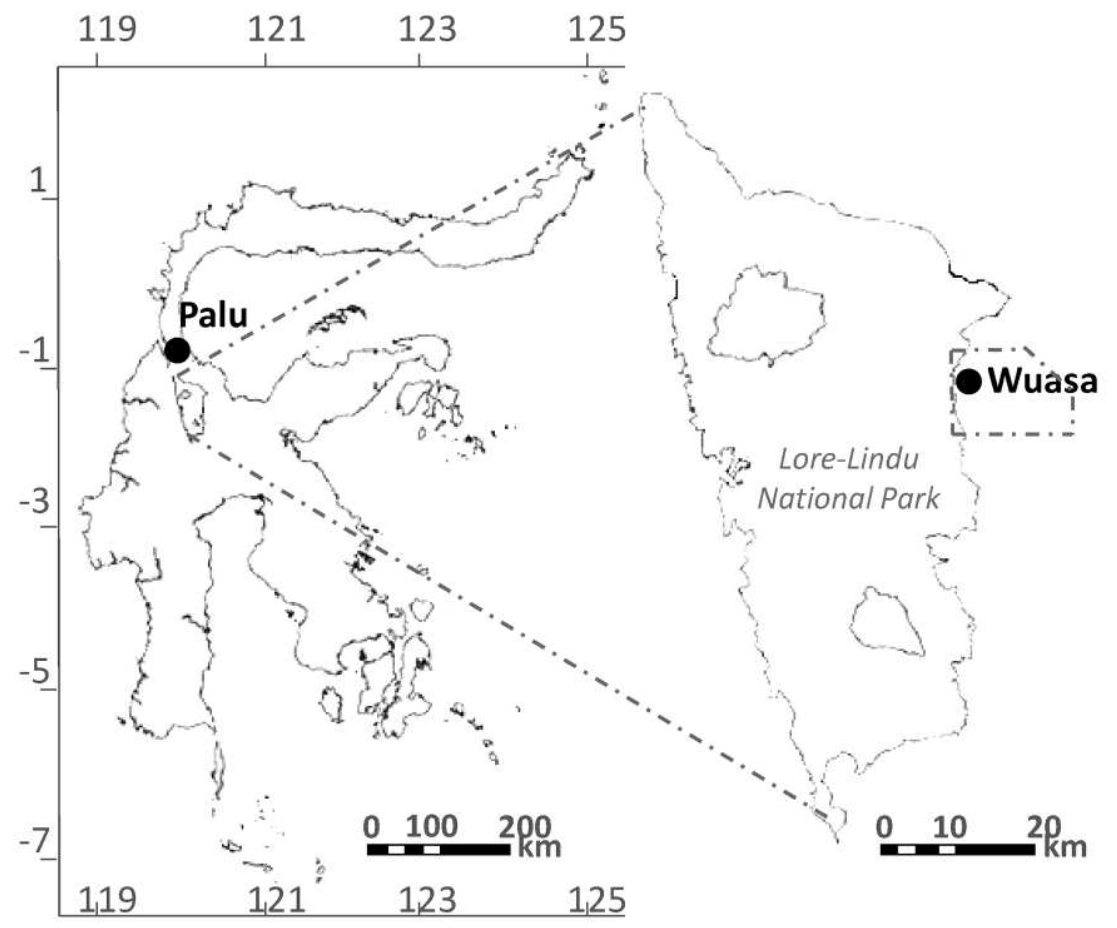

Fig. 2: Study area located on the island of Sulawesi (left side) at the eastern border of the Lore-Lindu National Park (LLNP; augmented at the right side) indicated by the dashed-line polygon around the central village Wuasa. 


\section{Results}

\section{Tree mapping}

In total, we mapped 547 dead trees ( $\mathrm{dbh}>20 \mathrm{~cm}$; tree height $>2 \mathrm{~m}$ ). GBS breeding holes were found on 24 of them. A total of $83.3 \%$ of these trees $(N=24)$ were actively occupied ( $N$ $=20)$ by GBS during the study period in 2008 .

Correlation between tree height and tree $\mathrm{dbh}$ was highly significant for all mapped trees $(\mathrm{N}=$ 547; $r=0.412 ; p<0.001)$, significant for all trees with breeding holes $(\mathrm{N}=24 ; r=0.456 ; p=$ $0.025)$ and not significant for occupied trees $(\mathrm{N}=20 ; r=0.269 ; p=0.252)$. The number of breeding holes per tree (log) was significantly correlated with tree dbh (Fig. 3a) but not with tree height (Fig. 3b). However, the percentage of colonized trees increased both for increased size of dbh classes (Fig. 3c) and tree height classes (Fig. 3d).
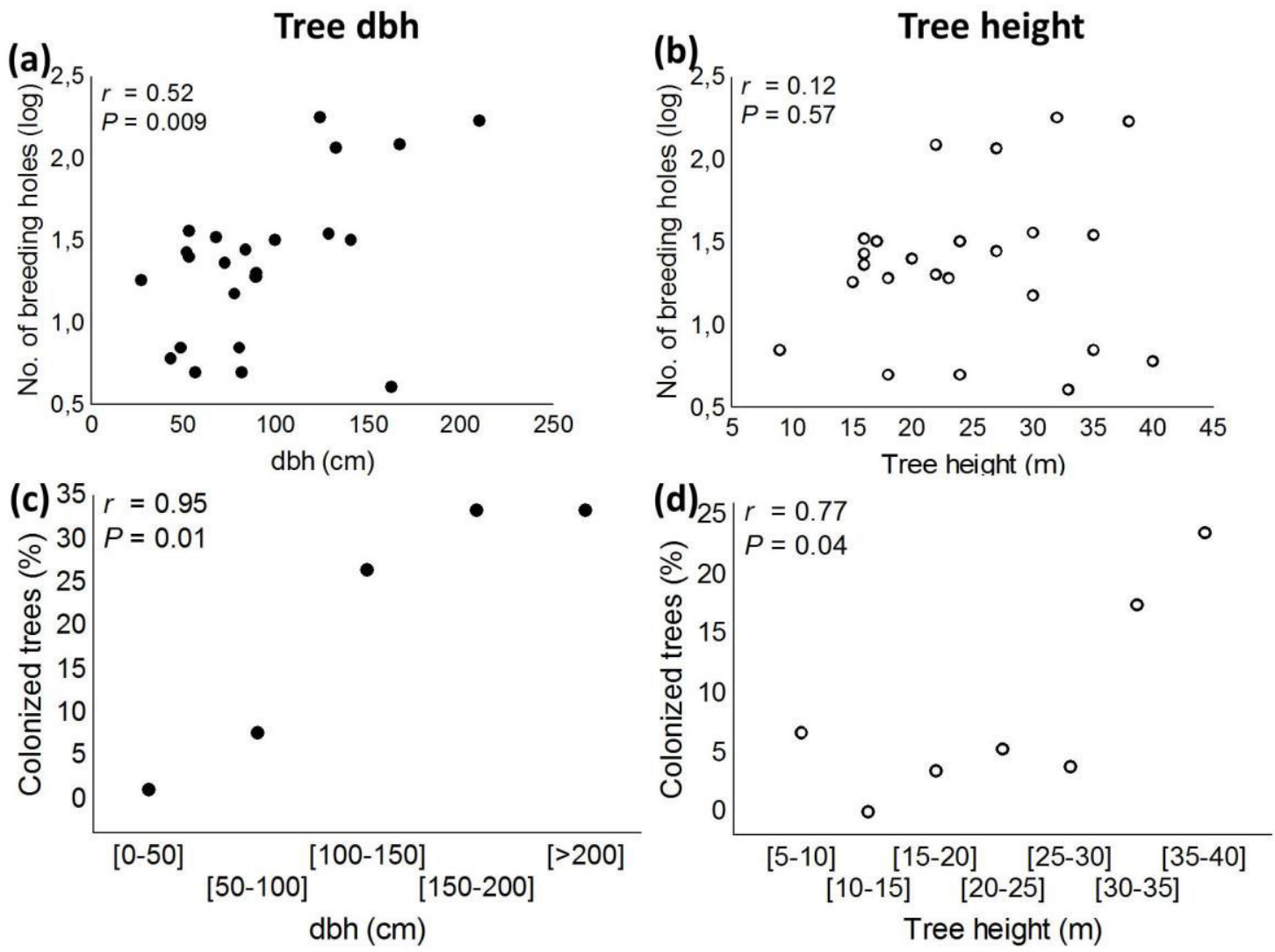

Fig. 3: Effects of tree $\mathrm{dbh}$ and tree height on colony size and the proportion of colonized trees. (a) The number of breeding holes is significantly correlated with the tree $\mathrm{dbh}(\mathrm{cm})$ of colonized GBS trees $(\mathrm{N}=24)$ whereas $(\mathrm{b})$ tree height is not related to colony size (see results of Pearson correlations). The percentage of colonized trees for different tree size classes ( $x$ axis) does significantly increase with increasing tree size although the effect is stronger for dbh classes (c) than for tree height classes (d) (results of Spearman rank correlations). 
Trees with breeding holes were between 16 and $40 \mathrm{~m}$ high and had a dbh of $43.3-210.4 \mathrm{~cm}$ (Fig. 4). Besides the preference for such large trees, GBS also preferred to build their breeding holes in the upper trunk of colonized trees. The minimum height of an occupied breeding hole was $11 \mathrm{~m}$ above ground level while the highest observed occupied breeding hole was $32 \mathrm{~m}$ above ground.

Larger GBS colonies also occupied larger trees. Some of the occupied trees were grouped to "super colonies" consisting of up to three colonized trees at one spot. The majority of trees with breeding holes was located in secondary forest habitats $(41.7 \%)$, followed by agroforestry systems (33.3\%), vegetable fields (12.5\%) and other intensified land use systems (> 5\%). Trees with breeding holes were represented by Erythrina subumbrans (Hassk.) in most cases $(41.7 \%, 10$ of 24 trees) while other trees could not be identified with complete certainty (Tab. A.1). The last logging event at the sites of located colonized trees was more than ten years ago for more than the half of the trees (66.7\%) while some trees remained within sites which have been cleared within the past 10 or 5 years (both 16.7\%).

From the 24 trees with breeding holes mapped in 2008, only two were left in the re-mapping survey in 2010. These two trees represent a super-colony formerly consisting of three GBS trees which remained within an uncultivated land area which is difficult to access due to small flooding areas and a more complex topography. All other 22 former colony trees were lost as a result of logging activities, land conversion or natural collapses.

\section{Population density of GBS}

On the 20 occupied trees, a total of 684 GBS individuals were observed within the study area of $45 \mathrm{~km}^{2}$ which corresponds to a local population density of 15.2 individuals per $\mathrm{km}^{2}$. The mean colony size per tree $( \pm$ SD) was 26.29 ( \pm 22.06$)$ birds.

We also recorded GBS breeding activity (feeding of chicks) during the first survey period in August and September 2008. So far, breeding was apparently only reported for the month of May (Craig \& Feare 2009). 


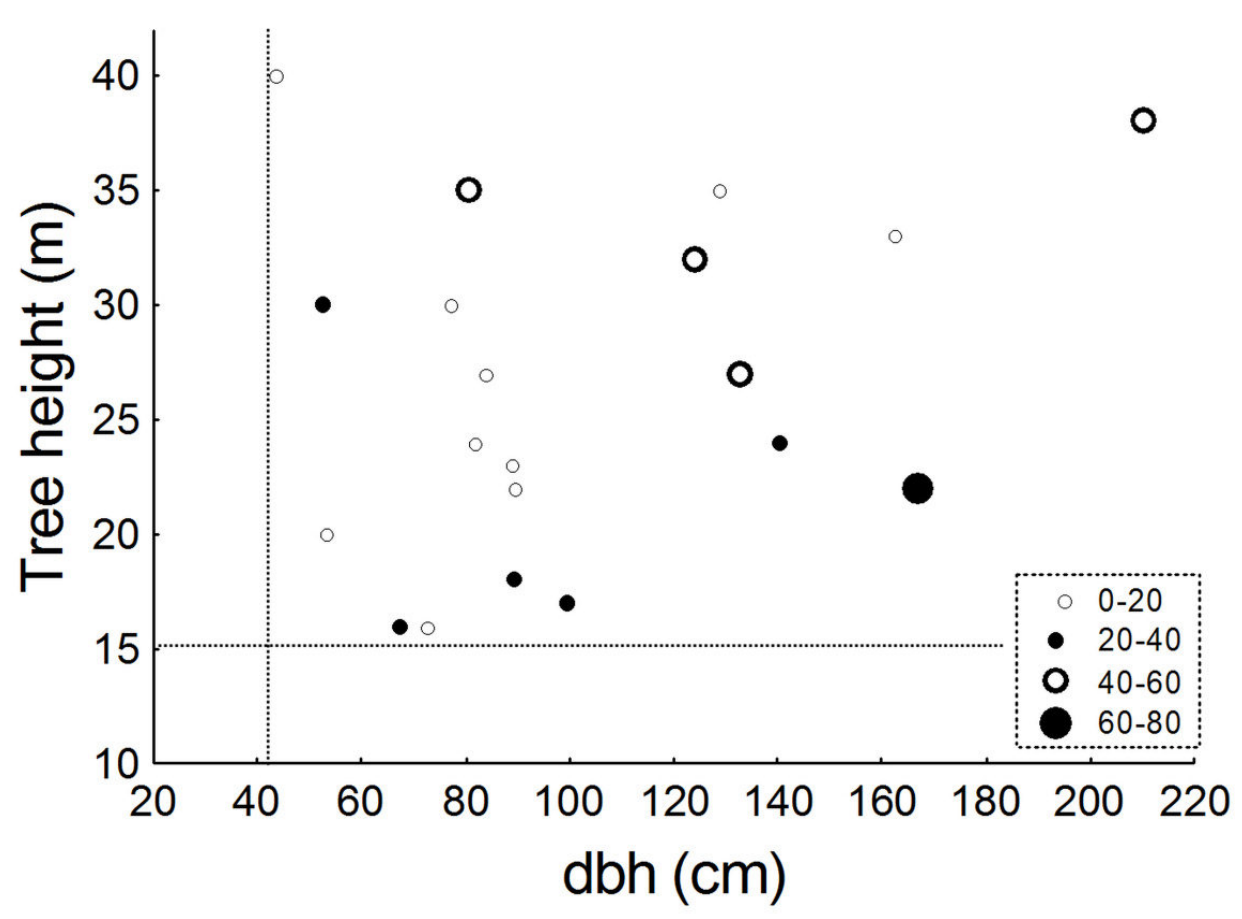

Fig. 4: Bubbleplot of tree height $(\mathrm{m})$ and $\mathrm{dbh}(\mathrm{cm})$ of occupied trees $(\mathrm{N}=20)$ with increasing colony size of GBS (intervals of 20 individuals per tree) indicated by circles of increasing size. Only trees outside the dashed lines (higher than $16 \mathrm{~m}$ and with dbh larger than $43.3 \mathrm{~cm}$ ) were occupied by GBS.

\section{Discussion}

Our results document a rapid local decline of the endemic Grosbeak Starling at the eastern margin of the Lore Lindu National Park in Central Sulawesi, which is closely related to the significant decrease of large remnant forest trees. In only two years, 22 of the 24 colony trees found in 2008 vanished from the study area, corresponding to a loss of $92 \%$. Hence, suitable nesting sites have become a potentially limiting factor in our study area.

The Southeast Asian avifauna is characterized by the highest proportion of threatened and endemic bird species in the tropics but also suffers from a deforestation rate which is three times higher than in other tropical areas (Sodhi et al. 2004; Sodhi et al. 2010b) .The rapid decline of the GBS population in our study area indicates that suitable nesting sites are likely to become the limiting factor for the survival of that species, at least at the local scale. In 2008, 4 of the 24 trees with breeding holes were not colonized of GBS. This amount of unoccupied trees could be explained by sufficient availability of nesting sites in 2008 or by 
abandoning of these former colonies due to high anthropogenic disturbance since all these trees were situated in agroforestry systems.

The conversion of forest margin areas and the intensification of land use systems are rapidly ongoing in Central Sulawesi as well as in other parts of the island (e.g. Riley 2010, Sodhi et al. 2012) and hence pose a pressure on the remaining local GBS populations. Wildlife trade (caged GBS for sale were frequently seen in Sulawesi and Java; Maas et al., unpublished results), local hunting activities (GBS is frequently confused with Aplonis minor by the local community in our study area and therefore being hunted as a land use pest; Maas et al., unpublished results) and the low law enforcement in maintaining protected areas with populations of GBS represent additional threats.

Being a forest species adapted to the forest edge, GBS depends on tall and large standing trees at the forest margin or in the adjacent cultivated area for establishing breeding colonies. We found that GBS trees could be best described using the dbh of colonized trees ( $\min 43.3 \mathrm{~cm}$ ), which was positively related to the number of breeding holes per tree. Furthermore, the proportion of colonized dead trees increased rapidly with increasing $\mathrm{dbh}$. Tree height was a rather poor indicator for colonization by GBS, probably due to the fact that thick, rotten trees were frequently broken at the top.

The majority of colonized trees were located in secondary forests and agroforestry systems as well as in systems in which the last logging event occurred more than ten years ago. Available studies from Neotropical forests illustrate the high variation of age (approximately from 15 to 115 years) of tree species with dbh values higher than $40 \mathrm{~cm}$ (see Fig. 3 in Schöngart 2008, Leoni et al. 2011). It is well understood that tree growth also strongly varies depending on the species and location-specific characteristics. Trees within secondary forests and agroforestry systems of Central Sulawesi with a tree height of $15 \mathrm{~m}$ or more are often remnants older than the respective forest succession stage or the land use systems themselves and were left during the forest conversion process (Michael Kessler, personal communication). Translated into the habitat requirements of GBS, an even longer and yet unknown period than the minimum available estimate (15 years) would be necessary to plant and grow new trees becoming future nesting sites for their colonies since the starling can only excavate breeding holes in trees which are already rotting and easy to perforate. GBS 
therefore mostly occupies tree remnants coming from the forest interior to the forest edge in consequence of former slash-and-burn activities. The other type of colonized GBS trees persists in patches of older and uncultivated secondary forests or agroforestry sites within the open land area adjacent to the eastern margin of the Lore Lindu National Park. Hence, hoping for aging secondary forest habitats or extensive agroforests as a suitable strategy to avoid further tree declines and GBS extinctions on the local scale seems to be unpromising in the near future.

\section{Conclusions and implications for management}

The ongoing loss and conversion of primary habitats and the proceeding removal of remnant large rotten trees within the forest margin area and secondary forests represent a serious and likely underestimated threat for the endemic Grosbeak Starling in Central Sulawesi. The number of mapped colony trees within the eastern area of the Lore Lindu National Park decreased notably (92\%) between 2008 and 2010. These findings represent an alarming trend ongoing in many tropical forest margin landscapes. Unfortunately, most of the world's species are still too poorly known to enter in the record lists of the World Conservation Union (IUCN) or other reports which effectively increase their conservation status (e.g. Brooks et al. 1997). Until now, the global population size of GBS has not been quantified (BirdLife International 2013) and more evidence is needed to see if the clearance of their breeding trees and the collapse of nesting sites are widespread. The Grosbeak Starling is not only attractive to ecotourism and ecological research but also may represent a useful bioindicator for the condition of the forest margin zone, e.g. of protected areas such as Lore Lindu National Park. The protection of big trees, such as the widespread Erythrina shade trees, in agricultural habitats, in agroforestry systems and in the rainforest margin area is necessary to maintain stable population densities of GBS, at least in a short to mid term. 


\section{Acknowledgements}

We thank all local smallholders within our study area for giving us permission to conduct this research on their land. Special thanks goes to Idris Tinulele who frequently guided B.M. during the first study period in the field and helped with identification of tree species. Michael Kessler and Peter Hietz provided very helpful input on tree growth and forest succession discussed within this study. We are very grateful for the kind support and the provision of all necessary research permits given by the city of Palu and Central Sulawesi (Kecamatan Lore Utara) as well as the Tadulako University (CTFM Office). This study was funded with private resources and conducted with the great support of many helping hands in the field as well as in Austria.

\section{References}

Abrahamczyk, S., Kessler, M., Dwi Putra, D., Waltert, M., Tscharntke, T., 2008. The value of differently managed cacao plantations for forest bird conservation in Sulawesi, Indonesia. Bird Conserv. Int. 18, 349-362.

Adiwibowo, S., 2005. Dongi-dongi - Culmination of a multi-dimensional ecological crisis: A political ecology perspective. Doctoral thesis, University of Göttingen, Germany.

Bakosurtanal, 1991. Peta Rupa Bumi Indonesia 1:50000 Edisi I. Bakosurtanal, Cibinong-Bogor.

BirdLife International, 2013. Species factsheet: Scissirostrum dubium. Downloaded from http://www.birdlife.org on 02/07/2013.

Brook, B.W., Sodhi, N.S., Ng, P.K., 2003. Catastrophic extinctions follow deforestation in Singapore. Nature 424, 420-426.

Brooks, T.M., Pimm, S.L., Collar, N.J., 1997. Deforestation predicts the number of threatened birds in insular Southeast Asia. Conserv. Biol. 11, 382-394.

Cardillo, M., Mace, G.M., Gittleman, J.L., Purvis, A., 2006. Latent extinction risk and the future battlegrounds of mammal conservation. Proc. Nat. Acad. Sci. USA 103, 4157-4161.

Coates, B.J., Bishop, K.D., Gardner, D., 1997. A field guide to the birds of Wallacea. Dove Publications, Alderley, Queensland, Australia.

Craig, A.J.F.K., Feare, C.J., 2009. Family Sturnidae (Starlings). In: del Hoyo, J., Elliott, A., Christie, D.A. (Eds.), Handbook of the Birds of the World. Vol. 14. Bush-shrikes to Old World Sparrows. Lynx Ediciones, Barcelona, Pp. 654-759.

ESRI. 2005. ArcGIS 9.1. Redlands, CA: ESRI Institute. 
Gardner, T.A., Barlow, J., Chazdon, R., Ewers, R.M., Harvey, C.A., Peres, C.A., Sodhi, N.S., 2009. Prospects for tropical forest biodiversity in a human-modified world. Ecol. Lett., 12, 561-582.

Lee, T.M., Sodhi, N.S., Prawiradilaga, D.M., 2007. The importance of protected areas for the forest and endemic avifauna of Sulawesi (Indonesia). Ecol. Appl. 17, 1727-1741.

Leoni, J.M., da Fonseca Júnior, S.F., Schöngart, J., 2011. Growth and population structure of the tree species Malouetia tamaquarina (Aubl.)(Apocynaceae) in the central Amazonian floodplain forests and their implication for management. Forest Ecol. Manag. 261, 62-67.

Maas, B., Putra, D.D., Waltert, M., Clough, Y., Tscharntke, T., Schulze, C.H., 2009. Six years of habitat modification in a tropical rainforest margin of Indonesia do not affect bird diversity but endemic forest species. Biol. Conserv. 142, $2665-2671$.

Madika, B., Putra, D.D., Harris, J.B.C., Yong, D.L., Mallo, F.N., Rahman, A., Prawiradilaga, D.M., Rasmussen, P.C., 2011. An undescribed Ninox hawk owl from the highlands of Central Sulawesi, Indonesia? Bull. British Ornithol. Club. 131, 21-29.

Myers, N., Mittermeier, R.A., Mittermeier, C.G., Da Fonseca, G.A., Kent, J., 2000. Biodiversity hotspots for conservation priorities. Nature 403, 853-858.

Riley, E.P., 2010. The endemic seven: Four decades of research on the Sulawesi macaques. Evol. Anthr. 19, 22-36.

Schöngart, J., 2008. Growth-Oriented Logging (GOL): A new concept towards sustainable forest management in Central Amazonian várzea floodplains. Forest Ecol. Manag. 256, 46-58.

Schulze, C.H., Waltert, M., Kessler, P.J.A., Pitopang, R., Shahabuddin, Veddeler, D., Mühlenberg, M., Gradstein, S.R., Leuschner, C., Steffan-Dewenter, I., Tscharntke, T., 2004. Biodiversity Indicator groups of tropical land use systems: comparing plants, birds, and insects. Ecol. Appl. 14, 1321-1333.

Schweithelm, J., Wirawan, N., Elliot, J., Khan, A., 1992. Sulawesi parks program land use and socioeconomic survey Lore Lindu National Park and Morowali Nature Reserve. Directorate General Forest Protection, Ministry of Forestry Republic of Indonesia and The Nature Conservancy, Arlington, Virginia, USA.

Sodhi, N.S., Koh, L.P., Brook, B.W., Ng, P.K., 2004. Southeast Asian biodiversity: an impending disaster. Trends Ecol. Evol. 19, 654-660.

Sodhi, N.S., Koh, L.P., Prawiradilaga, D.M., Tinulele, I., Putra, D.D., Tong Tan, T.H., 2005. Land use and conservation value for forest birds in Central Sulawesi (Indonesia). Biol. Conserv. 122, 547-558.

Sodhi, N.S., Posa, M.R.C., Lee, T.M., Bickford, D., Koh, L.P., Brook, B.W., 2010a. The state and conservation of Southeast Asian biodiversity. Biodiv. Conserv. 19, 317-328.

Sodhi, N.S., Wilcove, D.S., Lee, T.M., Sekercioglu, C.H., Subaraj, R., Bernard, H., et al. Brook, B.W., 2010b. Deforestation and avian extinction on tropical landbridge islands. Conserv. Biol. 24, 12901298.

Sodhi, N. S., Sekercioglu, C. H., Barlow, J., \& Robinson, S. K. (2011). Conservation of tropical birds. John Wiley \& Sons.

Sodhi, N.S., Posa, M.R.C., Peh, K.S., Koh, L.P., Soh, M.C., Lee, T.M., Brook, B.W., 2012. Land use changes imperil South-East Asian biodiversity. In: Lindenmayer, D., Cunningham, S. (Eds.) (2012), 
Land use intensification: effects on agriculture, biodiversity and ecological processes. CSIRO Publishing, Collingwood, pp. 39-46.

StatSoft, Inc. 2005. STATISTICA for Windows, Version 6.1. www.statsoft.com.

Stattersfield, A. J., Crosby, M. J., Long, A. J. \& Wege, D. C., 1998. Endemic Bird Areas of the World: Priorities for Biodiversity Conservation BirdLife International, Cambridge, UK.

Whitten, A.J., Mustafa, M., Henderson, G.S., 1987. The ecology of Sulawesi. Gadjah Mada University Press, Yogyakarta, Indonesia.

Wilcove, D.S., Giam, X., Edwards, D.P., Fisher, B., Koh, L.P., 2013. Navjot's nightmare revisited: logging, agriculture, and biodiversity in Southeast Asia. Trends Ecol. Evol. 28, 531-540. 


\section{Chapter V}

\section{Synthesis}

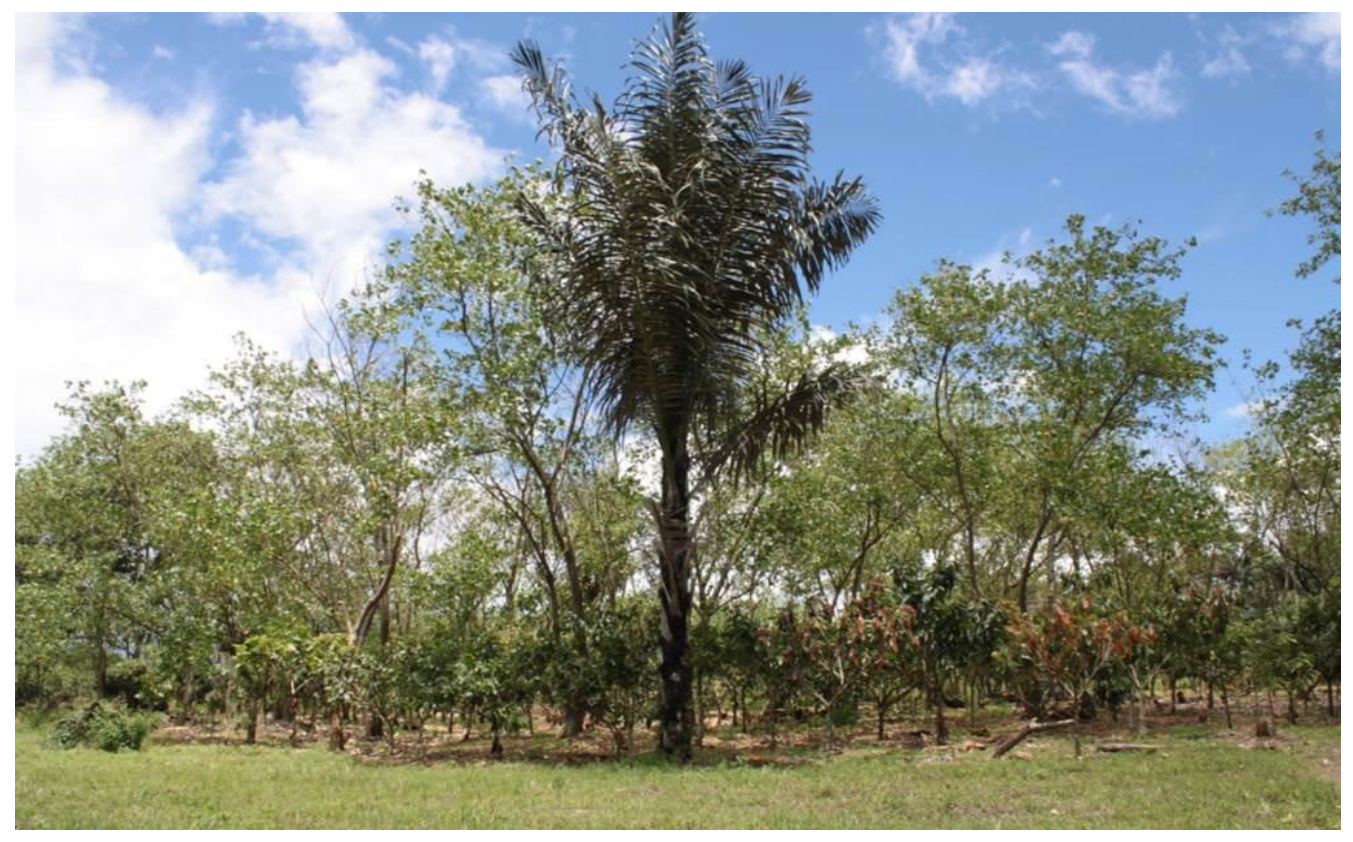




\section{Synthesis}

In our comprehensive full factorial exclusion experiment set up across local management and landscape gradients, we could detect multitrophic interactions between flying vertebrate predators (birds and bats), other natural enemies (ants and spiders) and pest insects (see chapter II). We could demonstrate an impressive impact of birds and bats on arthropods, fruit productivity and crop yield in tropical agroforestry. Using additional sampling methods (mist netting and point counts of birds) and field predation experiments, we could show the importance of species identity for the predation of common pest insects (see chapter III). Functional diversity and ecosystem services do not necessarily depend on the same management strategies and, besides their unequal importance for conservation and smallholder economics, are best assessed with different field methods. Nevertheless, the proximity to forest habitats and extensively used agroforests seems important for both biodiversity and ecosystem functioning. This could also be shown in our study on the habitat requirements of the Sulawesi endemic Grosbeak Starling which is highly adapted to anthropogenic land use areas but depends on large remnant forest trees as nesting sites (see chapter IV). The conversion of the forest margin landscape in Central Sulawesi caused a sharp decline of local nesting site availability and is likely to affect the diversity of other species in this area as well.

Our studies provide new arguments for wildlife-friendly management of agroecosystems, which is not only important for sustaining rural livelihoods, but also for the potential conservation of endangered species. To improve management and sustainable use of natural resources, a better understanding of the underlying ecological mechanism in agroforestry land use are needed (Perfecto et al. 2004; Philpott et al. 2009). Our results stress the economic impact of the underestimated group of night-active predators, such as insectivorous bats (Williams-Guillén et al. 2008). We also emphasize the relevance of single common bird species as drivers of arthropod suppression which are related to forest habitats and extensive land use. We underline the importance of taking into account the effects local and landscape management (Tscharntke et al. 2005; Clough et al. 2009) and consider different temporal and spatial scales simultaneously, also with respect to multitrophic interactions between birds, bats and predatory arthropods which jointly impact the productivity of agroforestry systems in complex ways. 
Traditional agroforestry practices have considerable potential to support biodiversity conservation, but this is conditional on factors such as sufficient areas of natural habitat and legal regulations of biodiversity and natural products (McNeely and Schroth 2006). Local shade tree management in tropical agroforestry is often considered a valuable management strategy to conserve species richness and functional diversity (e.g. Rice and Greenberg 2000; Perfecto et al. 2007). Modern trends towards increased planting of introduced fruiting tree species and the absence of native shade trees, have to be discussed with respect to possible impacts on native (shade tree associated) biodiversity and smallholder economics (Augusseau et al. 2006).

Native fruit trees not only provide valuable shade trees for agroforestry, they can also be used as food resources, fire wood or construction material (McNeely and Schroth 2006; 2008). Therefore, shade trees can not only be seen as a chance for biodiversity-friendly agroforestry management, but also as 'stored capital' and additional income for smallholder farmers (Tscharntke et al. 2011). The argument of extensive agroforestry management becomes even more attractive to smallholder farmers if high crop production can be combined with high biodiversity (Clough et al. 2011), which also increases the ecological resilience of ecosystems (Bengtsson et al. 2003; Loreau et al. 2003). Furthermore, intensive agriculture management (including pesticides, fertilizer and shade tree pruning) can reduce the ability of ecosystems to provide goods and services, for example through degraded soil and water quality (Tilman et al. 2002).

Tropical landscapes are highly fragmented due to ongoing habitat destruction, a fact which creates the need for farming systems and landscape structures which allow migration between fragments and therefore detain ongoing local and regional extinctions (Perfecto et al. 2010). This landscape matrix framing approach (Perfecto et al. 2010) has a better chance of capturing reality than the alternatives taking into account the consensus among ecologists that metapopulations, metacommunities and landscape processes are important determinants of biodiversity. The emergence of new agricultural diseases and pest species and the impact of climate change represent additional threats for the global agricultural food production system (Schroth et al. 2004). 
With increasing knowledge of the importance of biological and functional diversity for ecosystem functioning (Tscharntke et al. 2005; Whelan et al. 2008; Kunz et al. 2011 ), more sustainable land use practices are in great demand (Cullen et al. 2005; McNeely and Schroth 2006). It is known that extensive agricultural systems (shaded with no or low amounts of chemical compounds) can support high biodiversity depending on local shade tree diversity and availability (e.g. Perfecto et al. 1996; Rice and Greenberg 2000) as well as the respective landscape context (e.g. Fahrig et al. 2011), but the integration of local and landscape scales into the study of ecosystem functioning in tropical agroforestry is new.

In the context of such improved practices for productive and extensively used agricultural systems in the tropics, our findings represent an important addition to previous studies because they highlight the importance of these scales for the provision of ecosystem services. Besides the tremendous positive effects of birds and bats for the productivity of tropical agroforestry, we point out the importance of species identities for ecosystem services on a landscape scale and illustrate the impact of landscape conversion on species diversity and common species identities in tropical land use areas. Accordingly, we agree that conservation should be viewed from a larger landscape perspective (e.g. Tscharntke et al. 2005; Bos et al. 2007; Perfecto et al. 2010) and suggest that the consideration of spatial and temporal scales into management practices might even facilitate the beneficial impact of birds and bats on agroforestry crops. To allow for such a targeted local and landscape management, more quantitative evidence for spatial effects on the quality and quantity of ecosystem services, species identities and species specific functions are needed in tropical landscapes. 


\section{References}

Augusseau, X., Nikiéma, P. and Torquebiau, E. (2006) Tree biodiversity, land dynamics and farmers' strategies on the agricultural frontier of southwestern Burkina Faso. Biodiversity and Conservation 15: 613-630.

Bengtsson, J., Angelstam, P., Elmqvist, T., Emanuelsson, U., Folke, C., Ihse, M., Moberg, F. and Nyström, M. (2003) Reserves, resilience and dynamic landscapes. AMBIO: A Journal of the Human Environment 32: 389-396.

Bos, M.M., Steffan-Dewenter, I. and Tscharntke, T. (2007) The contribution of cacao agroforests to the conservation of lower canopy ant and beetle diversity in Indonesia. Biodiversity and Conservation 16: $2429-2444$.

Clough, Y., Dwi Putra, D., Pitopang, R. and Tscharntke, T. (2009) Local and landscape factors determine functional bird diversity in Indonesian cacao agroforestry. Biological Conservation 142: 1032-1041.

Clough, Y., Barkmann, J., Juhrbandt, J., Kessler, M., Wanger, T. C., Anshary, A., Buchori, D., Cicuzza, D., Darras, K., Dwi Putra, D. Erasmi, S., Pitopang, R., Schmidt, C., Schulze, C. H., Seidel, D., SteffanDewenter, I., Stenchly, K., Vidal, S., Weist M., Wielgoss A. C. and Tscharntke, T. (2011) Combining high biodiversity with high yields in tropical agroforests. Proceedings of the National Academy of Sciences 108: 8311-8316.

Cullen, L., Alger, K. and Rambaldi, D. M. (2005) Land reform and biodiversity conservation in Brazil in the 1990s: conflict and the articulation of mutual interests. Conservation Biology 19: 747-755.

Fahrig, L., Baudry, J., Brotons, L., Burel, F. G., Crist, T. O., Fuller, R. J., Sirami, C., Siriwardena, G. M. and Martin, J. L. (2011) Functional landscape heterogeneity and animal biodiversity in agricultural landscapes. Ecology Letters 14: 101-112.

Kunz, T. H., Braun de Torrez, E., Bauer, D., Lobova, T. and Fleming, T. H. (2011) Ecosystem services provided by bats. Annals of the New York Academy of Sciences 1223: 1-38.

Loreau, M., Mouquet, N. and Gonzalez, A. (2003) Biodiversity as spatial insurance in heterogeneous landscapes. Proceedings of the National Academy of Sciences 100: 12765-12770.

McNeely, J. A. and Schroth, G. (2006) Agroforestry and biodiversity conservation-traditional practices, present dynamics and lessons for the future. Biodiversity and Conservation 15: 549-554.

Perfecto, I., Rice, R. A., Greenberg, R. and Van der Voort, M. E. (1996) Shade coffee: a disappearing refuge for biodiversity. BioScience 46: 598-608.

Perfecto, I., Vandermeer, J. H., Bautista, G. L., Nunez, G. I., Greenberg, R., Bichier, P. and Langridge, S. (2004) Greater predation in shaded coffee farms: the role of resident neotropical birds. Ecology 85 : 2677-2681.

Perfecto, I., Armbrecht, I., Philpott, S. M., Soto-Pinto, L. and Dietsch, T. V. (2007) Shaded coffee and the stability of rainforest margins in northern Latin America. In Stability of Tropical Rainforest Margins (pp. 225-261). Springer Berlin Heidelberg. 
Perfecto, I. and Vandermeer, J. (2010) The agroecological matrix as alternative to the landsparing/agriculture intensification model. Proceedings of the National Academy of Sciences 107: 5786-5791.

Philpott, S. M., Soong, O., Lowenstein, J. H., Pulido, A. L., Lopez, D. T., Flynn, D. F. and DeClerck, F. (2009) Functional richness and ecosystem services: bird predation on arthropods in tropical agroecosystems. Ecological Applications 19: 1858-1867.

Rice, R. A. and Greenberg, R. (2000).Cacao cultivation and the conservation of biological diversity. AMBIO: A Journal of the Human Environment 29: 167-173.

Rice, R. A. (2008) Agricultural intensification within agroforestry: the case of coffee and wood products. Agriculture, Ecosystems and Environment 128: 212-218.

Schroth, G. (Ed.). (2004) Agroforestry and biodiversity conservation in tropical landscapes. Island Press.

Tilman, D., Cassman, K. G., Matson, P. A., Naylor, R. and Polasky, S. (2002) Agricultural sustainability and intensive production practices. Nature 418: 671-677.

Tscharntke, T., Klein, A. M., Kruess, A., Steffan-Dewenter, I. and Thies, C. ( 2005) Landscape perspectives on agricultural intensification and biodiversity-ecosystem service management. Ecology Letters 8: 857-874.

Tscharntke, T., Clough, Y., Bhagwat, S. A., Buchori, D., Faust, H., Hertel, D., Hölscher, D., Juhrbandt, J., Kessler, M., Perfecto, I., Scherber, C., Schroth, G., Veldkamp, E. and Wanger, T. C. (2011) Multifunctional shade-tree management in tropical agroforestry landscapes-a review. Journal of Applied Ecology 48: 619-629.

Whelan, C. J., Wenny, D. G. and Marquis, R. J. (2008) Ecosystem services provided by birds. Annals of the New York Academy of Sciences 1134: 25-60.

Williams-Guillén, K., Perfecto, I. and Vandermeer, J. (2008) Bats limit insects in a neotropical agroforestry system. Science 320: 70-70. 


\section{Publications}

Maas, B., Clough, Y., \& Tscharntke, T. (2013) Bats and birds increase crop yield in tropical agroforestry landscapes. Ecology Letters 16: 1480-1487.

Maas, B., Karp, D., Van Bael, S., Williams-Guillén, K., Michel, Sekercioglu, C. H., N., Morrison, M., Philpott, S., Taylor, P., Perfecto, I., et al. (in prep.) Review article on 'Functional importance of insectivorous bird and bat communities in tropical human-dominated landscapes' with focus on existing experimental exclosure studies, impacts of birds and bats on global cash crop yields and functional diversity patterns along landscape scales.

Williams-Guillen, K., Arlettaz, R., Taylor P., Olimpi, E. and Maas, B. (in prep.) Book chapter for the upcoming book 'Bats in the Anthropocene' with focus on bats in the anthropogenic matrix.

Maas, B., Tscharntke and Schulze C. H. (in prep.) Logging of large dead forest remnant trees at tropical forest margins causes a local population collapse of the endemic Grosbeak Starling

Maas, B., Tscharntke, T., Dwi Putra, D. and Clough, Y. (in prep.) Avian species identity drives predation success in tropical cacao agroforestry

Maas, B., Dwi Putra D., Waltert M., Clough Y., Tscharntke T. and C.H. Schulze. (2009) Six years of habitat modification in a tropical rainforest margin of Indonesia do not affect bird diversity but endemic forest species. Biological Conservation 142: 2665-2671.

\section{Conferences and Tutorials}

10/2013 - (Talk and booklet contribution) at the 142nd Conference of DO-G/German Society of Ornithology (Regensburg/Germany). Title: Schädlingskontrolle insektivorer Vögel in regendwaldnahen Kakaoagroforstsystemen Zentralsulawesis (Indonesien). - honored with award for $2^{\text {nd }}$ best student's presentation

09/2013 - Talk at the 'Beringertagung Helgoland' of the Ornithological Research Institute IFV (Institut für Vogelforschung) on Helgoland, Germany. Title: Vogelberingung auf Sulawesi (Indonesien) Einblicke in 4 Jahre Forschung.

06/2013 - (Talk and booklet contribution) at the international symposium "Association for Tropical Biology and Conservation" (ATBC in San José, Costa Rica). Title: Birds and bats increase crop yield in tropical agroforestry landscapes.

04/2013 - (Talk and booklet contribution) at the "Annual Conference of the Society for Tropical Ecology" (gtö in Vienna, Austria). Title: Birds and bats sustain productivity in agroforests of Central Sulawesi, Indonesia.

03/2013 - (Talk and booklet contribution) at the "3rd International Bat Meeting: Bats in the Anthropocene" (Berlin, Germany). Title: Bats in South East Asian agroforestry contribute more to cacao pest control than birds - honored with the Thomas H. Kunz award for best student's presentation 
02/2011 - (Talk and booklet contribution) at the workshop of "Environmental and Land-Use Change in Sulawesi, Indonesia" (ELUC in Palu, Indonesia). Title: Functional diversity of birds and bats in agroforestry landscapes of Indonesia: biological control and seed dispersal

07/2010 - (Talk and booklet contribution) at the international symposium "Association for Tropical Biology and Conservation" (ATBC in Bali, Indonesia). Title: Six years of habitat modification in a tropical rainforest margin do not affect bird species richness but endemic forest species - Indonesia: results from 2001-2008, outline of current study

10/2009 - (Poster and booklet contribution) Six years of habitat modification in a tropical rainforest margin of Indonesia do not affect bird diversity but endemic forest species. 142nd Conference of DOG/German Society of Ornithology. - Kärnten/Austria -

08/2009 - (Tutorial) Biogeography of the Krakatau Islands: rapid biodiversity assessment of birds and butterflies in Indonesia. Tutorial in the range of tropical ecology, cooperation of the Universities Vienna, Austria- and -Bogor, Indonesia-.

10/2008 - (Talk and booklet contribution) at the international symposium "Tropical Rainforests and Agroforests under Global Change"(Bali, Indonesia). Title: Six years of habitat modification in a tropical rainforest margin do not affect bird species richness but endemic forest species

\section{Upcoming publications, talks and conferences in 2014}

07/2014 - Invited talk at the ATBC conference in Cairns, Australia. Symposium "Post-conversion conservation: biodiversity and ecosystem function in emerging tropical agricultural landscapes" (Convenors: Prof. Dr. William Foster from Cambridge University and Prof. Dr. Teja Tscharntke from Göttingen University). - Abstract accepted

07/2014 - Invited project presentation at the institutions of LIPI and IPB Bogor (Indonesia) in context of German-Indonesian SFB research projects by the DFG (Deutsche Forschungsgemeinschaft) with focus on applied ecological research in Indonesia.

08/2014 - Submitted abstract for IOC conference in Tokyo, Japan: 'Bird predation services in tropical agroforestry: multitrophic interactions and increase of crop yield' - Abstract accepted 



\section{Curriculum Vitae}

Name:

Email :

Born:

Nationalities:

$\underline{\text { Scientific education }}$

2013

$2009-2013$

2009

$2008-2009$

$2004-2008$

$\underline{\text { Secondary school }}$

2004
Bea Maas

beamaas@gmx.at

5 June 1986; San Francisco (USA)

German, USA

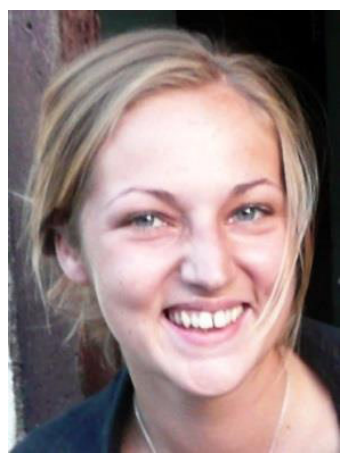

PhD in Agricultural Sciences (Dr. sc. agr.) at the Georg-August-University of Göttingen, Germany - passed with 'summa cum laude' (Nov. 2013)

Doctoral researcher at the University of Göttingen, Germany (Agroecology Group), supervised by Prof. Dr. Teja Tscharntke and PD Dr. Yann Clough. Field work in cacao agroforestry systems in Indonesia.

Diploma in Biology/Ecology (Mag. rer. nat.) at the University of Vienna, Austria. - thesis evaluated as excellent (grade 1)

Diploma thesis at the University of Vienna, Austria (Department of Population Ecology) supervised by Dr. Christian H. Schulze and in close cooperation with the University of Göttingen (Germany), the Tadulako University in Palu and IPB Bogor (Indonesia).

Study in the field of Biology, specialization in Ecology at the University of Vienna; pre-degree in 02/2006

- major subjects in community ecology, statistics, arthropods and ornithology (Department of Population Ecology, Prof. Dr. Fiedler)

- minor subjects in conservation biology, ecology of plants and alpine environments (Department of Conservation Biology, Vegetation Ecology and Landscape Ecology, Prof. Dr. Grabherr)

Completion of secondary education at the 'BG/BRG Biondekgasse'; Baden bei Wien, Austria - passed with distinction (grade 1.2) 


\section{$\underline{\text { Scholarships and travel grants }}$}

2010-2013 German National Academic Foundation (Studienstiftung des deutschen Volkes) The Studienstiftung awards scholarships to intellectually outstanding students at institutions of higher education.

The PhD project was also partly funded from the German Science Foundation (DFG Grant CL-474/1-1 to PD Dr. Yann Clough)

2013

Travel grant by the 'Universitätsbund Göttingen e.V.' for attendance of the ATBC conference in San José, Costa Rica.

Scholarship from the University of Vienna and funding from DFG project (SFB 552) during the conduction of my diploma thesis at the University of Vienna

\section{$\underline{\text { Scientific experience and skills }}$}

Language skills

Computer literacy

Methodic

Field work/Teaching

Club memberships

Volunteering
German; English; Indonesian; Spanish; Italian

Statistical software (e.g. R, Statistica, MS Office, Estimate, Distance, Primer, Canoco, Maxent, Arc GIS and Q-GIS)

Image editing software (e.g. AdobePremierePro, Photoshop CS3, IrfanView, Dreamweaver, Inkscape)

- Official bird banding license (from IFV, Helgoland)

- Census and survey methods (e.g. Field mapping, distance sampling, mist netting and banding of birds; taxidermy of arthropods)

- Scientific Writing (e.g. lectures by Dr. Michael Hochberg)

- Driving license (class B)

03/2008 - 08/2011: Central Sulawesi (Indonesia) - field work and data collection during diploma and doctoral studies; teaching of international students on Sulawesi and in field course on the Krakatau islands 06-07/ 2007: Austrian Alps - Field assistant; study on alpine Tiger Beetles 01/ 2007: Costa Rica - practical course, tropical biodiversity 07/ 2006: Austrian Alps - botanical field course

BirdLife Austria; OBC (Oriental Bird Club); ATBC (Association for Tropical Biology and Conservation); D-OG (Deutsche Ornithologen Gesellschaft); ProRing e.V.; ÖAV (Österreichischer Alpenverein e.V.) and DAV (Deutscher Alpenverein e.V.) - accedence since 2004

Volunteer activities and assistance have been provided for (selection): 'The Orang-Utang Project'; Scientific symposia; WWF; BirdLife International; Lebenshilfe e.V.; ABNÖ nature reserve project

Reviewing activities for the scientific journals Acta Chiropterologica; Agroforestry Systems; Biological Conservation; Biotropica; Community Ecology and PloS One 


\section{Acknowledgments}

This dissertation would not have been possible without the immense support of many different people. First and foremost, I would like to thank my supervisors Teja Tscharntke and Yann Clough, who already supported me during my diploma thesis in Indonesia and continued to do so the entire way of my dissertation. Teja, thank you for the clear lines of thought that you drew in my multitude of ideas, for your many valuable suggestions and your dedication to all aspects of this thesis. Yann, thanks for everything I was fortunate enough to learn from you about statistics. I thank you both for your stimulating and productive cooperation in this comprehensive project and for everything that I take away from my time in the 'Agroecology Group' in Göttingen. At this point, I would also like to thank Christian H. Schulze as a greatly valued colleague and friend, whose keen sense for interesting and 'sexy' scientific questions has inspired me since my course of studies in Vienna and who has provided much appreciated advice on many occasions since then. Flo, thanks for the encouraging words that you continued to find throughout this time. They often helped me to focus on the things that really matter. Like the sincerity and loyalty of my friends and colleagues in Vienna, for which I am indescribably grateful. Isa, thank you for your clarity, warmth and your contagiously cheery nature. Anna, I thank you from the bottom of my heart for preserving originality and ingenuity in my day to day life, no matter how mundane it threatens to become. Vera, thank you for being so courageous, strong and generous. Stefan, thank you for your letters and your way with words. Benji, I thank you for being such a good and understanding colleague and friend and that you helped me so often until here. I draw my inspiration and strength from people and friends like you. I wish there could be more of you in this world.

Sharif and Ben, thank you for 'Beatbird' and a little 'coolness' in between. Nina, thanks for all the good conversations and the great fun! I thank my flatmates from the 'good old house' in Göttingen for the laughter, sympathy and inspiring diversity - it was a great time with each and every one of you and we missed you after you've left. Thank you also, Marie - wherever you are at the moment, no doubt making the world a better place.

No words can properly express my gratitude for the hard work, commitment and support that I received from so many sides in Indonesia. Above all, my thanks go to the people of Napu who supported me since my first study in 2008 and to all those who joined me later on. 
I owe thanks to all of the cocoa farmers and local helpers who assisted me during the fieldwork for this thesis. Without you, it would only have turned out half as good. Edi, thanks for rising so expertly to the challenge of being team leader and for the great job that you did. Opu, Papa Ifer and Sinto, thanks for all the hard work that you put in. Pak Dadang, I thank you for everything that you taught me. There is no better bird expert in Central Sulawesi than you and I consider myself very lucky to have been able to work with you twice. The many helping hands at Tadulako University were as central to the success of this thesis as the support of the city of Palu (Kecamatan Lore Utara), the National Park office (Departemen Kehutanan) and RISTEK (Jakarta). Thanks also to everyone who assisted in the completion of the individual papers. I hope I have mentioned each of you in their acknowledgement sections. I thank the ,Agroecology Group' for every form of support they have given me.

A big thank you to my dear colleagues from the German National Academic Foundation (Studienstiftung des deutschen Volkes). Veit, Stefan, Manuel and Susanne: one cannot hope for a better 'Werkstatt'! You were simply indispensable on the journey to this point. Thank you for the great times at the doctoral forums and for every stimulating exchange besides you are unique! I thank the German National Academic Foundation for granting me a PhD fellowship - the financial basis that first made my studies in Indonesia possible - but also and especially for their non-material support, the invaluable experiences and exceptional exchange with the many colleagues I was allowed to meet during this time.

These final words and all of my gratitude belong to my family. My dear Constantin, you are the best partner one could wish for. Thank you for standing by me every day of this journey, no matter where we were, no matter how bizarre the circumstances. And thank you for believing in me so strongly and for supporting me with all of your understanding and love. My dear parents and Sanni, I thank you from the bottom of my heart for simply everything that makes you what you are. You support all of my plans from the first day onwards, facing all of the challenges, never ceasing to believe in me, always there for me. All of the strength and courage that you have given me, I would like to pass on to the world as best I can. You know this. You support me in this. And for that I love you with all of my heart. 